This is the author's final, peer-reviewed manuscript as accepted for publication. The publisher-formatted version may be available through the publisher's web site or your institution's library.

\title{
Quantitative profiling and pattern analysis of triacylglycerol species in Arabidopsis seeds by electrospray ionization mass spectrometry
}

Maoyin Li, Ethan Baughman, Mary R. Roth, Xianlin Han, Ruth Welti, and Xuemin Wang

\section{How to cite this manuscript}

If you make reference to this version of the manuscript, use the following information:

Li, M., Baughman, E., Roth, M. R., Han, X., Welti, R. and Wang, X. (2014). Quantitative profiling and pattern analysis of triacylglycerol species in Arabidopsis seeds by electrospray ionization mass spectrometry. Retrieved from http://krex.ksu.edu

\section{Published Version Information}

Citation: Li, M., Baughman, E., Roth, M. R., Han, X., Welti, R. and Wang, X. (2014). Quantitative profiling and pattern analysis of triacylglycerol species in Arabidopsis seeds by electrospray ionization mass spectrometry. The Plant Journal, 77(1), 160-172.

Copyright: ( 2013 The Authors

The Plant Journal @ 2013 John Wiley \& Sons Ltd

Digital Object Identifier (DOI): doi:10.1111/tpj.12365

Publisher's Link: http://onlinelibrary.wiley.com/doi/10.1111/tpj.12365/full

This item was retrieved from the K-State Research Exchange (K-REx), the institutional repository of Kansas State University. K-REx is available at http://krex.ksu.edu 


\title{
Quantitative Profiling and Pattern Analysis of Triacylglycerol Species in Arabidopsis Seeds by Electrospray Ionization Mass Spectrometry
}

Maoyin $\mathrm{Li}^{1,2,{ }^{*}}$, Ethan Baughman ${ }^{3}$, Mary R. Roth ${ }^{4}$, Xianlin $\mathrm{Han}^{5}$, Ruth Welti ${ }^{4,{ }^{*}}$, and Xuemin Wang ${ }^{1,2,{ }^{*}}$

${ }^{1}$ Department of Biology, University of Missouri, St. Louis, Missouri 63121; ${ }^{2}$ Donald Danforth Plant Science Center, St. Louis, Missouri 63132; ${ }^{3}$ Division of Plastic and Reconstructive Surgery, Washington University in Saint Louis School of Medicine, Saint Louis, MO. 63105; ${ }^{4}$ Kansas Lipidomics Research Center, Division of Biology, Kansas State University, Manhattan, Kansas 66506; ${ }^{5}$ Diabetes and Obesity Research Center, Sanford-Burnham Medical Research Institute, Orlando, FL, 32827. For correspondence (mali@danforthcenter.org, welti@ksu.edu, or swang@danforthcenter.org).

\author{
Authors: \\ Maoyin Li mali@danforthcenter.org \\ Ethan Baughman baughmane@wudosis.wustl.edu \\ Mary Roth mrroth@ksu.edu \\ Xianlin Han $\quad$ xhan@sanfordburnham.org \\ Ruth Welti $\quad$ welti@ksu.edu \\ Xuemin Wang swang@danforthcenter.org
}

Running title: Rapid triacylglycerol species profiling

Estimated length of article: 8 pages

Keywords: Arabidopsis thaliana, mass spectrometry, lipidomics, seed oil, triacylglycerol profiling. 


\section{SUMMARY}

Plant triacylglycerols (TAGs), or vegetable oils, provide approximately $25 \%$ of dietary calories to humans and are becoming an increasingly important source of renewable bioenergy and industrial feedstocks. TAGs are assembled, by multiple enzymes in the endoplasmic reticulum, from building blocks that include an invariable glycerol backbone and variable fatty acyl chains. It remains a challenge to elucidate the mechanism of synthesis of hundreds of different TAG species in planta. One reason is the lack of an efficient analytical approach quantifying individual molecular species. Here we report a rapid and quantitative TAG profiling approach for Arabidopsis seeds based on electrospray ionization tandem mass spectrometry with direct infusion and multiple neutral loss scans. The levels of 93 TAG molecular species, identified by their acyl components, were determined in Arabidopsis seeds. Quantitative TAG pattern analyses revealed that the TAG assembly machinery preferentially produces TAGs with one elongated fatty acid. The importance of the selectivity in oil synthesis was consistent with an observation that an Arabidopsis mutant overexpressing a patatin-like phospholipase had enhanced seed oil content with elongated fatty acids. This quantitative TAG profiling approach should facilitate investigations aimed at understanding the biochemical mechanisms of TAG metabolism in plants.

\footnotetext{
Abbreviations:

DAG, diacylglycerol; ESI, electrospray ionization; FA, fatty acid or acyl; LPC, lysophosphatidylcholine; m/z: mass-to-charge ratio; $\mathrm{m}: \mathrm{n}$, acyl chain containing $\mathrm{m}$ carbon atoms and $\mathrm{n}$ double bonds; MS, mass spectrometric or mass spectrometry; NL, neutral loss scans or scanning; OE, pPLAIIIס overexpressor; PC, phosphatidylcholine; PLA, phospholipase A; TAG, triacylglycerol; WT, wild-type Arabidopsis.
} 


\section{INTRODUCTION}

Triacylglycerols (TAGs) from plant seeds and fruits, or vegetable oils, provide approximately $25 \%$ of dietary calories in developed countries and are widely utilized as industrial feedstocks and renewable biofuels (Chapman and Ohlrogge, 2012; Bates and Browse, 2012). It is predicted that the demand for vegetable oils will be doubled by 2030 and can be met only by increasing the oil production (Chapman and Ohlrogge, 2012). TAG component fatty acyl chains are synthesized in plastids and trafficked to the endoplasmic reticulum (ER). There, glycerolipids, including TAGs, consisting of a glycerol backbone and three acyl chains (FA), are assembled (Bates and Browse, 2012; Bates et al., 2013).

There are several proposed pathways by which the fatty acids are processed and assembled to form TAGs (Bates and Browse, 2012; Bates et al., 2013). Fatty acids exported from plastids can be directly incorporated into glycerol-3-phosphate (G3P) to form TAG via the conventional Kennedy pathway, G3P $\rightarrow$ lysophosphatidic acid (LPA) $\rightarrow$ phosphatidic acid $(P A) \rightarrow$ diacylglycerol (DAG) $\rightarrow$ TAG. Further studies have indicated that phosphatidylcholine (PC) is extensively involved in TAG synthesis (Bates et al., 2007; 2009; Tjellström et al., 2012). Modification of fatty acids, including desaturation, takes place while fatty acids are esterified to PC; modified fatty acids are indeed incorporated into TAGs. PC with modified acyl chains can be converted to DAG that can subsequently be acylated to form TAG by acylCoA:DAG acyltransferase (DGAT). Modified acyl chains in PC also can be transferred directly to DAG to form TAG by phospholipid:DAG acyltransferase (PDAT). The relative extent of flux through the different TAG-forming pathways needs clarification; this information is crucial for engineering crops with specific, designed fatty acid compositions (Bates and Browse, 2012; Bates et al., 2013). Comprehensive profiling of TAG molecules is a necessary component of the toolbox of analytical techniques needed to facilitate our understanding of the TAG biosynthetic pathways. However, a simple, efficient TAG analytical approach for profiling plant TAG species quantitatively has been lacking.

Various methods have been applied to the analysis of intact TAGs. Liquid chromatography-mass spectrometry approaches (LC-MS) have been utilized to analyze TAGs in sunflower and olive oils (Herrera et al., 2010), yellow-green algae (Rezanka et al., 2011), microalgae (MacDougall et al., 2011), pine seed (Acheampong et al., 2011), peanut (Hu et al., 2012; Yang et al., 2012), and human chylomicron (Bonham et al., 2013). Techniques based on matrix-assisted laser desorption ionization-time-of-flight MS 
have been applied to analysis of TAGs from olive oil (Chapagain and Wiesman, 2009), grape seeds (Marchi et al., 2011), and microalgae (Danielewicz et al., 2011). Nanospray ion trap MS has been utilized to fingerprint TAGs in lipid droplets extracted from cotton and Arabidopsis seeds (Horn et al., 2011).

Using multiple neutral loss (NL) scan modes, a multi-dimensional MS-based shotgun lipidomics approach was used to analyze the lithium adducts of TAG species extracted from tissues of mouse heart, muscle, and liver (Han and Gross, 2001; Han et al., 2013). In addition, ammonium-adducted ions of TAG in mammalian samples have been analyzed (Thomas et al., 2007; Murphy et al. 2007; Ståhlman et al., 2012). Recently, electrospray ionization tandem mass spectrometry (ESI-MS/MS) was applied to analyze ammonium-adducted ions of TAG from soybean seeds (Lee 2011; 2012), but detailed information on the acyl combinations of each plant TAG was not obtained.

Here, we describe establishment of a plant TAG profiling method based on electrospray ionization (ESI) tandem mass spectrometry (MS) with a triple quadrupole MS in multiple NL scan modes for TAG analysis without prior derivation or separation. The levels of 93 individual TAG molecules and 13 TAG molecular groups were determined in wild-type (WT) Arabidopsis seeds. The analysis reveals an interesting pattern of the levels of TAGs containing elongated acyl chains, implying selectivity of the TAG assembly machinery. The method was utilized to analyze the TAG molecular patterns in mutant seeds overexpressing an Arabidopsis patatin-like phospholipase pPLAIIIס. This efficient TAG profiling approach should facilitate future studies of TAG synthesis in plants.

\section{RESULTS AND DISCUSSION}

\section{Determination of fatty acid composition and TAG groups in Arabidopsis seeds}

The fatty acid composition of Arabidopsis seeds was determined by gas chromatography with flame ionization detection (GC-FID) (Figure S1). Nine fatty acids were detected at levels over 1\%; the five most abundant fatty acid species were 18:2, 18:3, 20:1, 18:1, and 16:0; four were less abundant: 18:0, 20:0, 20:2, and 22:1 (Figure S1). Additionally, trace amounts of 22:0 were detected. Two 18:1 isomeric

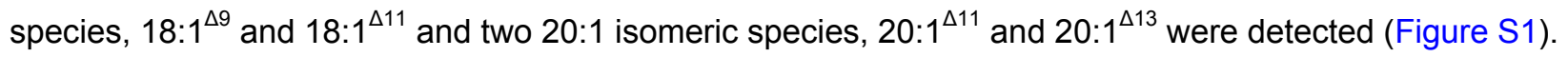
In further analyses, isomeric species were combined, i.e., only numbers of carbons and double bonds are considered hereafter in the description and calculation of TAG species containing specific acyl chains. 
TAG species were analyzed by direct infusion of crude lipid extracts by ESI MS in positive mode. TAG molecular species can be described by total carbon number and the number of double bonds in their three acyl chains. For example, TAG 16:0-18:2-18:3 can be expressed as C52:5. A spectrum of ammonium adducts of TAG, $\left[\mathrm{M}+\mathrm{NH}_{4}\right]^{+}$, shows six clusters of MS peaks, representing $\mathrm{C} 50, \mathrm{C} 52, \mathrm{C} 54, \mathrm{C} 56$, C58, and C60 (Figure 1a). The most abundant signals represent TAGs with 56 carbons in the acyl chains, followed by C54, C58, C52, C60, and C50 (Figure 1a).

\section{Identification of TAG molecules by multiple NL scans}

The combination of acyl chains of TAG(s) at a particular mass/charge ratio $(\mathrm{m} / \mathrm{z})$ can be revealed by fragmentation (collision induced dissociation; CID) in ESI triple quadrupole MS. TAG 18:1-18:1-18:1, C54:3, detected at $m / z 902.8$ as $\left[\mathrm{M}+\mathrm{NH}_{4}\right]^{+}$, can undergo $\mathrm{NL}$ of $18: 1$ with $\mathrm{NH}_{3}$. NL of $299.2(18: 1)$ forms a DAG product ion at $m / z 603.6$ (Figure 1b, c). In another example, TAG 16:0-18:1-18:3, C52:4, detected at $\mathrm{m} / \mathrm{z} 872.8$ as $\left[\mathrm{M}+\mathrm{NH}_{4}\right]^{+}$, can undergo $\mathrm{NL}$ of any of the three fatty acids complexed with $\mathrm{NH}_{3}$. $\mathrm{NL}$ of 273.2 (16:0) forms a DAG product ion at $\mathrm{m} / \mathrm{z}$ 599.6; NL of 299.2 (18:1) and 295.2 (18:3) form DAG product ions at $\mathrm{m} / \mathrm{z} 573.6$ and $\mathrm{m} / \mathrm{z} 577.6$, respectively (Figure S2a). Similarly another isomer of C52:4, TAG 16:0-18:2-18:2, can undergo NL of 273.2 (16:0) and 297.2 (18:2) (Figure S2b). The fragments produced by $\mathrm{CID}$ of the $\left[\mathrm{M}+\mathrm{NH}_{4}\right]^{+}$ion at $\mathrm{m} / \mathrm{z} 872.8$ in an Arabidopsis seed extract are shown (Figure S2c). Product ions at $m / z 573.6,575.6,577.6$, and 597.6 are formed by neutral losses of $18: 1,18: 2,18: 3$, and 16:0, respectively, implying C52:4 in Arabidopsis seeds includes an acyl combination of 16:0-18:2-18:2, as well as 16:0-18:1-18:3 (Figure S2c).

To comprehensively detect TAG species in Arabidopsis seeds, intact TAGs were extracted and the ammonium adducts $\left(\left[\mathrm{M}+\mathrm{NH}_{4}\right]^{+}\right)$of the TAGs were subjected to ten NL scans, corresponding to the ten fatty acids detected in seed TAG (Figure S1). Each scan was performed over an $\mathrm{m} / \mathrm{z}$ range of 820 to 1000 to detect TAG molecules containing 16:0, 18:3, 18:2, 18:1, 18:0, 20:2, 20:1, 20:0, 22:1, and 22:0 (Figure 2). An eleventh NL scan for tri17:1 TAG, utilized as an internal standard, also was performed; tri17:1 TAG was chosen as an internal standard because no naturally occurring $17: 1$ is detectable in Arabidopsis seeds (Figure S1). Taken together, the NL scans show the fatty acid combinations of TAG at a particular $\mathrm{m} / \mathrm{z}$. For example, at $\mathrm{m} / \mathrm{z} 870.8$ (C52:5), peaks were detected in scans for NL273.6 (Figure 
2b), NL295.2 (Figure 2c), and NL297.2 (Figure 2d), indicating that the TAG at $\mathrm{m} / \mathrm{z} 870.8$ includes 16:0, 18:3, and 18:2. The sn-position of acyl chains and the double bond locations are not specified in the description of TAG molecules in this work.

One TAG mass $(\mathrm{m} / \mathrm{z})$ can be resolved into TAGs with multiple acyl combinations. For example, at $\mathrm{m} / \mathrm{z} 872.8$, a singly charged ammonium adduct with a molecular formulae of $\mathrm{C}_{55} \mathrm{H}_{102} \mathrm{O}_{6} \mathrm{~N}$, represents TAG molecule(s) with 52 carbons and 4 double bonds in the three acyl chains (C52:4). Ten different NL scans were conducted for $\mathrm{m} / \mathrm{z}$ 872.8, and the acyl abundance at each scan mode was normalized with an internal standard in the same infusion (Figure 2). The detection of 16:0,18:1, 18:2, and 18:3 at this TAG mass indicated that C52:4 ( $\mathrm{m} / \mathrm{z}$ 872.8) includes molecular species with all four of these fatty acids (Figure 2). Based on the total carbon number, number of double bonds, and signals detected by NL scanning, two acyl combinations of TAG for this $m / z, 16: 0-18: 2-18: 2$ and 16:0-18:1-18:3, can be deduced (Figure 3a), consistent with the data derived from product ion analysis (Figure S2c). Similarly, the fatty acyl chains in C56:6 (m/z 924.8) include 18:3, 18:2, 18:1, 20:2, 20:1, and 20:0; TAGs that make up the C56:6 group can include 18:3-18:3-20:0, 18:2-18:3-20:1, 18:2-18:2-20:2, and 18:1-18:3-20:2 (Figure 3b). The TAG mass $\mathrm{m} / \mathrm{z} 926.8$ (C56:5) can be deduced to have 5 different fatty acyl combinations (Figure 3c).

\section{Quantification of TAG molecular species}

The deduced TAG species were quantified. First, the intensities of each peak were corrected ("deconvoluted") by subtracting signals due to TAG isotopic variants. Primarily, the relevant isotopic variants contain $2{ }^{13} \mathrm{C}$; these signals occur at the same $\mathrm{m} / \mathrm{z}$ as the all- ${ }^{12} \mathrm{C}$ isotope of TAG with one fewer double bond. Second, a correction was made for variable mass spectral response observed for TAG species varying in acyl carbon number and overall number of double bonds. To develop standard curves for the response adjustment, commercially available symmetric TAGs present at known concentrations were analyzed by NL scanning of the $\left[\mathrm{M}+\mathrm{NH}_{4}\right]^{+}$ions. Drawing on previous work by Han and Gross (2001), the data from the synthetic TAGs were fitted and the curves extrapolated to cover all TAG acyl and double bond combinations detected in Arabidopsis seeds. Details of the fitting and extrapolation are shown in Table S1, Figure S3-6, and Method S1. Adjustment factors for TAG species at each $\mathrm{m} / \mathrm{z}$, i.e. for each group with a common number of total acyl carbons and total double bonds, were determined in 
comparison to the response for the internal standard, tri17:1 (C51:3), which was set at 1 (Table S1). These adjustment factors were applied to the sum of isotopically deconvoluted intensities (from the NL spectra) at each $\mathrm{m} / \mathrm{z}$ (i.e., to each TAG group defined by total acyl carbon number: total double bond number). At the same time, the data were normalized to the observed internal standard signal for the sample, so that the abundance of each fatty acid in TAGs at a particular $\mathrm{m} / \mathrm{z}$ was calculated (in nmol) as: [observed TAG intensity $\mathrm{x}$ internal standard amount $(\mathrm{nmol}) \mathrm{x}$ adjustment factor] / [observed internal standard intensity].

The calculated abundances of fatty acids in TAG at each $\mathrm{m} / \mathrm{z}$ showing in Table S2 were utilized to calculate the level of each TAG molecular species using the formulae indicated in Table S3. For example, the assortment of calculated abundances of fatty acids in TAG at $\mathrm{m} / \mathrm{z} 872.8$ (C52:4), $\mathrm{m} / \mathrm{z} 924.8$ (C56:6) and $m / z 926.8$ (C56:5) was utilized to calculate the multiple TAG molecular species to which they are assigned (Figure 3). The derivation of the calculation formulae for calculating the levels of each TAG molecular species at $\mathrm{m} / \mathrm{z} 872.8$ (C52:4), $\mathrm{m} / \mathrm{z} 924.8$ (C56:6), m/z 926.8 (C56:5), m/z 960.9 (C58:2), and m/z 984.9 (C60:4) are illustrated in detail (Method S2; Figure 3, S7). In all, the multiple NL scans allow us to quantify mass spectral signals from 93 individual TAG species in Arabidopsis seeds (Table 1). In several cases, the signals could not be resolved into individual TAG species, and some TAGs with the same $\mathrm{m} / \mathrm{z}$ were grouped for quantification (Table 1).

The quantitative method was validated by spike-in experiments, in which known amounts of commercially obtained 16:0-18:1-18:2-TAG were mixed without and with seed TAG (Figure 4a-c). The input amounts were linear with the amounts measured by the TAG profiling method with a slope close to 1 , indicating that the method can measure TAG amount with reasonable accuracy. The presence of the seed TAG that was used for spiking resulted in an offset on the y-axis (Figure 4b-c). In addition, the presence of other TAGs, and any potential ion suppression that they may cause, did not impact the quantitative accuracy for determination of individual TAG species.

The ability to determine TAG amount when the total TAG levels was varied was also determined. The measured levels of C52:3-TAG isomers, 16:0-18:1-18:2-TAG and 16:0-18:0-18:3-TAG, were linear with added amounts of total seed TAG (Figure 4d-e), indicating the levels of individual TAG species can be accurately measured as total seed TAG is varied within the tested range. The total amount of 
measured seed TAG was also linear with the added seed TAG with a slope close to 1.0 (Figure 4f), indicating the TAG levels can be accurately measured from $20 \mathrm{nmol}$ to $400 \mathrm{nmol}$ of total seed TAG per profiling sample. These amounts correspond to TAG extracts of $0.05 \mathrm{mg}$ to $1.0 \mathrm{mg}$ Arabidopsis seeds in each profiling sample.

\section{Elongated acyl chains are incorporated into TAG in Arabidopsis seeds in a non-random pattern}

Of the nine major acyl chains in Arabidopsis seeds (Figure S1), acyl chains, 16:0, 18:0, and 18:1, are exported from plastids; $18: 1$ is desaturated to form 18:2 and then 18:3; and 20:0, 20:1, 20:2, and 22:1 are formed by elongation (Dyer et al., 2008; Weselake et al., 2009; Bates et al., 2013). We speculated that the TAG assembly machinery may have selectivity for acyl chains based on their metabolic history. The acyl chains were classified into pools (Figure 5a). Acyl chains 16:0, 18:0, and 18:1 were designated as A-pool (28.9\%), 18:2 and 18:3 as B-pool (42.3\%), and 20:0, 20:1, 20:2, and 22:1 were designated as C-pool (28.8\%).

A random arrangement for acyl species from the three pools was calculated and compared with the observed (measured) arrangement. The results are shown in Figure 5b and additional information on the calculation is shown in Table S4. The difference between the predicted TAG pattern and the measured one was significant and showed that the TAG assembly machinery favors accumulation of TAGs with one elongated acyl chain (Figure 5b). The TAG pattern analysis implied that the TAG assembly machinery incorporates acyl chains originating from elongation reactions into a specific subset of TAG species. The accumulation of more-than-random amounts of TAG with single elongated-chain species could suggest that the elongated fatty acids are more likely than average to be the third fatty acid added to a DAG originating from de novo synthesis or acyl editing. It also raises a question of whether

alterations in the levels of elongated chains may affect the rate of TAG assembly and impact oil accumulation.

\section{Quantification of the TAG levels in transgenic Arabidopsis seeds overexpressing pPLAllI}

The TAG pattern analysis predicts the importance of acyl elongation in oil synthesis (Figure $5 b$ ). This prediction was consistent with the observation that overexpressing patatin-related pPLAllI $\delta$ resulted 
in higher levels of elongated fatty acids and a higher level of oil content (Li et al., 2013). Seeds of pPLAllI overexpressors (OE) contained $40.5 \%$ oil whereas the wild-type (WT) had $35.5 \%$ (Li et al., 2013). Two independent overexpression lines, OE1 and OE2, had similar phenotypes and OE1 was further analyzed in seed morphology. OE1 seeds were bigger and rounder than WT seeds (Figure S8a) and were $41 \%$ heavier and contained $52 \%$ more oil per seed than WT seeds (Figure S8b, c). The OE1 seeds were $13 \%$ wider and $4 \%$ shorter than WT ones (Figure S8e, f). The ratio of width over length of seeds was $14 \%$ larger in OE1 than in WT (Figure S8f). In addition to seed shape, pPLAIllס overexpression also altered the TAG profile. Of the 93 individual TAG species analyzed, the levels of 43 individual TAG species (nmol per mg dry mass) were significantly higher in OE1 than in WT seeds (Table S3). Of the most abundant 25 TAG species, the levels of 17 species were significant higher in OE than in WT seeds and 20:1-containing species were drastically different in the two genotypes (Figure S9a). The OE seeds also had a different TAG pool pattern compared with WT. TAG with one elongated fatty acid was more abundant in the OE seeds than in WT (Figure S9b). The increased levels of acyl chains originating from elongation reactions may facilitate oil accumulation in OE seeds.

The correlation of the fatty acid composition with oil content was also suggested by a quantitative trait loci (QTL) study of high and low seed oil content between Arabidopsis ecotypes, in which the strongest correlation was 18:1 (correlation co-efficiency 0.54$)$, followed by $20: 1(0.27), 18: 0(0.12), 16: 0$ (0.12), 18:3 (0.06), and 18:2 (0.05) (Hobbs et al., 2004). Acyl-CoA:diacylglycerol acyltransferase (DGAT) is one enzyme primarily responsible for TAG synthesis (Bates et al., 2013). The N-terminal region of BnDGAT1 from canola seeds displays an 8-fold greater affinity for elongated acyl chain compared to a long-chain one based on analysis of apparent dissociation constants (22:1-CoA over 18:0-CoA) (Weselake et al., 2006). The $\mathrm{N}$-terminal region of MmDGAT1 from mouse also has a 50 -fold higher affinity to $22: 1-C o A$ over $16: 0-C o A$ and 18:0-CoA based on analysis of apparent dissociation constants (Siloto et al., 2008). Knockout of DGAT1 resulted in approximately $75 \%$ decrease of $20: 1$ and approximately $10 \%$ decrease of oil in Arabidopsis seeds (Zhang et al., 2009). Acyl chains with 18C and 16C may be released from PC by enzymes like PPLAIII and elongated. If the elongated acyl chains are favorable substrates for the synthesis of TAG by DGAT, it may explain, at least in part, why the overexpression of pPLAIII enhances seed oil content with elongated acyl chains (Figure S9). 
In summary, we have established an efficient TAG profiling method for Arabidopsis seeds based on ESI-MS/MS using multiple NL scanning. The method, as practiced for quantitative analysis, can be summarized in four steps: (1) MS scanning for NL of fatty acyl components identified by GC (Figure 2), (2) isotopic deconvolution of MS intensities in NL scans, (3) application of response adjustment factors (Table S1) to the sum of isotopically deconvoluted intensities at each $\mathrm{m} / \mathrm{z}$ (i.e., to each TAG group defined by total acyl carbon number: total double bond number) and normalization of TAG intensities to internal standard intensity, and (4) allocation the signal in each TAG group to individual molecular species (as defined by acyl combination) using formulae based on analysis of the fatty acyl combinations (Table S3). The analysis measures TAG species in terms of individual acyl chains, but does not specify acyl positions on the glycerol backbone. Inclusion of adjustment factors in the quantification procedure allows accurate determination of tested TAG species and overall TAG amount with good accuracy. Still, the adjustment factors for each TAG are estimated based on extrapolation from synthetic standards, and others have demonstrated discrimination in response among TAG species with varied acyl arrangements (Murphy et al., 2007). Indeed, additional accuracy could undoubtedly be achieved if more varied TAG standards were available and used to formulate the adjustment factors. This method was utilized to analyze Arabidopsis mutant seeds overexpressing pPLAIIIס, where it revealed the importance of elongated acyl chains in oil content. The utilization of TAG profiling should improve our capability to identify TAG synthesis pathways and design engineering strategies for enhanced production of plant oils.

\section{EXPERIMENTAL PROCEDURES}

\section{Plant growth and seed harvest}

The generation of transgenic mutants overexpressing pPLAllI was described previously (Li et al., 2013). Both the wild type and mutant Arabidopsis thaliana plants are in Columbia-0 background. Plants were grown in growth chambers with a $12 \mathrm{~h}$ light $/ 12 \mathrm{~h}$ dark cycle, $23 / 21^{\circ} \mathrm{C}, 50 \%$ humidity, at $200 \mu \mathrm{mol} \mathrm{m}{ }^{-2}$ $\sec ^{-1}$ of light intensity, and watered with fertilizer once a week. The mature seeds were harvested and dried at room temperature at least one week before TAG extraction and analysis.

\section{Analysis of fatty acids by gas chromatography}


Ten milligrams of Arabidopsis seeds were placed in glass tubes with Teflon-lined screw caps and $1.5 \mathrm{~mL} 5 \%(\mathrm{v} / \mathrm{v}) \mathrm{H}_{2} \mathrm{SO}_{4}$ in methanol with $0.2 \%$ butylated hydroxytoluene was added. The samples were incubated for $1 \mathrm{~h}$ at $90^{\circ} \mathrm{C}$ for oil extraction and transmethylation. Fatty acid methyl esters (FAMEs) were extracted with hexane and quantified using gas chromatography on a Supelcowax-10 $(0.25 \mathrm{~mm} \times 30 \mathrm{~m})$ column, a split/splitless injector, and flame ionization detection. FAME analysis was performed by autoinjection of $1 \mu \mathrm{L}$ of each sample at a split ratio of 50:1. Carrier gas was helium with a flow rate of $20 \mathrm{~mL}$ $\mathrm{min}^{-1}$. The oven temperature was maintained at $170^{\circ} \mathrm{C}$ for $1 \mathrm{~min}$ and then ramped to $210^{\circ} \mathrm{C}$ at $3^{\circ} \mathrm{C} \min ^{-1}$. FAMEs from TAG were identified by comparing their retention times with FAMEs in a standard mixture. Heptadecanoic acid (17:0) was used as the internal standard to quantify the amount of individual fatty acid. Fatty acid composition was expressed as percentage of dry weight.

\section{TAG extraction and profiling sample preparation}

Seed TAGs were extracted by a modified Bligh and Dyer method (1959). Briefly, dry Arabidopsis seeds, $25 \mathrm{mg}$, were ground with $0.5 \mathrm{nmol}$ tri17:1-TAG (internal standard; Avanti Polar Lipids) with a mortar and pestle in $1.0 \mathrm{~mL}$ of chloroform/methanol $(2: 1, \mathrm{v} / \mathrm{v})$. The mixture was extracted with vigorous shaking for $1 \mathrm{~h}$ at room temperature and centrifuged to pellet the debris. The profiling samples were prepared by combining $50 \mu \mathrm{L}$ TAG sample with $310 \mu \mathrm{L}$ chloroform and $840 \mu \mathrm{L}$ of chloroform/methanol/300 mM ammonium acetate in water (300:665:35, v/v/v). The final volume was 1.2 $\mathrm{mL}$ for each sample in TAG profiling.

\section{Mass spectrometry analysis of TAGs}

Lipid extracts were introduced by continuous infusion into the ESI source on a triple quadrupole mass spectrometer (API4000, Applied Biosystems, Foster City, CA). Samples were infused at $30 \mu \mathrm{L}$ min $^{-}$ ${ }^{1}$ with an autosampler (LC Mini PAL, CTC Analytics AG, Zwingen, Switzerland) fitted with an appropriate loop for the acquisition time. The procedure is a modification of the procedure used by Lee et al. (2011).

TAGs were detected as $\left[\mathrm{M}+\mathrm{NH}_{4}\right]^{+}$ions by a series of NL scans. The scans targeted losses of fatty acids as neutral ammoniated fragments: NL285.2 (17:1, for the TAG internal standard); NL273.2 (16:0); NL301.2 (18:0); NL299.2 (18:1); NL297.2 (18:2); NL295.2 (18:3); NL329.2 (20:0); NL327.2 (20:1); 
NL325.2 (20:2); NL357.2 (22:0); and NL355.2 (22:1). The scan speed was $100 \mathrm{u} \mathrm{s}^{-1}$. The collision energy, with nitrogen in the collision cell, was $+25 \mathrm{~V}$; declustering potential was $+100 \mathrm{~V}$; entrance potential was $+14 \mathrm{~V}$; and exit potential was $+14 \mathrm{~V}$. Sixty continuum scans were averaged in the multiple channel analyzer mode. For product ion analysis, the first quadrupole mass spectrometer (Q1) was set to select the TAG mass $(\mathrm{m} / \mathrm{z})$, and Q3 for the detection of products fragmented by collision induced dissociation.

For all analyses the collision gas pressure was set on "low", and the mass analyzers were adjusted to a resolution of $0.7 \mathrm{u}$ full width at half height. The source temperature (heated nebulizer) was $100^{\circ} \mathrm{C}$; the interface heater was on; $+5.5 \mathrm{kV}$ was applied to the electrospray capillary; the curtain gas was set at 20 (arbitrary units); and the two ion source gases were set at 45 (arbitrary units).

\section{Data processing and TAG quantification}

For TAG analyses, the background of each spectrum was subtracted; the data were smoothed; and peak areas were integrated using a custom script and Applied Biosystems Analyst software. Peaks corresponding to the target lipids in these spectra were identified, and the data were corrected for $A+2$ isotopic overlap (based on the mass to charge ratio, $\mathrm{m} / \mathrm{z}$, of the charged fragments) within each spectra. Signals were also corrected for isotopic overlap across spectra, based on the A+2 overlaps and masses of the neutral fragments. A sample containing internal standard alone, run through the same series of scans, was used to correct for chemical or instrumental noise: amounts of each target lipid detected in the "internal standard-only" sample were subtracted from the molar amounts of each target lipid calculated from the plant lipid spectra. The "internal standard-only" spectra were used to correct the data from the following five samples run on the instrument.

The extracted data from all acyl NL scans at each TAG mass, as defined by $\mathrm{m} / \mathrm{z}$, which corresponds to total acyl carbons: total double bonds (e.g. 52:3), were used to calculate the amount of each individual TAG species. Because variations occur in ionization efficiency among acyl glycerol species with different acyl groups (Han and Gross, 2001), the values are not directly proportional to the TAG content of each species. The levels of 46 TAG mass $(\mathrm{m} / \mathrm{z})$ were corrected using adjustment factors. 
The relative adjustment factors of 15 commercial TAG species as compared with internal standard tri17:1-TAG (C51:3) (NuChek Prep, Inc.) were measured. The TAGs were C42:0 (tri14:0), C45:0 (tri15:0), C48:3 (tri16:1), C48:0 (tri16:0), C51:0 (tri17:0), C54:6 (tri18:2), C54:3 (tri18:1), C54:0 (tri18:0), C57:6 (tri19:2), C57:3 (tri19:1), C57:0 (tri19:0), C60:9 (tri20:3), C60:6 (tri20:2), C60:3 (tri20:1), and C60:0 (tri20:0) (Nu-Chek Prep, Inc.). Adjustment factor was defined as the NL signal intensity of internal standard/ the NL signal intensity for the tested TAG, when the tested TAG and the internal standard were equimolar as determined by gas chromatographic analysis. The adjustment factor is a reciprocal type of factor in relation to the "correction factor" used by Han and Gross (2001). The adjustment factor for the internal standard C51:3 (tri17:1) was 1, and the adjustment factors of the synthetic TAGs were determined (Table S1).

Plotting the adjustment factor data for the commercially-obtained TAG adjustment factors as a function of $\mathrm{m} / \mathrm{z}$, it was observed that at each carbon number, there was a trend for a minimum adjustment factor with 3 double bonds and higher adjustment factors with lower and higher numbers of double bonds (Figure S3a). Using the procedure described in Method S1 and shown in Figures S3-S6, additional adjustment factors were derived and, finally, the data from TAGs of each carbon number were separately fitted. Seven formulas, derived from fitting the data on the measured commercially-obtained TAGs, were used to deduce the adjustment factors of TAGs at various $\mathrm{m} / \mathrm{z}$ in Arabidopsis seeds:

(1) for C48: $y=3.683643205 \cdot 10^{-2} x^{2}-60.50552674 x+24846.21534$;

(2) for C50: $y=3.46746497 \cdot 10^{-2} x^{2}-58.86757496 x+24985.86983$;

(3) for C52: $y=3.325379635 \cdot 10^{-2} x^{2}-58.26811836 x+25526.04116$;

(4) for C54: $y=3.446858344 \cdot 10^{-2} x^{2}-62.25190933 x+28109.47254$;

(5) for C56: $y=4.26841342 \cdot 10^{-2} x^{2}-79.39525526 x+36922.90311$;

(6) for C58: $y=6.766414371 \cdot 10^{-2} x^{2}-129.6274322 x+62087.37777$;

(7) for C60: $y=8.725995023 \cdot 10^{-3} x^{3}-25.70443916 x^{2}+25238.65356 x-8260163.188$;

where " $y$ " is the adjustment factor and " $\mathrm{x}$ " is the $\mathrm{m} / \mathrm{z}$ of the ammoniated ions. The resulting adjustment factors for the seed TAG of each $\mathrm{m} / \mathrm{z}$ are shown in Table S1. The abundance of each fatty acid in TAGs at a particular $\mathrm{m} / \mathrm{z}$ was calculated (in $\mathrm{nmol}$ ) as: [observed TAG intensity $\mathrm{x}$ internal standard amount (nmol) $\mathrm{x}$ adjustment factor] / [observed internal standard intensity]. The values were divided by dry mass to get 
the fatty acid abundances in $\mathrm{nmol} \mathrm{mg}{ }^{-1}$. Values for individual TAG molecular species were deduced from these fatty acid abundances using the formulae in Table S3 with the resulting values in TAG abundances in $\mathrm{nmol} \mathrm{mg}{ }^{-1}$. The amount of each TAG was also expressed as a percentage of the total values for all TAG species (i.e., mol \%).

\section{Validation of the TAG profiling method}

TAG 16:0-18:1-18:2 was purchased from Cayman Chemical Company and quantified by gaschromatography using heptadecanoic acid (17:0) as internal standard. Various amounts of commercial TAG 16:0-18:1-18:2 were mixed with tri17:1-TAG, the internal standard, and 0, $55 \mathrm{nmol}$, or $275 \mathrm{nmol}$ total seed TAG, and multiple NL scans were performed. Furthermore, different amounts of total seed TAG, from $0 \mathrm{nmol}$ to $380 \mathrm{nmol}$, were mixed with tri17:1-TAG, the internal standard, and multiple NL scans were performed. The seed TAG content and fatty acid composition were measured by gas chromatography. The average molecular weight of seed TAGs was calculated to be $892.2 \mathrm{~g} \mathrm{~mol}^{-1}$ based on the measured fatty acid composition by gas chromatography.

\section{TAG pattern analysis}

The contribution of acyl chains in two pools on the formation of different types of TAG molecules was examined. Fatty acid composition for this analysis was determined by calculation of the acyl species found to be present in the total pool from the ESI-MS/MS TAG analysis. The randomly expected amounts of each combination would be: $A-A-A=a^{*} a^{*} a ; B-B-B=b^{*} b^{*} b ; C-C-C=c^{*} C^{*} C ; A-A-B=3^{*} a^{*} a^{*} b ; A-A-C=$ $3^{*} a^{*} a^{*} c ; B-B-A=3^{*} b^{*} b^{*} a ; B-B-C=3^{*} b^{*} b^{*} c ; C-C-A=3^{*} C^{*} C^{*} a ; C-C-B=3^{*} c^{*} C^{*} b ; A-B-C=6^{*} a^{*} b^{*} c$, where $a$, b, and c represents the pool size of $A, B$, and C, respectively, as illustrated in Figure 5a. Combining to simplify consideration of the unresolved TAG molecular species groups: $X-X-C=A-A-C+B-B-C+A-B-C$ and $\mathrm{X}-\mathrm{C}-\mathrm{C}=\mathrm{A}-\mathrm{C}-\mathrm{C}+\mathrm{B}-\mathrm{C}-\mathrm{C}$, where $\mathrm{X}$ represents $\mathrm{A}$ or $\mathrm{B}$. The sn-position of acyl chains are not specified in the description of TAG molecules in this work. The values calculated for random arrangement of fatty acids in TAGs were compared with the measured distribution of TAG molecular species and the detailed calculation process is illustrated in Table S4. 


\section{ACKNOWLEDGMENTS}

Work by X.W. was supported by the U.S. Department of Energy (DOE), Office of Science, Office of Basic Energy Sciences (BES), Materials Sciences and Engineering Division under Award \# DESC0001295. Work by M.L. was supported by the National Science Foundation (MCB-0922879). Instrument acquisition and method development at the Kansas Lipidomics Research Center were supported by grants from the National Science Foundation (MCB-0920663, DBI-0521587, each to R.W., and a Kansas Experimental Program to Stimulate Competitive Research Award EPS-0236913 subaward to X.W. and R.W.). Contribution no. 14-035-J from the Kansas Agricultural Experiment Station. The authors are grateful for Dr. Howard Berg at the Donald Danforth Plant Science Center's Integrated Microscopy Facility for assistance on Arabidopsis seed imaging, and Jia Li and Dr. Jan Jaworski for GCMS instrument, and Dr. David Osborn at the Center for Nanoscience at the University of Missouri-St. Louis for assistance on maintenance of mass spectrometry machine.

\section{SUPPORTING INFORMATION}

Figure S1. Fatty acyl composition of Arabidopsis seeds.

Figure S2. Fragmentation patterns of ammoniated ions of intact TAG molecules.

Figure S3. Measured adjustment factors for commercially available TAGs and deduction of adjustment factors for TAGs with 0 and 3 double bonds.

Figure S4. Derivation of adjustment factors for TAGs with 6 fatty acyl double bonds (TAG:6).

Figure S5. Derivation of the regression curves for deduction of the adjustment factors at TAG groups of C48, C50, C52, C54, C56, C58, and C60.

Figure S6. Measured adjustment factors for commercially available TAGs and deduced adjustment factors for seed oil TAGs.

Figure S7. The abundance of 10 fatty acyl chains in TAGs at $\mathrm{m} / \mathrm{z} 860.9$ and $\mathrm{m} / \mathrm{z}$ 984.9.

Figure S8. Characterization of Arabidopsis mutant seeds overexpressing pPLAllIס.

Figure S9. Levels of individual TAG species in Arabidopsis wild-type and pPLAIIIס overexpressing seeds. Table S1. Measured and deduced adjustment factors for commercially available TAGs and seed oil TAGs at $46 \mathrm{~m} / \mathrm{z}$. 
Table S2. The abundance of 10 fatty acyl chains in each TAG $\mathrm{m} / \mathrm{z}$ group in Arabidopsis seed oil extract.

Table S3. Levels of TAG molecular species in wild-type and pPLAIll overexpressing seeds of Arabidopsis.

Table S4. Fatty acyl combination analysis of seed oil TAGs.

Method S1. Derivation of the regression curves for deduction of the adjustment factors at 46 seed oil TAG $m / z s$.

Method S2. Derivation of the formulae for calculation of the fatty acyl combinations at each TAG $\mathrm{m} / \mathrm{z}$.

\section{REFERENCES:}

Acheampong, A., Leveque, N., Tchapla, A. and Heron, S. (2011) Simple complementary liquid chromatography and mass spectrometry approaches for the characterization of triacylglycerols in Pinus koraiensis seed oil. J. Chromatogr. A. 1218, 5087-5100.

Bates, P.D. and Browse, J. (2012) The significance of different diacylgycerol synthesis pathways on plant oil composition and bioengineering. Front. Plant Sci. 3, 147.

Bates, P.D., Durrett, T.P., Ohlrogge, J.B. and Pollard, M. (2009) Analysis of acyl fluxes through multiple pathways of triacylglycerol synthesis in developing soybean embryos. Plant Physiol. 150, 5572.

Bates, P.D., Fatihi, A., Snapp, A.R., Carlsson, A.S., Browse, J. and Lu, C. (2012) Acyl editing and headgroup exchange are the major mechanisms that direct polyunsaturated fatty acid flux into triacylglycerols. Plant Physiol. 160, 1530-1539.

Bates, P.D., Ohlrogge, J.B. and Pollard, M. (2007) Incorporation of newly synthesized fatty acids into cytosolic glycerolipids in pea leaves occurs via acyl editing. J. Biol. Chem. 282, 31206-31216.

Bates, P.D., Stymne, S. and Ohlrogge, J. (2013) Biochemical pathways in seed oil synthesis. Curr. Opin. Plant Biol. 16,

Bligh, E.G. and Dyer, W.J. (1959) A rapid method of total lipid extraction and purification. Can. J. Biochem. Physiol. 37, 911-917. 
Bonham, M.P., Linderborg, K.M., Dordevic, A., Larsen, A.E., Nguo, K., Weir, J.M., Gran, P., Luotonen, M.K., Meikle, P.J., Cameron-Smith, D., Kallio, H.P. and Sinclair, A.J. (2013) Lipidomic profiling of chylomicron triacylglycerols in response to high fat meals. Lipids $\mathbf{4 8}, 39-50$.

Chapagain, B.P. and Wiesman, Z. (2009) MALDI-TOF/MS fingerprinting of triacylglycerols (TAGs) in olive oils produced in the Israeli Negev desert. J. Agric. Food Chem. 57, 1135-1142.

Chapman, K.D. and Ohlrogge, J.B. (2012) Compartmentation of triacylglycerol accumulation in plants. J. Biol. Chem. 287, 2288-2294.

Danielewicz, M.A., Anderson, L.A. and Franz, A.K. (2011) Triacylglycerol profiling of marine microalgae by mass spectrometry. J. Lipid Res. 52, 2101-2108.

De Marchi, F., Seraglia, R., Molin, L., Traldi, P., De Rosso, M., Panighel, A., Dalla Vedova, A., Gardiman, M., Giust, M. and Flamini, R. (2012) Seed oil triglyceride profiling of thirty-two hybrid grape varieties. J. Mass Spectrom. 47, 1113-1119.

Han, R.H., Wang, M., Fang, X. and Han, X. (2013) Simulation of triacylglycerol ion profiles: bioinformatics for interpretation of triacylglycerol biosynthesis. J. Lipid Res. 54, 1023-1032.

Han, X. and Gross, R.W. (2001) Quantitative analysis and molecular species fingerprinting of triacylglyceride molecular species directly from lipid extracts of biological samples by electrospray ionization tandem mass spectrometry. Anal. Chem. 295, 88-100.

Herrera, L.C., Potvin, M.A. and Melanson, J.E. (2010) Quantitative analysis of positional isomers of triacylglycerols via electrospray ionization tandem mass spectrometry of sodiated adducts. Rapid Commun. Mass Spectrom. 24, 2745-2752.

Hobbs, D.H., Flintham, J.E., and Hills M.J. (2004) Genetic control of storage oil synthesis in seeds of Arabidopsis. Plant Physiol. 136, 3341-3349.

Horn, P.J., Ledbetter, N.R., James, C.N., Hoffman, W.D., Case, C.R., Verbeck, G.F. and Chapman, K.D. (2011) Visualization of lipid droplet composition by direct organelle mass spectrometry. J. Biol. Chem. 286, 3298-3306.

Hu, J., Wei, F., Dong, X.Y., Lv, X., Jiang, M.L., Li, G.M. and Chen, H. (2013) Characterization and quantification of triacylglycerols in peanut oil by off-line comprehensive two-dimensional liquid 
chromatography coupled with atmospheric pressure chemical ionization mass spectrometry. J Sep Sci. 36, 288-300.

Lee, J., Welti, R., Roth, M.R., Schapaugh, W.T., Li, J. and Trick, H.N. (2012) Enhanced seed viability and lipid compositional changes during natural ageing by suppressing phospholipase Da in soybean seed. Plant Biotechnol. J. 10, 164-173.

Lee, J., Welti, R., Schapaugh, W.T. and Trick, H.N. (2011) Phospholipid and triacylglycerol profiles modified by PLD suppression in soybean seed. Plant Biotechnology J. 9, 359-372.

Li, M., Bahn, S.C., Fan, C., Li, J., Phan, T., Ortiz, M., Roth, M.R., Welti, R., Jaworski, J. and Wang, X. (2013) Patatin-related phospholipase pPLAIII increases seed oil content with long chain fatty acids in Arabidopsis. Plant Physiol. 162, 39-51.

MacDougall, K.M., McNichol, J., McGinn, P.J., O'Leary, S.J. and Melanson, J.E. (2011) Triacylglycerol profiling of microalgae strains for biofuel feedstock by liquid chromatography-highresolution mass spectrometry. Anal. Bioanal. Chem. 401, 2609-2616.

Murphy, R.C., James, P.F., McAnoy, A.M., Krank, J., Duchoslav, E. and Barkley, R.M. (2007) Detection of the abundance of diacylglycerol and triacylglycerol molecular species in cells using neutral loss mass spectrometry. Anal. Biochem. 366, 59-70.

Rezanka, T., Lukavský, J., Nedbalová, L. and Sigler, K. (2011) Effect of nitrogen and phosphorus starvation on the polyunsaturated triacylglycerol composition, including positional isomer distribution, in the alga Trachydiscus minutus. Phytochemistry 72, 2342-2351.

Samarakoon, T., Shiva, S., Lowe, K., Tamura, P., Roth, M.R., and Welti, R. (2012) Arabidopsis thaliana membrane lipid molecular species and their mass spectral analysis. Methods Mol. Biol. 918, 179-268.

Siloto, R.M., Madhavji, M., Wiehler, W.B., Burton, T.L., Boora, P.S., Laroche, A. and Weselake, R.J. (2008) An N-terminal fragment of mouse DGAT1 binds different acyl-CoAs with varying affinity. Biochem. Biophys. Res. Commun. 373, 350-354.

StåhIman, M., Pham, H.T., Adiels, M., Mitchell, T.W., Blanksby, S.J., Fagerberg, B., Ekroos, K. and Borén, J. (2012) Clinical dyslipidaemia is associated with changes in the lipid composition and 
inflammatory properties of apolipoprotein-B-containing lipoproteins from women with type 2 diabetes. Diabetologia 55, 1156-1166.

Thomas, M.C., Mitchell, T.W., Harman, D.G., Deeley, J.M., Murphy, R.C. and Blanksby, S.J. (2007) Elucidation of double bond position in unsaturated lipids by ozone electrospray ionization mass spectrometry. Anal Chem. 79, 5013-5022.

Tjellström, H., Yang, Z., Allen, D.K. and Ohlrogge, J.B. (2012) Rapid kinetic labeling of Arabidopsis cell suspension cultures: implications for models of lipid export from plastids. Plant Physiol. 158, 601-611.

Weselake, R.J., Madhavji, M., Szarka, S.J., Patterson, N.A., Wiehler, W.B., Nykiforuk, C.L., Burton, T.L., Boora, P.S., Mosimann, S.C., Foroud, N.A., Thibault, B.J., Moloney, M.M., Laroche, A. and Furukawa-Stoffer, T.L. (2006) Acyl-CoA-binding and self-associating properties of a recombinant 13.3 kDa N-terminal fragment of diacylglycerol acyltransferase-1 from oilseed rape. BMC Biochem. 7, 24.

Yang, Q., Shi, X., Gu, Q., Zhao, S., Shan, Y. and Xu, G. (2012) On-line two dimensional liquid chromatography/mass spectrometry for the analysis of triacylglycerides in peanut oil and mouse tissue. J. Chromatogr. B Analyt. Technol. Biomed. Life Sci. 895-896, 48-55.

Zhang, M., Fan, J., Taylor, D.C., and Ohlrogge, J.B. (2009) DGAT1 and PDAT1 acyltransferases have overlapping functions in Arabidopsis triacylglycerol biosynthesis and are essential for normal pollen and seed development. Plant Cell 21, 3885-3901. 
(a)

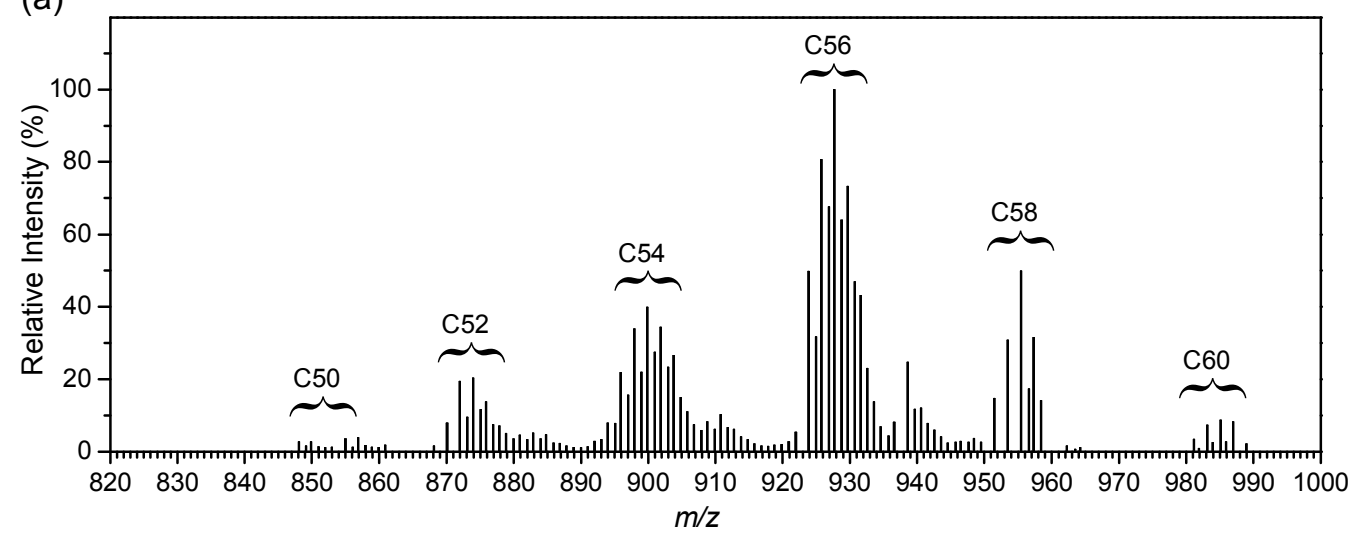

(b)

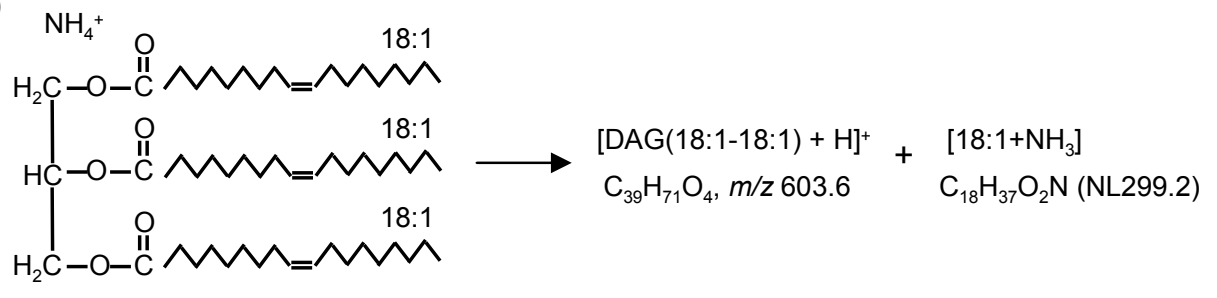

$\left[T A G(18: 1-18: 1-18: 1)+\mathrm{NH}_{4}\right]^{+}$

$\mathrm{C}_{57} \mathrm{H}_{108} \mathrm{O}_{6} \mathrm{~N} ; \mathrm{m} / \mathrm{z} 902.8$

(c)

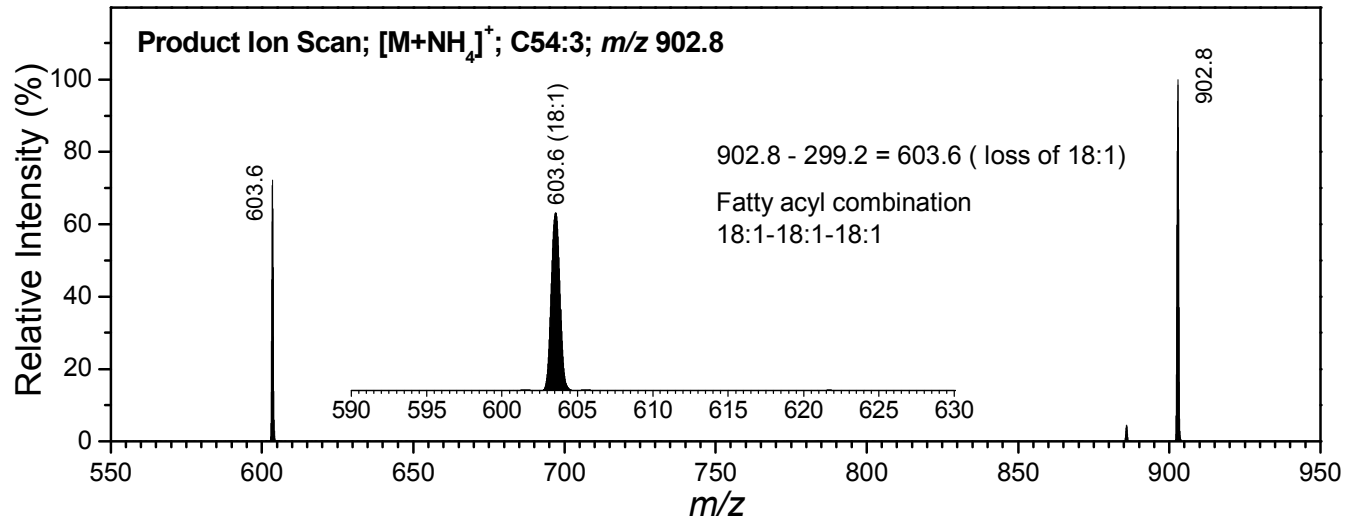

Figure 1. TAG groups in Arabidopsis seeds and fragmentation of ammoniated ions of intact TAG molecules. (a) Mass spectrum of intact ammoniated ions of TAG molecules from crude extract of Arabidopsis seeds, ionized by electrospray. C50, C52, C54, C56, C58, and C60 refer to the number of carbons in the three fatty acyl chains. The variation in $\mathrm{m} / \mathrm{z}$ within each carbon-number group is due to variation in number of double bonds. (b) Diagram illustrating the potential fatty acyl neutral losses from the ammoniated molecular ion of TAG 18:1-18:1-18:1. TAG 18:1-18:1-18:1 can also be expressed as C54:3 to indicate that there are 54 carbons and 3 double bonds in its fatty acyl chains. NL of 18:1 is predicted to generate a fragment ion of $m / z$ 603.6. (c) Product ion scanning of commercial TAG 18:118:1-18:1. The theoretical $\mathrm{m} / \mathrm{z}$ of the singly charged ammoniated ion of TAG $18: 1-18: 1-18: 1$ is 902.8 . The generation of a product ion of $m / z 603.6$ indicates the NL of 18:1. Fatty acids undergo neutral loss in combination with $\mathrm{NH}_{3}$. 


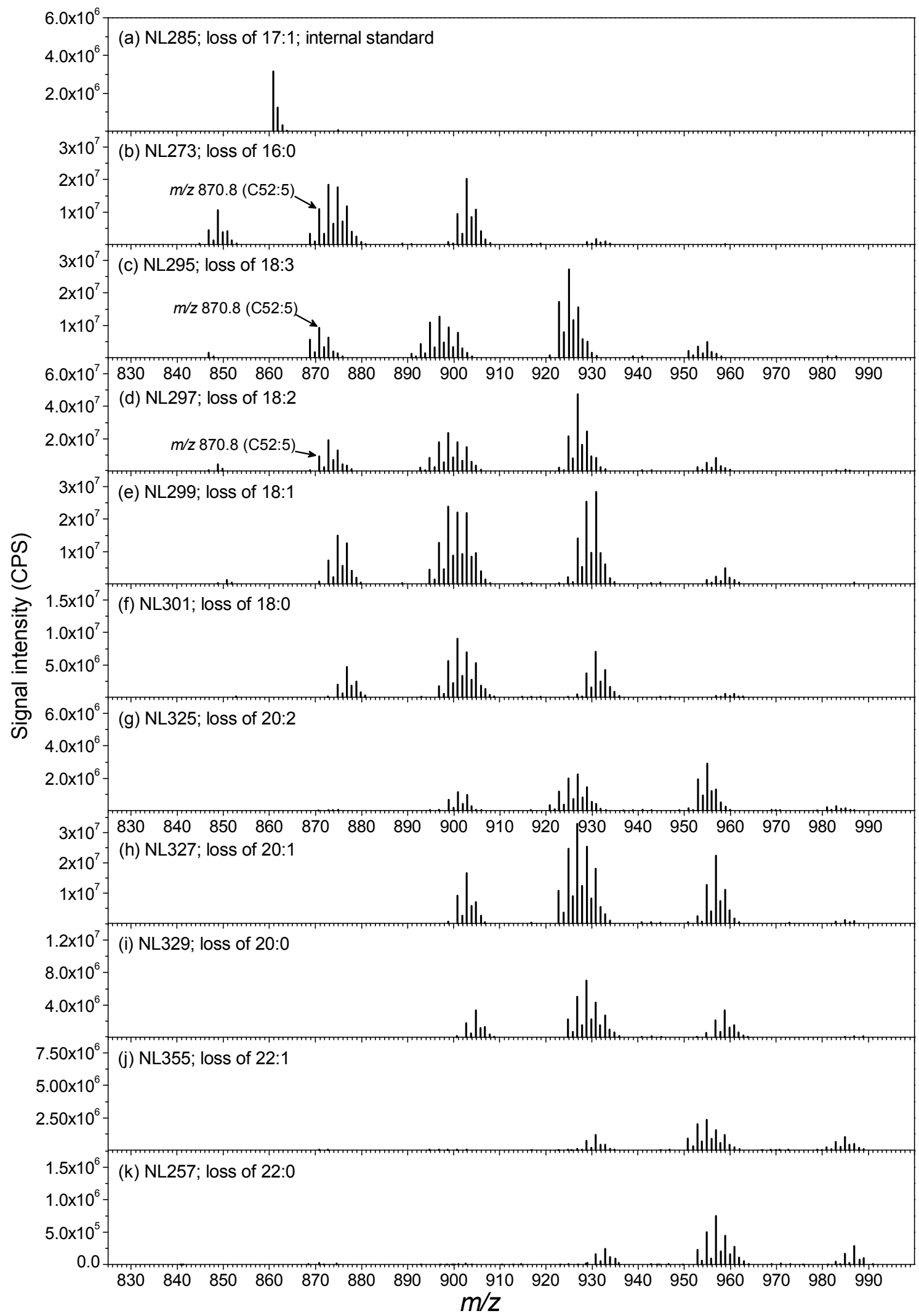

Figure 2. Multiple NL scans of ammoniated TAG molecular ions in extracts of Arabidopsis seeds. (a) NL scan of ammoniated tri17:1-TAG (internal standard TAG 17:1-17:1-17:1) in a seed oil sample. (b-k) Scanning in NL mode for precursors of neutral fragments corresponding to ten fatty acyl chains. The $\mathrm{m} / \mathrm{z}$ of signals in the spectra were used to determine the identities of each ammoniated TAG molecular ion and the intensity is used to determine TAG amount. 
(a)

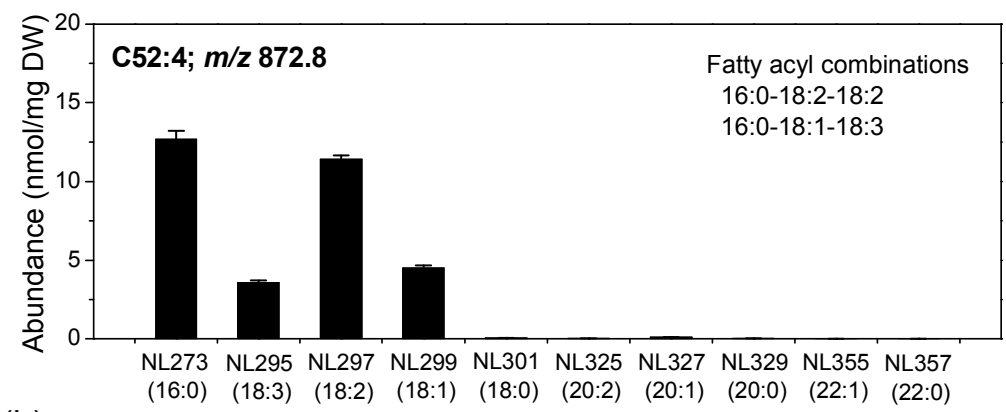

(b)

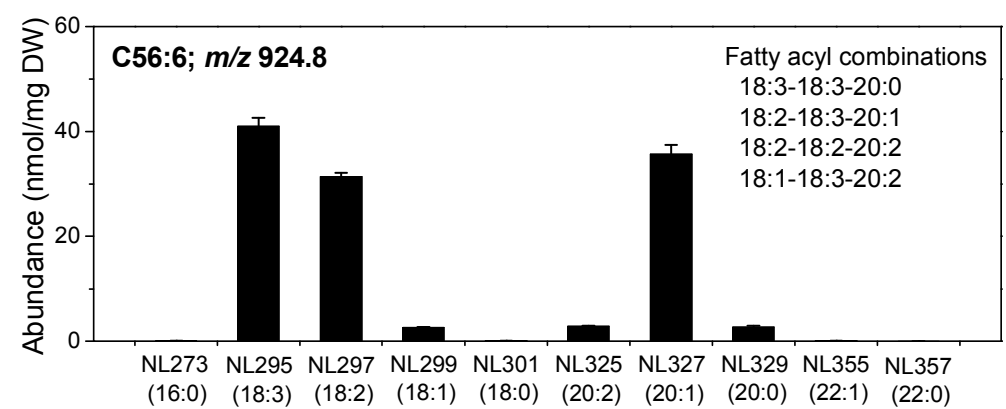

(c)

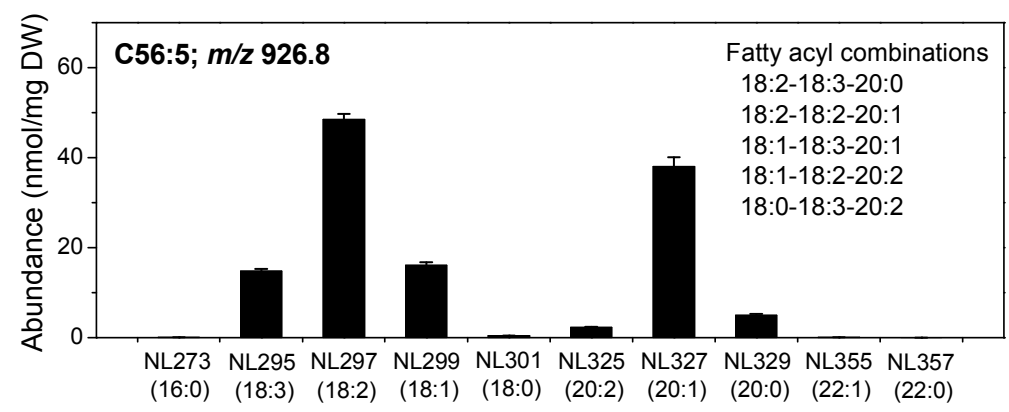

Figure 3. The abundance of ten fatty acyl chains at TAG mass of $m / z 872.8,924.8$, and 926.8. Data from NL scans have been isotopically deconvoluted and adjustment factors have been applied. TAG abundance was determined by comparing the deconvoluted, corrected intensities with those of the internal standards. (a) The abundance of each fatty acyl chain at TAG $\mathrm{m} / \mathrm{z} 872.8$ was calculated from the spectra acquired in each of $10 \mathrm{NL}$ scan modes. Two fatty acyl chain combinations can be deduced for $\mathrm{m} / \mathrm{z} 872.8$ (C52:4) based on numbers of acyl carbons and double bonds. (b) The abundance of each fatty acyl chain at TAG $\mathrm{m} / \mathrm{z} 924.8$ was calculated from the NL spectra. Four fatty acyl chain combinations can be deduced for $\mathrm{m} / \mathrm{z} 924.8$ (C56:6). (c) The abundance of each fatty acyl chain at TAG $\mathrm{m} / \mathrm{z}$ 926.8 was calculated from the NL spectra. Five fatty acyl chain combinations can be deduced for $\mathrm{m} / \mathrm{z} 926.8$ (C56:5). The complete data for the fatty acyl abundance at each TAG mass are listed in Table S2. Values are means \pm SE $(n=5)$. 
(a)

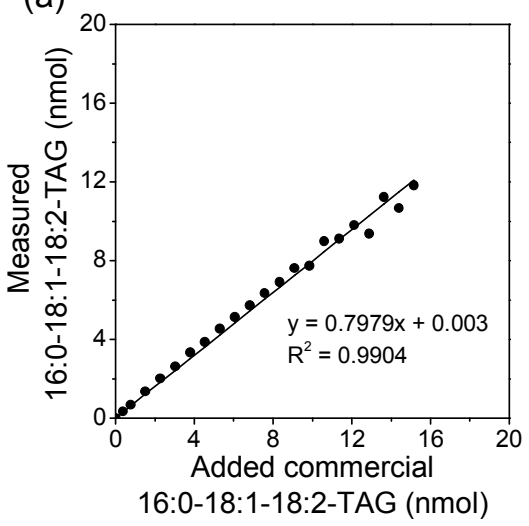

(d)

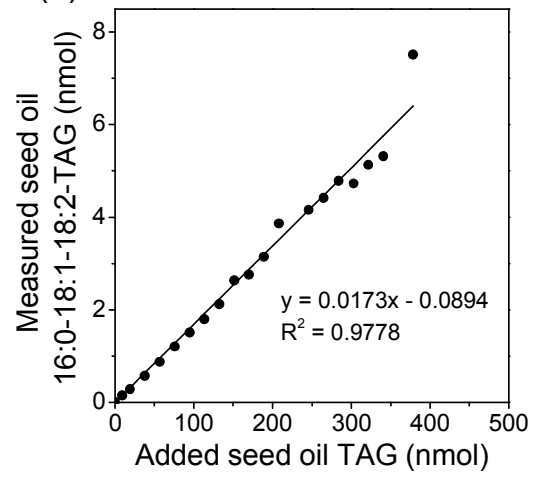

(b)

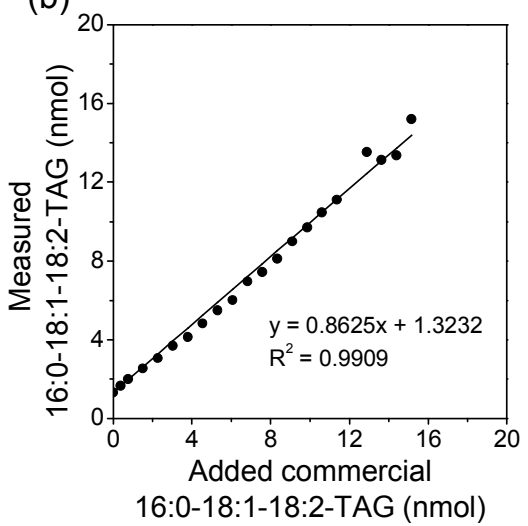

(e)

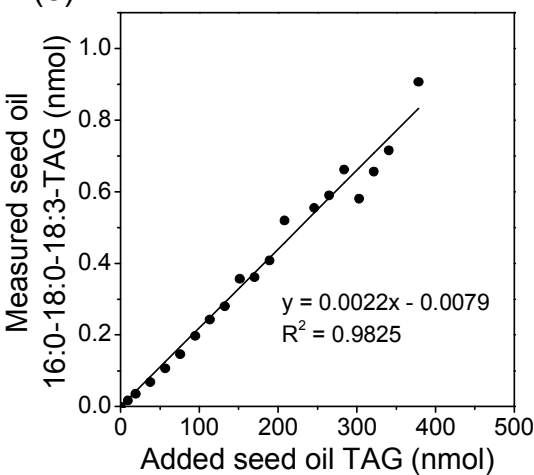

(c)

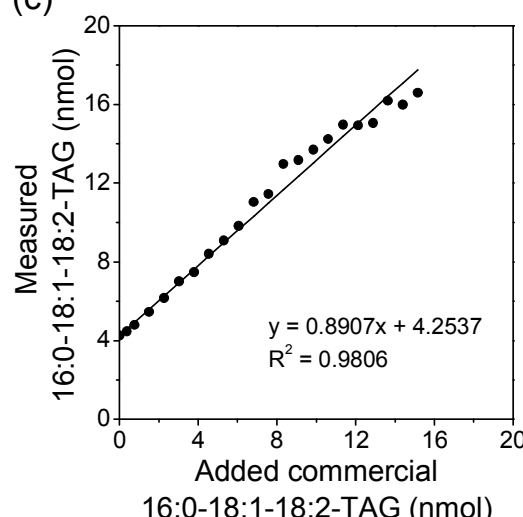

(f)

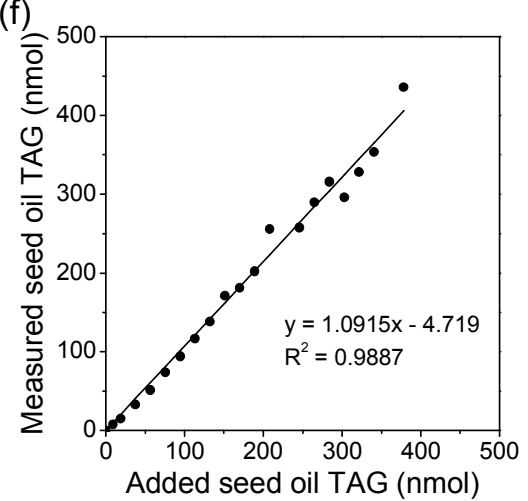

Figure 4. Validation of the quantitative TAG profiling method. (a-c) Measurement of TAG 16:0-18:1-18:2 after spike-in of commercially obtained TAG 16:0-18:1-18:2 in the presence of around (a) $0 \mathrm{nmol}$, (b) $55 \mathrm{nmol}$, and (c) $275 \mathrm{nmol}$ of Arabidopsis seed oil. Tri17:1-TAG was used as an internal standard, and quantitation was performed as described in the Text. The confidence interval on the slope at $95 \%$ is $(0.80,0.90)$ for the slopes among a-c. (d-f) Measurement of seed TAGs in the presence of increasing amounts of seed oil. Measured TAGs were (d) 16:0-18:1-18:2, (e) 16:0-18:0-18:3-TAG, and (f) total seed TAG. Added commercial and seed TAGs were quantified by gas chromatographic analysis as described in Experimental Procedures. 
(a)

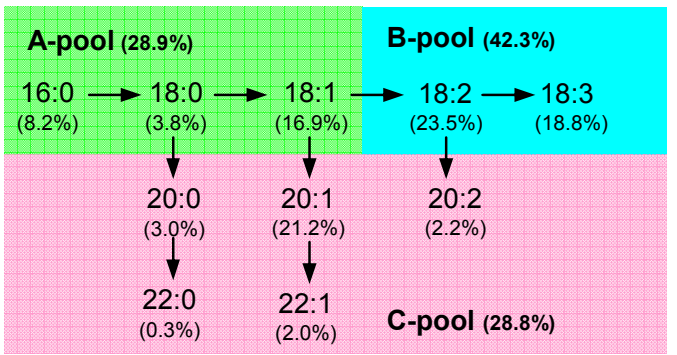

(b)

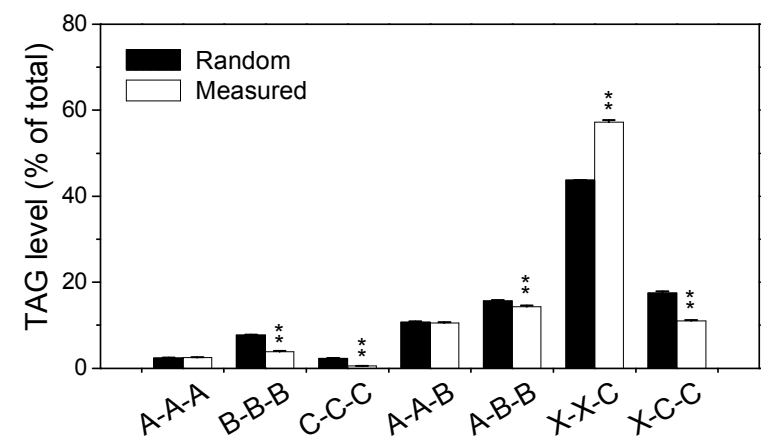

Figure 5. Distribution of fatty acyl chains among TAG groups. (a) Definition of three hypothetical pools of fatty acyl chains destined to TAG assembly. The fatty acyl chains 16:0, 18:0, and 18:1 are collectively designated as the A-pool; the fatty acyl chains $18: 2$ and $18: 3$ are collectively designated as the B-pool; and the fatty acyl chains 20:0, 20:1, 20:2, 22:0, and 22:1 are collectively designated as the C-pool. (b) TAG pattern comparison between random fatty acyl selection from the fatty acyl pools and the measured pattern. The sn-position of acyl chains are not specified in the description of TAG molecules in this work. A-A-A refers to TAGs with three fatty acyl chains from A-pool; B-B-B refers to TAGs which have three fatty acyl chains from B-pool, and so on. $X$ refers to either $A$ or $B$. A chi-square test has been performed to compare the difference between observed group pattern and expected group pattern and the $p$ value is 0.0098 , which is smaller than 0.05 and indicates that the difference is significant. "**" refers to $\mathrm{P}<0.01$ as compared with the randomized acyl combination and measured combination, based on Student's $t$ test. Values were means \pm SE $(n=5)$. 
Table 1. Levels of TAG molecular species in wild-type seeds of Arabidopsis. The fatty acyl abundances were determined from ion intensities in the multiple neutral loss scans of ammoniated intact TAG ions as described in the text using the adjustment factors in Table S1 and the complete results are shown in Table S2. The levels of fatty acyl combinations at each of $46 \mathrm{~m} / \mathrm{z}$ were calculated from the fatty acyl abundance using the "Calculation formulae" listed in Table S3. The TAG levels are expressed in absolute level (nmol/mg dry mass) and relative level (\% of total). Values are means \pm SE $(n=5)$.

\begin{tabular}{|c|c|c|c|c|c|c|c|c|c|}
\hline \multicolumn{2}{|l|}{$m / z$} & \multirow{2}{*}{$\begin{array}{c}\text { Combination } \\
16: 0-16: 0-16: 0\end{array}$} & \multirow{2}{*}{$\frac{\mathrm{nmol} / \mathrm{mg}}{0.007^{ \pm 0.00}}$} & \multirow{2}{*}{$\frac{\mathrm{mol} \%}{0.002^{ \pm 0.00}}$} & \multicolumn{2}{|l|}{$m / z$} & \multirow{2}{*}{$\frac{\text { Combination }}{16: 0-18: 2-20: 0}$} & \multirow{2}{*}{$\frac{\mathrm{nmol} / \mathrm{mg}}{2.265^{ \pm 0.12}}$} & \multirow{2}{*}{$\frac{\mathrm{mol} \%}{0.604^{ \pm 0.01}}$} \\
\hline 824.8 & C48:0 & & & & 904.8 & C54:2 & & & \\
\hline 846.8 & C50:3 & $16: 0-16: 0-18: 3$ & $0.871 \pm 0.03$ & $0.234^{ \pm 0.01}$ & & & 16:0-18:1-20:1 & $4.880 \pm 0.31$ & $1.299 \pm 0.03$ \\
\hline 848.8 & C50:2 & $16: 0-16: 0-18: 2$ & $1.839 \pm 0.05$ & $0.494^{ \pm 0.02}$ & & & $18: 0-18: 0-18: 2$ & $0.000 \pm 0.00$ & $0.000 \pm 0.00$ \\
\hline 850.8 & C50:1 & $16: 0-16: 0-18: 1$ & $0.618^{ \pm 0.02}$ & $0.165^{ \pm 0.01}$ & & & 18:0-18:1-18:1 & $0.270^{ \pm 0.02}$ & $0.072^{ \pm 0.01}$ \\
\hline 852.8 & C50:0 & $16: 0-16: 0-18: 0$ & $0.013^{ \pm 0.00}$ & $0.004^{ \pm 0.00}$ & 906.9 & C54:1 & $\begin{array}{c}16: 0-16: 0-22: 1 \\
16 \cdot 0-18 \cdot 1-20 \cdot 0\end{array}$ & $\begin{array}{l}0.000^{ \pm 0.00} \\
0768 \pm 0.06\end{array}$ & $0.000^{ \pm 0.00}$ \\
\hline 868.7 & C52:6 & $16: 0-18: 3-18: 3$ & $3.718^{ \pm 0.17}$ & $0.995^{ \pm 0.04}$ & & & $16: 0-18: 0-20: 1$ & $0.000 \pm 0.00$ & $0.000 \pm 0.00$ \\
\hline 870.8 & C52:5 & $16: 0-18: 2-18: 3$ & $8.879^{ \pm 0.27}$ & $2.385^{ \pm 0.12}$ & & & 18:0-18:0-18:1 & $0.232^{ \pm 0.02}$ & $0.061^{ \pm 0.00}$ \\
\hline \multirow[t]{2}{*}{872.8} & C52:4 & $16: 0-18: 2-18: 2$ & $5.701 \pm 0.13$ & $1.530 \pm 0.05$ & 908.9 & C54:0 & Not detectable & & \\
\hline & & $16: 0-18: 1-18: 3$ & $4.043^{ \pm 0.13}$ & $1.082^{ \pm 0.02}$ & 920.8 & C56:8 & $18: 3-18: 3-20: 2$ & $0.966^{ \pm 0.04}$ & $0.259 \pm 0.01$ \\
\hline \multirow[t]{2}{*}{874.8} & C52:3 & $16: 0-18: 0-18: 3$ & $0.681 \pm 0.04$ & $0.182^{ \pm 0.00}$ & 922.8 & C56:7 & $18: 3-18: 3-20: 1$ & $19.905 \pm 1.10$ & $5.304^{ \pm 0.10}$ \\
\hline & & $16: 0-18: 1-18: 2$ & $6.222^{ \pm 0.24}$ & $1.663^{ \pm 0.02}$ & & & $18: 2-18: 3-20: 2$ & $3.092^{ \pm 0.06}$ & $0.830 \pm 0.03$ \\
\hline \multirow[t]{3}{*}{876.8} & C52:2 & $16: 0-16: 0-20: 2$ & $0.001^{ \pm 0.00}$ & $0.000^{ \pm 0.00}$ & 924.8 & C56:6 & $18: 3-18: 3-20: 0$ & $2.719 \pm 0.20$ & $0.722^{ \pm 0.03}$ \\
\hline & & $16: 0-18: 0-18: 2$ & $1.646 \pm 0.07$ & $0.440^{ \pm 0.01}$ & & & $18: 2-18: 3-20: 1$ & $35.694^{ \pm 1.68}$ & $9.524^{ \pm 0.06}$ \\
\hline & & $16: 0-18: 1-18: 1$ & $2.709 \pm 0.14$ & $0.723^{ \pm 0.01}$ & & & $18: 2-18: 2-20: 2$ & $0.000^{ \pm 0.00}$ & $0.000^{ \pm 0.00}$ \\
\hline \multirow[t]{2}{*}{878.8} & C52:1 & $16: 0-16: 0-20: 1$ & $0.020 \pm 0.00$ & $0.005^{ \pm 0.00}$ & & & $18: 1-18: 3-20: 2$ & $2.603^{ \pm 0.13}$ & $0.694^{ \pm 0.01}$ \\
\hline & & $16: 0-18: 0-18: 1$ & $0.690 \pm 0.04$ & $0.184^{ \pm 0.01}$ & 926.8 & C56:5 & $18: 2-18: 3-20: 0$ & $5.050 \pm 0.24$ & $1.347 \pm 0.02$ \\
\hline \multirow[t]{2}{*}{880.8} & C52:0 & $16: 0-16: 0-20: 0$ & $0.003^{ \pm 0.00}$ & $0.001 \pm 0.00$ & & & $18: 2-18: 2-20: 1$ & $24.324^{ \pm 1.63}$ & $6.477^{ \pm 0.22}$ \\
\hline & & $16: 0-18: 0-18: 0$ & $0.020^{ \pm 0.00}$ & $0.005^{ \pm 0.00}$ & & & $18: 1-18: 3-20: 1$ & $13.721^{ \pm 0.53}$ & $3.667 \pm 0.05$ \\
\hline & & & & & & & $18: 1-18: 2-20: 2$ & $1.924 \pm 0.08$ & $0.515^{ \pm 0.02}$ \\
\hline 890.7 & C54:9 & $18: 3-18: 3-18: 3$ & $1.218^{ \pm 0.08}$ & $0.325^{ \pm 0.02}$ & & & $18: 0-18: 3-20: 2$ & $0.468^{ \pm 0.03}$ & $0.125^{ \pm 0.00}$ \\
\hline 892.7 & C54:8 & $18: 2-18: 3-18: 3$ & $4.727^{ \pm 0.21}$ & $1.268^{ \pm 0.06}$ & 928.8 & C56:4 & $16: 0-18: 3-22: 1$ & $0.838^{ \pm 0.04}$ & $0.225^{ \pm 0.01}$ \\
\hline \multirow[t]{2}{*}{894.8} & C54:7 & $18: 1-18: 3-18: 3$ & $6.160^{ \pm 0.32}$ & $1.644^{ \pm 0.05}$ & & & 16:0-20:2-20:2 & $0.050^{ \pm 0.02}$ & $0.014^{ \pm 0.01}$ \\
\hline & & $18: 2-18: 2-18: 3$ & $6.252^{ \pm 0.25}$ & $1.676^{ \pm 0.07}$ & $18: 1-18$ & $3-20: 0$ an & nd 18:2-18:2-20:0 & $5.909 \pm 0.20$ & $1.580^{ \pm 0.02}$ \\
\hline \multirow[t]{3}{*}{896.8} & C54:6 & $18: 0-18: 3-18: 3$ & $1.753^{ \pm 0.11}$ & $0.467 \pm 0.02$ & $\begin{array}{l}18: 0-1 \varepsilon \\
18: 0-1 \varepsilon\end{array}$ & $\begin{array}{l}3-20: 1 \text { an } \\
2-20: 2 \text { an }\end{array}$ & $\begin{array}{l}\text { nd } 18: 1-18: 2-20: 1 \\
\text { nd } 18: 1-18: 1-20: 2\end{array}$ & $\begin{array}{r}22.004^{ \pm 1.19} \\
1.149^{ \pm 0.06}\end{array}$ & $\begin{array}{l}5.869 \pm 0.13 \\
0.307 \pm 0.01\end{array}$ \\
\hline & & $18: 1-18: 2-18: 3$ & $14.951 \pm 0.71$ & $3.990 \pm 0.06$ & $10.0-10$ & $2-\angle U .2$ & $10.1-10.1-20.2$ & & \\
\hline & & $18: 2-18: 2-18: 2$ & $2.319 \pm 0.06$ & $0.624^{ \pm 0.03}$ & 930.9 & C56:3 & $16: 0-18: 3-22: 0$ & $0.136^{ \pm 0.02}$ & $0.036^{ \pm 0.00}$ \\
\hline \multirow[t]{4}{*}{898.8} & C54:5 & $16: 0-18: 3-20: 2$ & $0.613^{ \pm 0.04}$ & $0.163^{ \pm 0.01}$ & & & $16: 0-18: 2-22: 1$ & $1.193 \pm 0.05$ & $0.321 \pm 0.02$ \\
\hline & & $18: 0-18: 2-18: 3$ & $4.616^{ \pm 0.19}$ & $1.234^{ \pm 0.03}$ & & & $\begin{array}{l}16: 0-20: 1-20: 2 \\
18 \cdot 0-18 \cdot 3-20 \cdot 0\end{array}$ & $\begin{array}{l}0.439 \pm 0.07 \\
0.077 \pm 0.02\end{array}$ & $\begin{array}{l}0.119 \pm 0.02 \\
0.021 \pm 0.01\end{array}$ \\
\hline & & $18: 1-18: 1-18: 3$ & $16.273^{ \pm 0.88}$ & $4.340 \pm 0.11$ & & & $18: 1-18: 2-20: 0$ & $3.406^{ \pm 0.23}$ & $0.906^{ \pm 0.03}$ \\
\hline & & $18: 1-18: 2-18: 2$ & $7.987^{ \pm 0.42}$ & $2.129^{ \pm 0.04}$ & & & $18: 0-18: 2-20: 1$ & $0.883^{ \pm 0.17}$ & $0.243^{ \pm 0.06}$ \\
\hline \multirow[t]{5}{*}{900.8} & C54:4 & $16: 0-18: 3-20: 1$ & $7.545^{ \pm 0.43}$ & $2.010^{ \pm 0.04}$ & & & $18: 1-18: 1-20: 1$ & $14.258^{ \pm 1.46}$ & $3.769 \pm 0.22$ \\
\hline & & $16: 0-18: 2-20: 2$ & $0.991^{ \pm 0.03}$ & $0.266^{ \pm 0.01}$ & & & $18: 0-18: 1-20: 2$ & $0.001 \pm 0.00$ & $0.000 \pm 0.00$ \\
\hline & & $18: 0-18: 1-18: 3$ & $0.000^{ \pm 0.00}$ & $0.000^{ \pm 0.00}$ & 932.9 & C56:2 & $16: 0-18: 2-22: 0$ & $0.258^{ \pm 0.02}$ & $0.069 \pm 0.00$ \\
\hline & & $18: 0-18: 2-18: 2$ & $5.927^{ \pm 0.26}$ & $1.582^{ \pm 0.01}$ & & & $16: 0-18: 1-22: 1$ & $0.342^{ \pm 0.02}$ & $0.092^{ \pm 0.01}$ \\
\hline & & $18: 1-18: 1-18: 2$ & $7.803^{ \pm 0.37}$ & $2.083^{ \pm 0.04}$ & & & $16: 0-20: 1-20: 1$ & $0.247 \pm 0.04$ & $0.067 \pm 0.01$ \\
\hline \multirow[t]{6}{*}{902.8} & C54:3 & $16: 0-18: 3-20: 0$ & $1.208^{ \pm 0.07}$ & $0.322^{ \pm 0.01}$ & & & $16: 0-20: 0-20: 2$ & \multicolumn{2}{|c|}{ Not detectable } \\
\hline & & $16: 0-18: 2-20: 1$ & $12.259 \pm 0.66$ & $3.268^{ \pm 0.04}$ & & & $18: 0-18: 2-20: 0$ & $0.075^{ \pm 0.05}$ & $0.019 \pm 0.01$ \\
\hline & & $16: 0-18: 1-20: 2$ & $0.668^{ \pm 0.02}$ & $0.179 \pm 0.01$ & & & $18: 1-18: 1-20: 0$ & $2.165^{ \pm 0.18}$ & $0.575^{ \pm 0.02}$ \\
\hline & & $18: 0-18: 0-18: 3$ & $0.000^{ \pm 0.00}$ & $0.000 \pm 0.00$ & & & $18: 0-18: 1-20: 1$ & $0.708 \pm 0.25$ & $0.181 \pm 0.06$ \\
\hline & & $18: 0-18: 1-18: 2$ & $0.000^{ \pm 0.00}$ & $0.000 \pm 0.00$ & & & $18: 0-18: 0-20: 2$ & \multicolumn{2}{|c|}{ Not detectable } \\
\hline & & $18: 1-18: 1-18: 1$ & $4.733^{ \pm 0.34}$ & $1.258^{ \pm 0.05}$ & 934.9 & C56:1 & $16: 0-18: 1-22: 0$ & $0.084^{ \pm 0.01}$ & $0.023^{ \pm 0.00}$ \\
\hline
\end{tabular}


Table 1 (Continued-2)

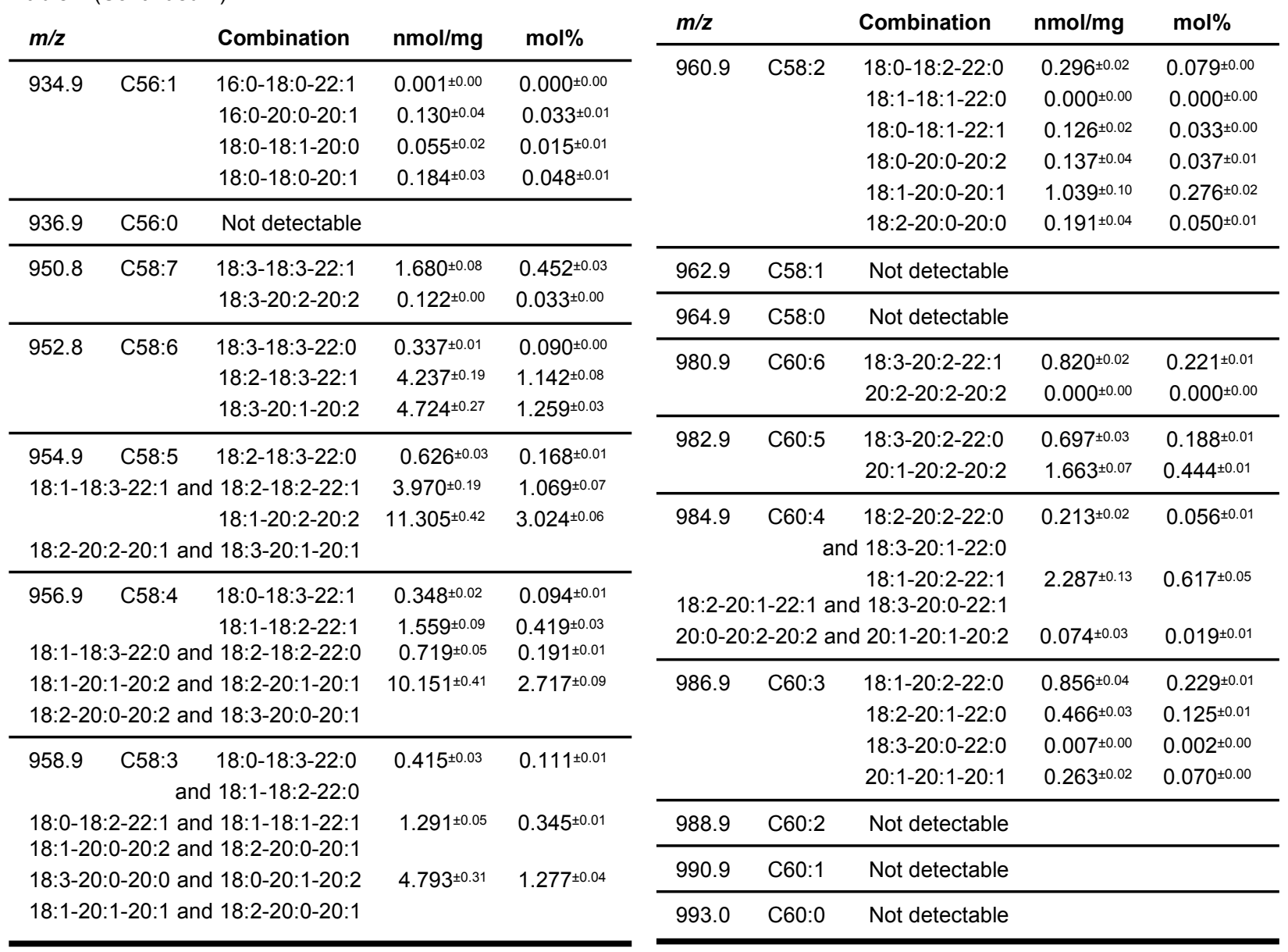




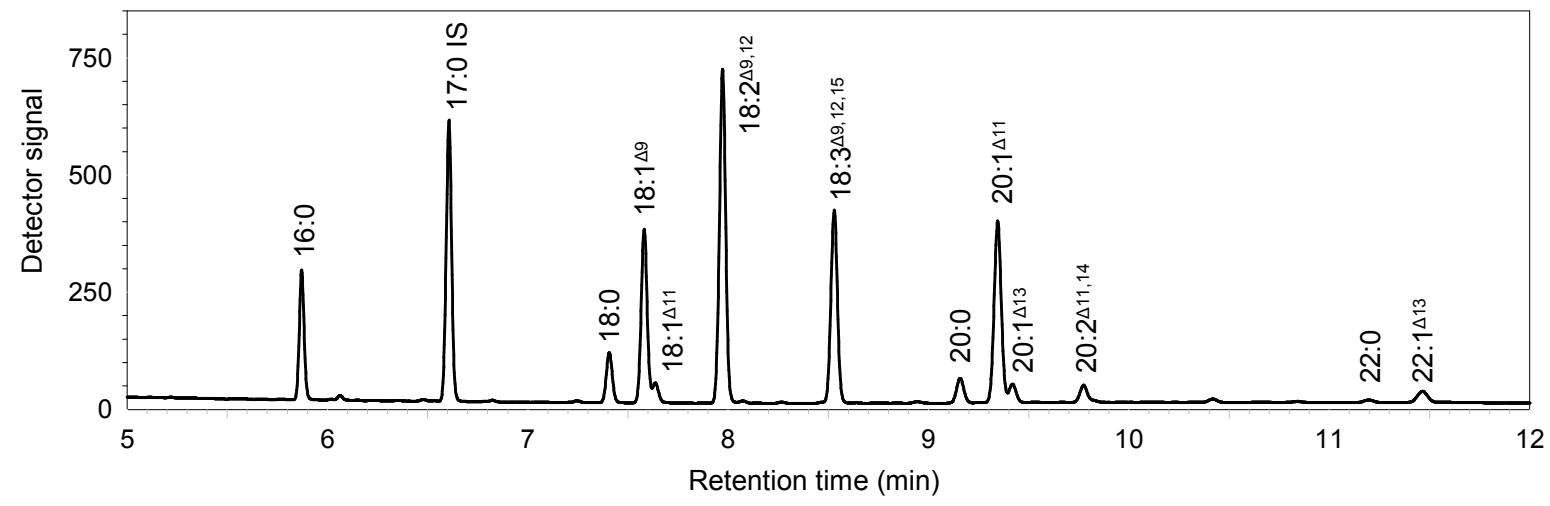

Figure S1. Fatty acyl composition of Arabidopsis seeds. Fatty acyl methyl esters (FAMEs) derived from Arabidopsis seeds were profiled by gas chromatography and detected by flame ionization. 
(a)

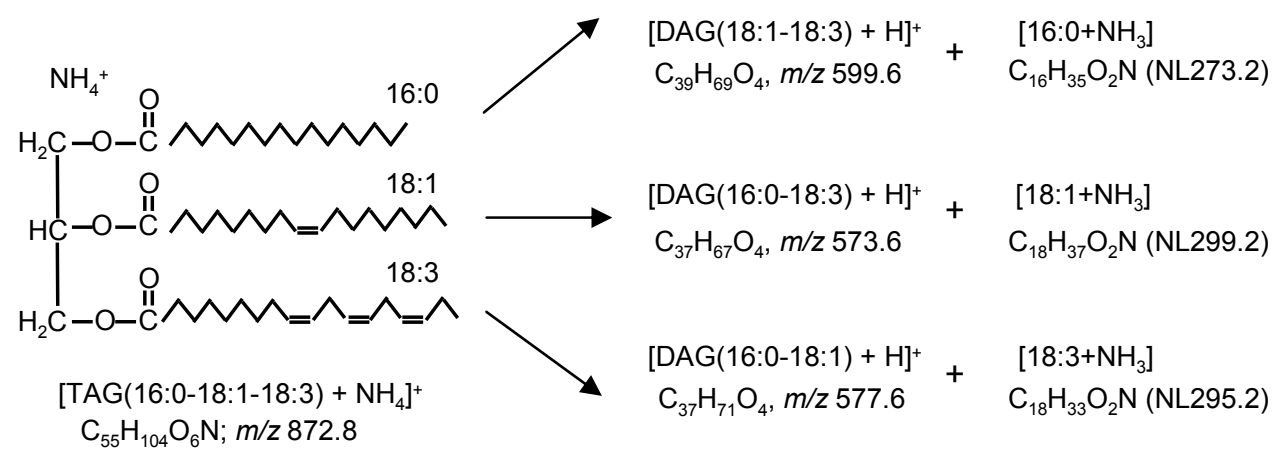

(b)

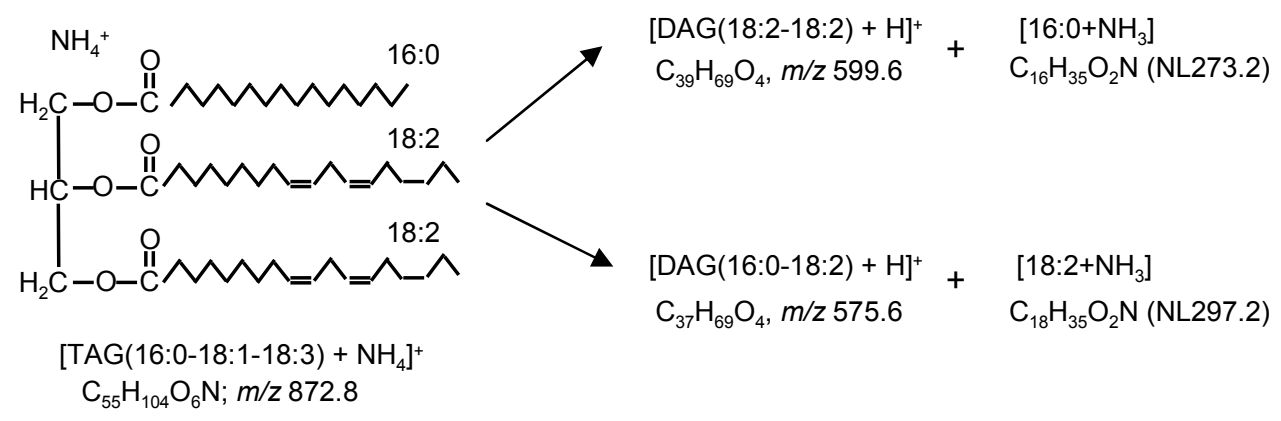

(c)

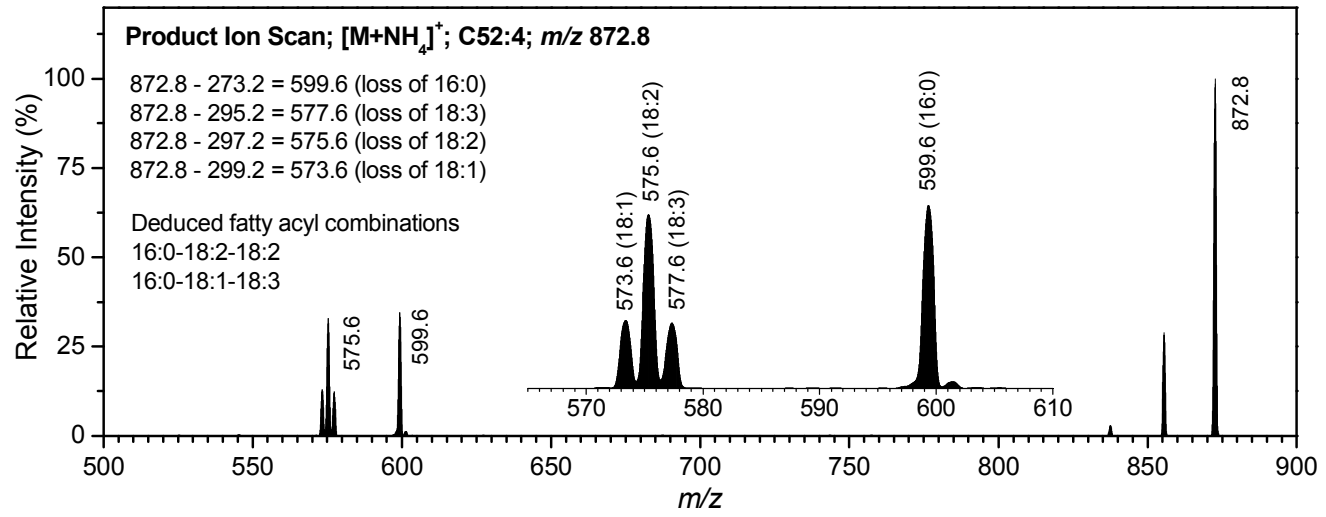

Figure S2. Fragmentation patterns of ammoniated ions of intact TAG molecules. (a) Diagram illustrating the three potential fatty acyl neutral losses from the ammoniated molecular ion of TAG 16:0-18:1-18:3. TAG 16:0-18:1-18:3 can also be expressed as C52:4 to indicate that there are 52 carbons and 4 double bonds in its fatty acyl chains. NL of $16: 0,18: 1$, or $18: 3$ is predicted to generate fragment ions of $\mathrm{m} / \mathrm{z}$ $599.6,573.6$, or 577.6 , respectively. (b) Diagram illustrating the three potential fatty acyl neutral losses from the ammoniated molecular ion of TAG 16:0-18:2-18:2. TAG 16:0-18:2-18:2 can also be expressed as C52:4 to indicate that there are 52 carbons and 4 double bonds in its fatty acyl chains. NL of 16:0 or 18:2 is predicted to generate fragment ions of $m / z 599.6$ or 575.6 , respectively. (c) Product ion scanning of $\mathrm{m} / \mathrm{z} 872.8$ in an Arabidopsis seed extract reveals the potential fatty acyl combination of TAGs at this mass. The theoretical $\mathrm{m} / \mathrm{z}$ of the singly charged ammoniated ion of C52:4 is 872.8 . The generation of product ions of $m / z 573.6,575.6,577.6$, and 599.6 indicate the $\mathrm{NL}$ of $18: 1,18: 2,18: 3$, and 16:0, respectively. Fatty acids undergo neutral loss in combination with $\mathrm{NH}_{3}$. 
(a)

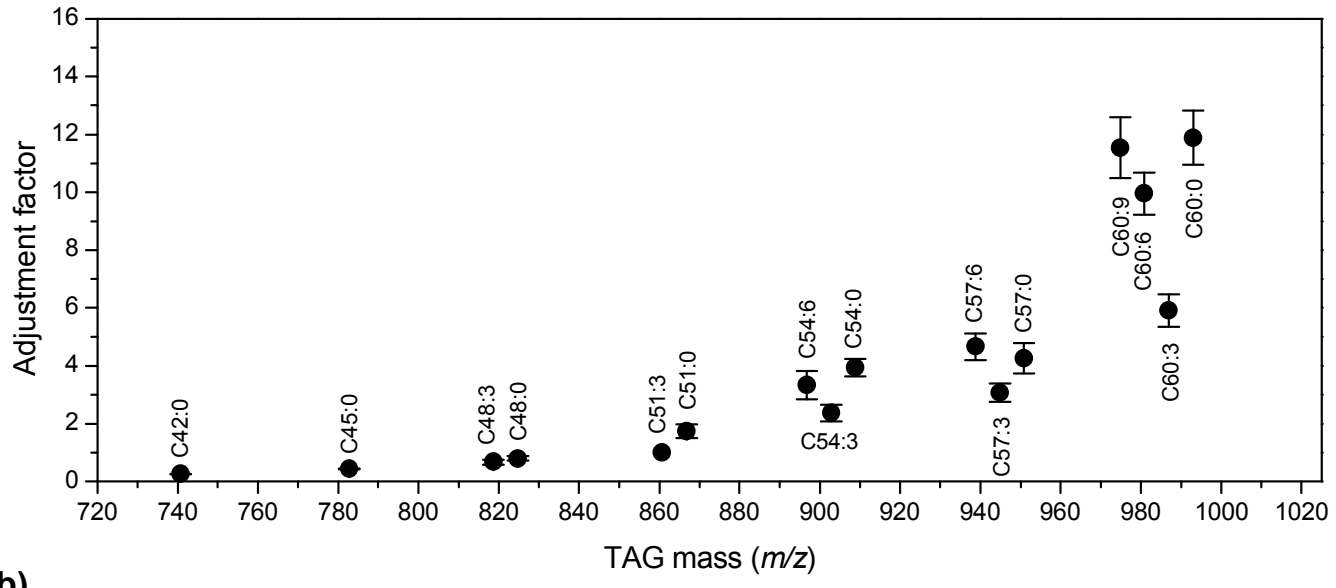

(b)

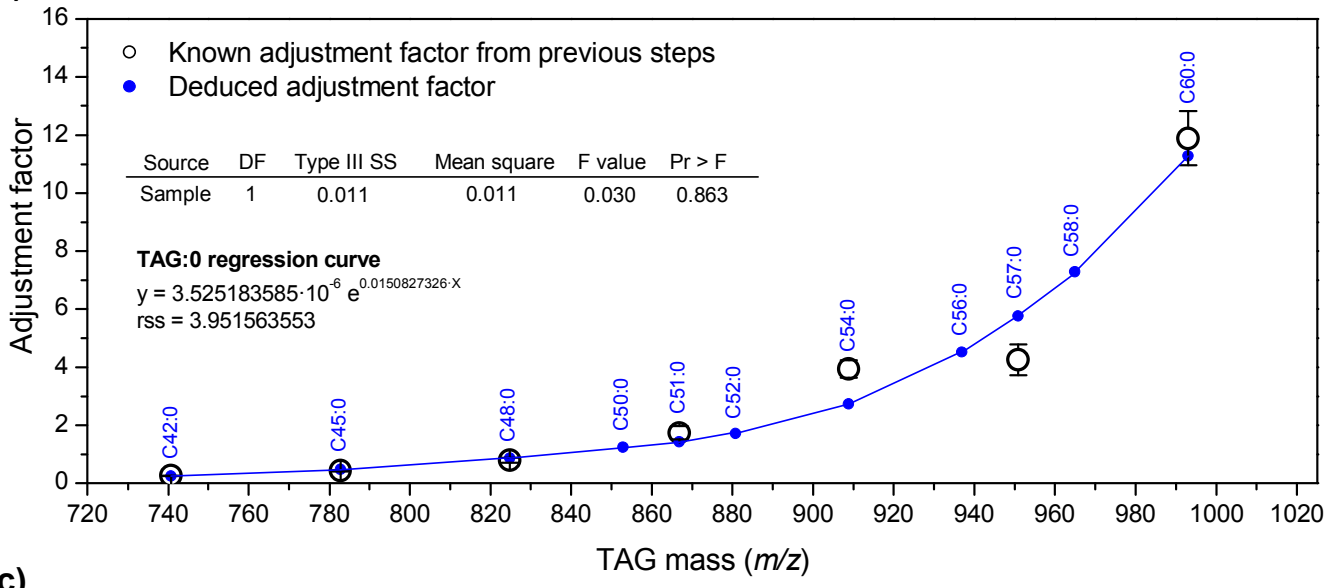

(c)

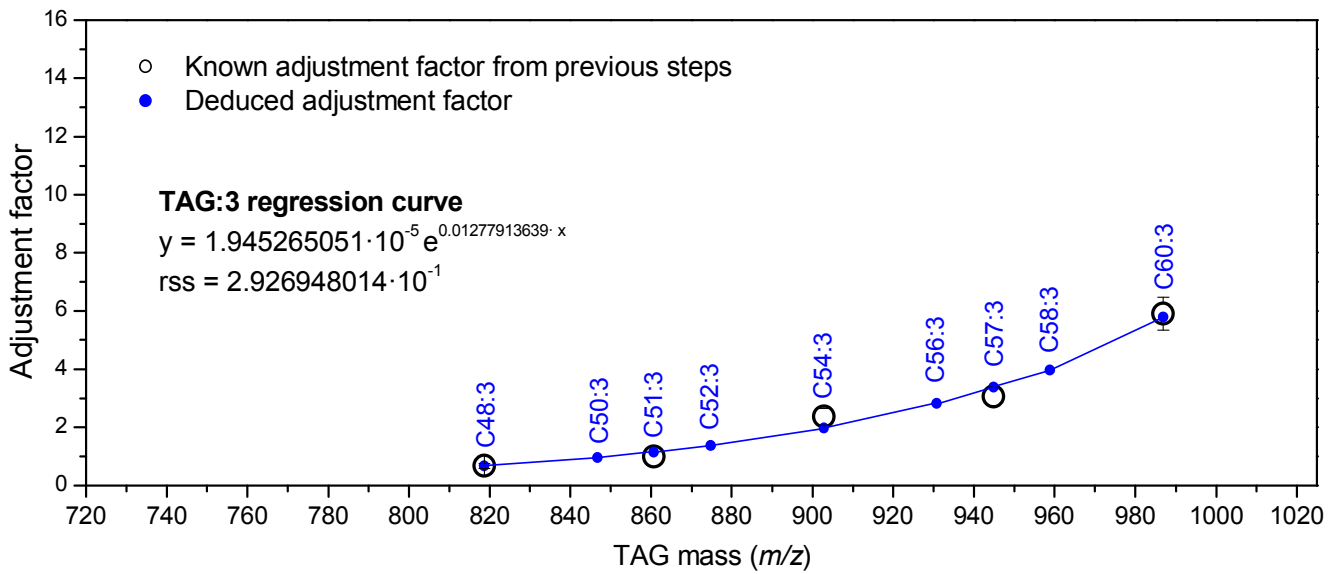

Figure S3. Measured adjustment factors for commercially available TAGs and deduction of adjustment factors for TAGs with 0 and 3 double bonds. (a) 15 measured adjustment factors for commercially available TAGs. The adjustment factor for the internal standard C51:3 (tri17:1) is 1. Adjustment factor is defined as the NL signal intensity of internal standard divided by the NL signal intensity for each TAG, when the TAG and the internal standard are equimolar. The adjustment factors are listed in Table S1. The values are means $\pm S E(n \geq 5)$. (b) Regression curve of saturated TAGs. Online tools were used to generate this exponential regression analysis (www.xuru.org). The adjustment factors utilized to derive the regression curve and the adjustment factors deduced from the regression curve were statistically analyzed for difference with the software SAS 9.1.3 running on Linux 2.6.32. The results are shown in an inserted ANOVA table, in which $\operatorname{Pr}>\mathrm{F}(0.863)$ indicates that there is no significant difference between the input and the resulting dataset. (c) Regression curve of TAGs with 3 double bonds (TAG:3). The derived regression formulae are shown in the insert. Online tools were used to generate this exponential regression analysis (www.xuru.org). In the equations shown in panels b and c, where " $x$ " represents the $m / z$ of the ammoniated TAG ions, "y" represents the resulting adjustment factor, and "rss" stands for "residual sum of squares". 
(a)

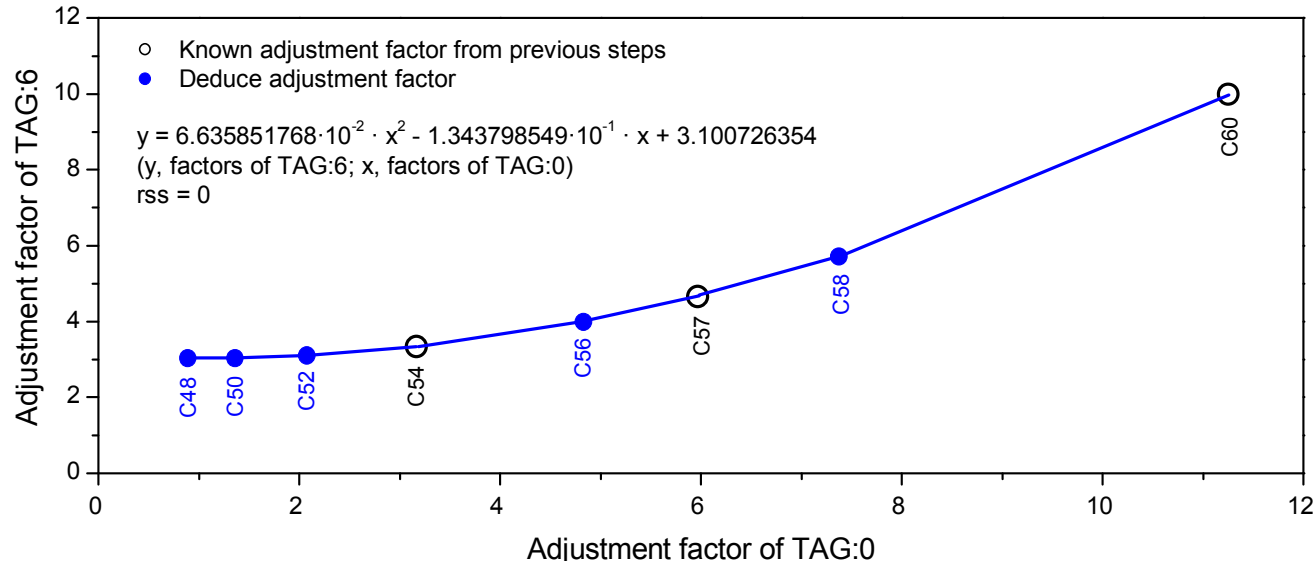

(b)

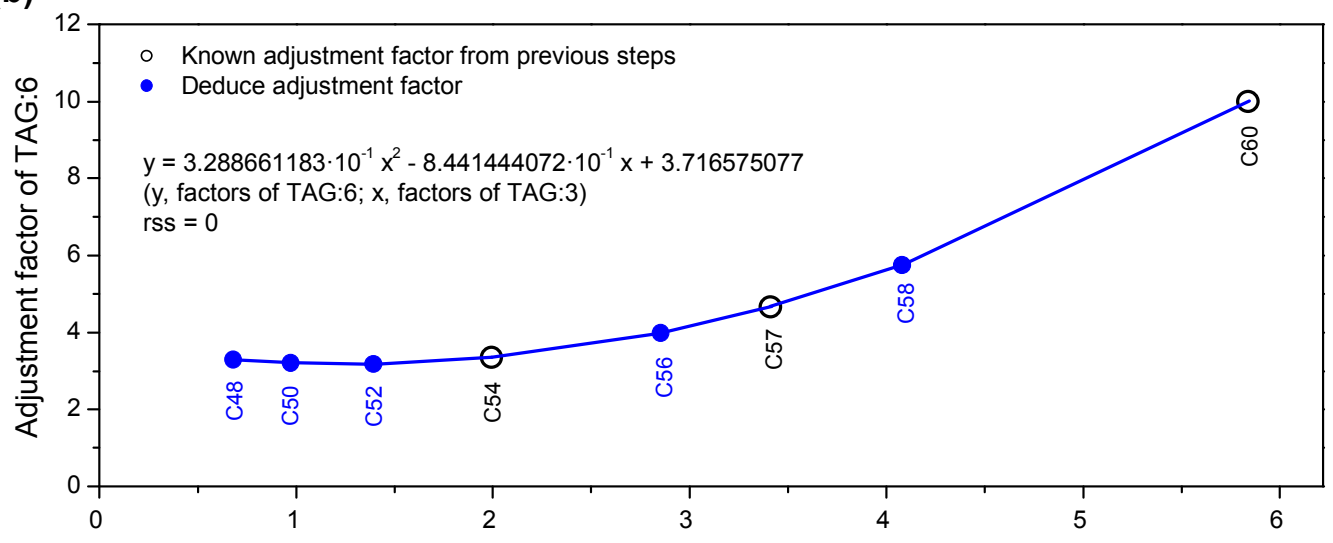

Adjustment factor of TAG:3

(c)

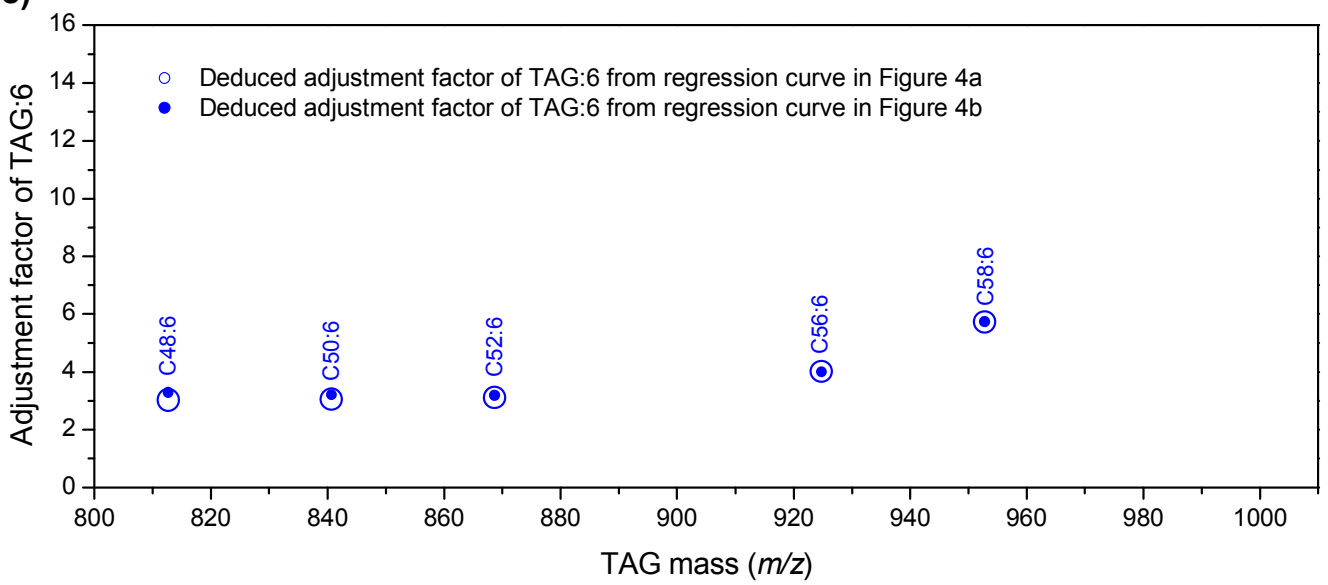

Figure S4. Derivation of adjustment factors for TAGs with 6 fatty acyl double bonds (TAG:6). (a) Deduction of adjustment factors of C48:6, C50:6, C52:6, C56:6, C58:6 from a regression curve derived from the adjustment factor pairs of TAG:0 $\rightarrow$ TAG:6. The measured values for three adjustment factor pairs, (C54:0, C54:6), (C57:0, C57:6), and (C60:0, C60:6), were plotted and fitted in a regression curve, in which " $y$ " represents the adjustment factor of TAG:6; and " $x$ " represents the adjustment factors of TAG:0. From the deduced adjustment factors of C48:0, C50:0, C52:0, C56:0, C58:0 in Figure S3b, the factors for C48:6, C50:6, C52:6, C56:6, C58:6 could be deduced from the curve. (b) Deduction of adjustment factors of C48:6, C50:6, C52:6, C56:6, C58:6 from the regression curve derived from adjustment factor pairs of TAG:3 $\rightarrow$ TAG:6. Three measured adjustment factor pairs, including (C54:3, C54:6), (C57:3, C57:6), and (C60:3, C60:6), were fit with a regression curve, in which "y" represents the adjustment factor of TAG:6; and " $x$ " represents the adjustment factors of TAG:3. From the deduced adjustment factor values of C48:3, C50:3, C52:3, C56:3, C58:3, the factors for C48:6, C50:6, C52:6, C56:6, C58:6 could be deduced from the curve. (c) The adjustment factors of C48:6, C50:6, C52:6, C56:6, C58:6 from regression curves derived from the adjustment pairs of TAG:0 $\rightarrow$ TAG: 6 and TAG:3 $\rightarrow$ TAG: 6 . There is no significant difference between these two datasets of adjustment factor values, as indicated by a log likelihood test $(p=0.32>$ 0.05). The two values for each adjustment factor were then averaged for further applications. 
(a)

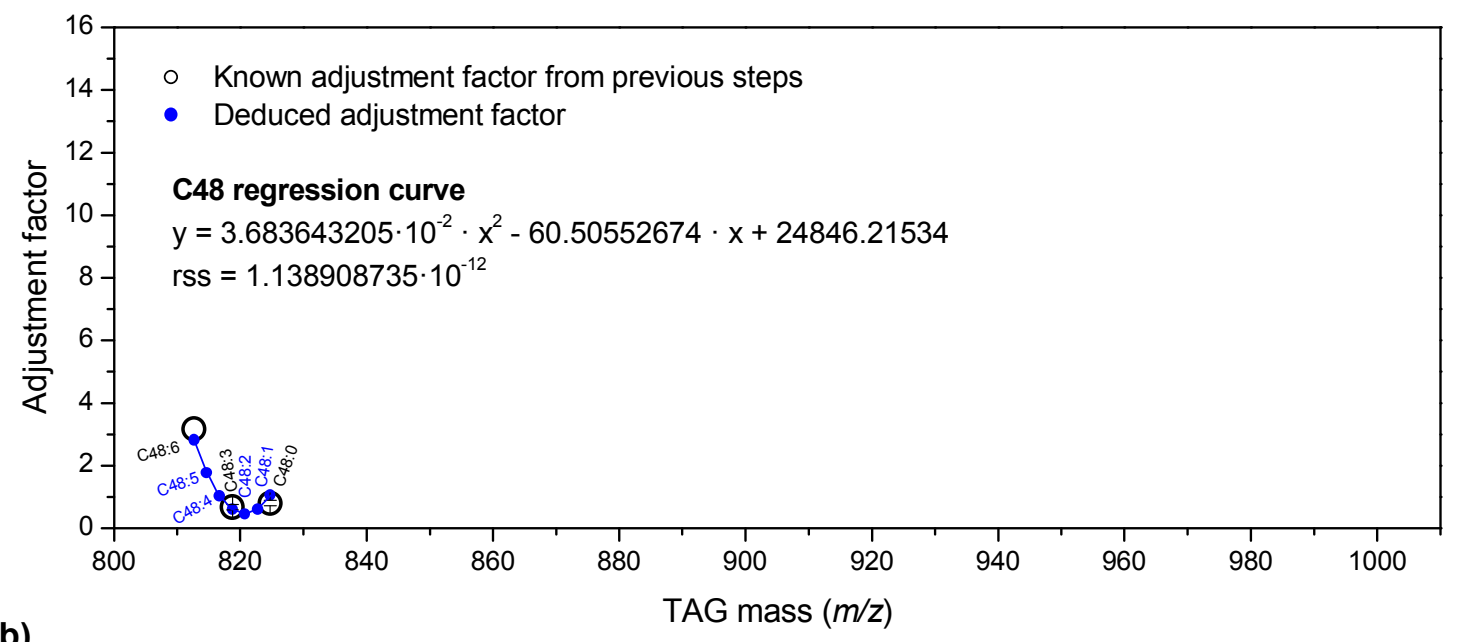

(b)

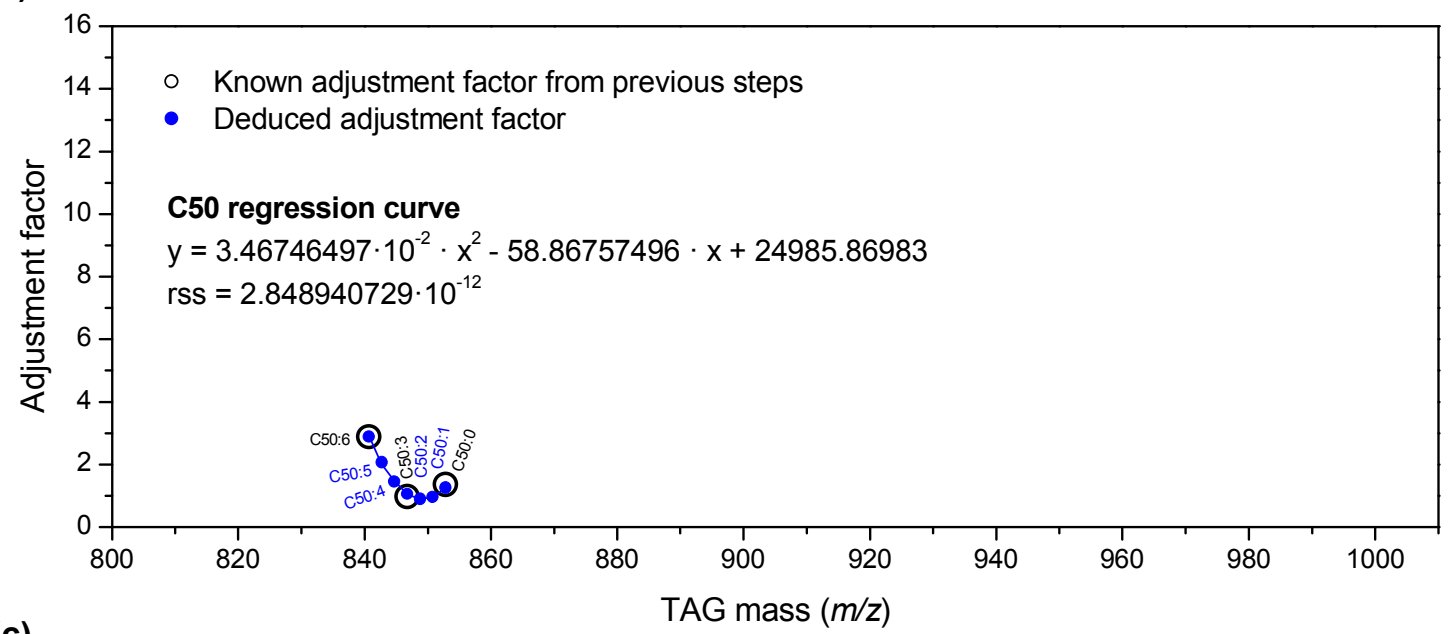

(c)

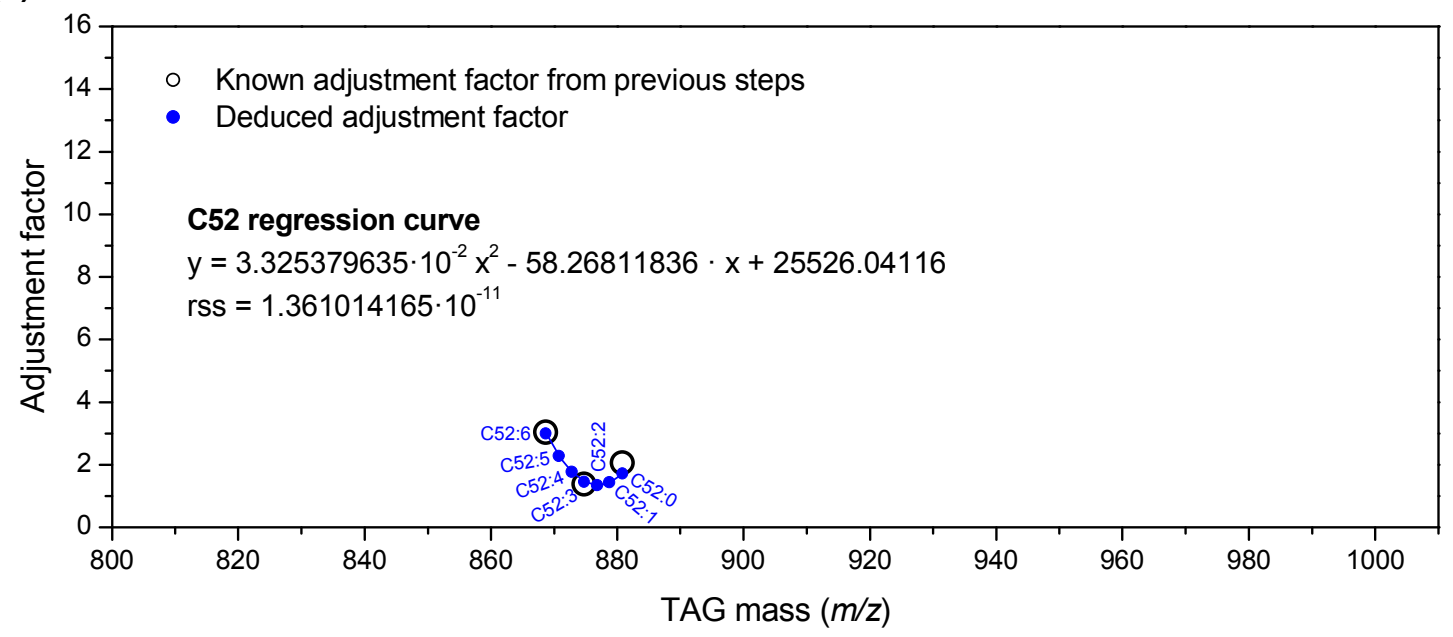


(d)

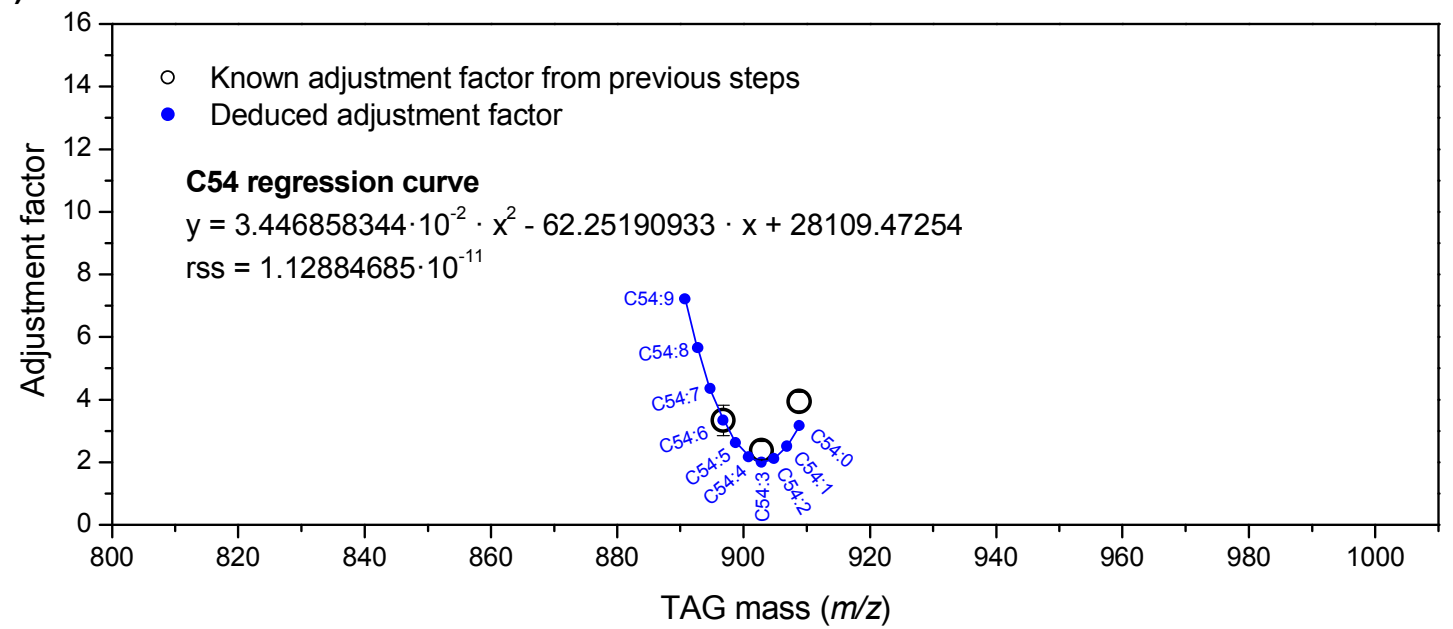

(e)

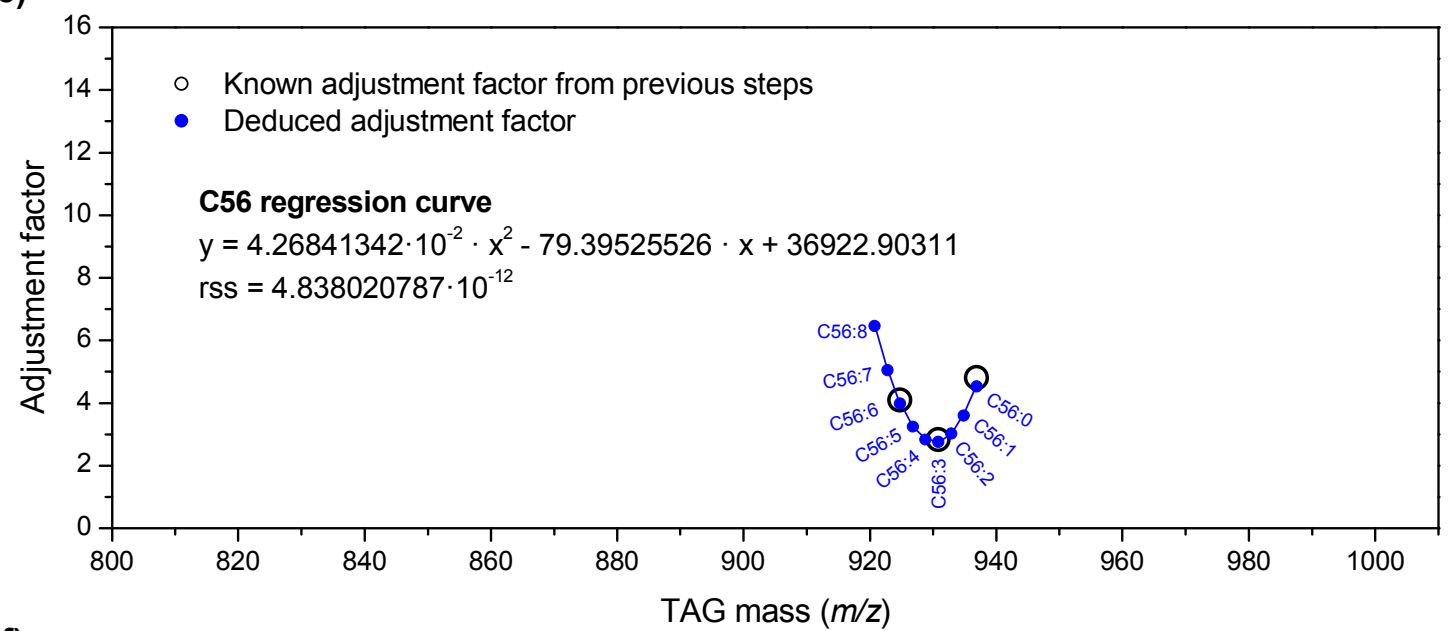

(f)

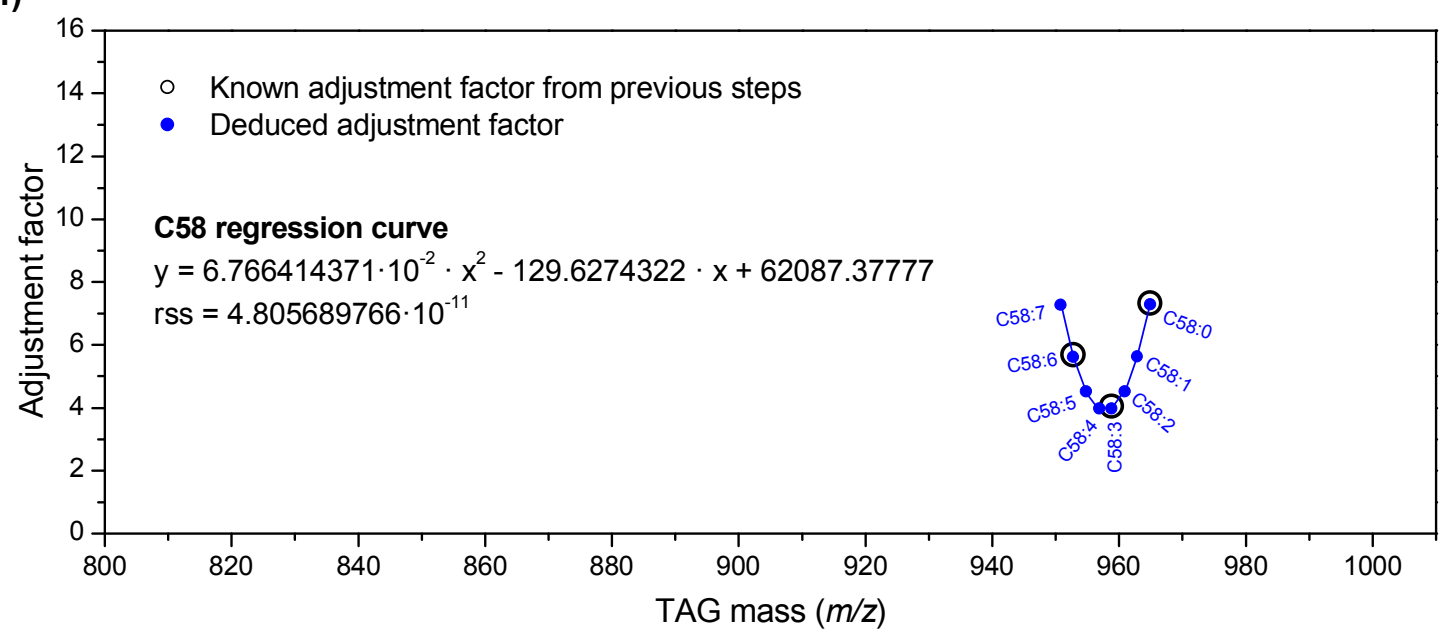


(g)

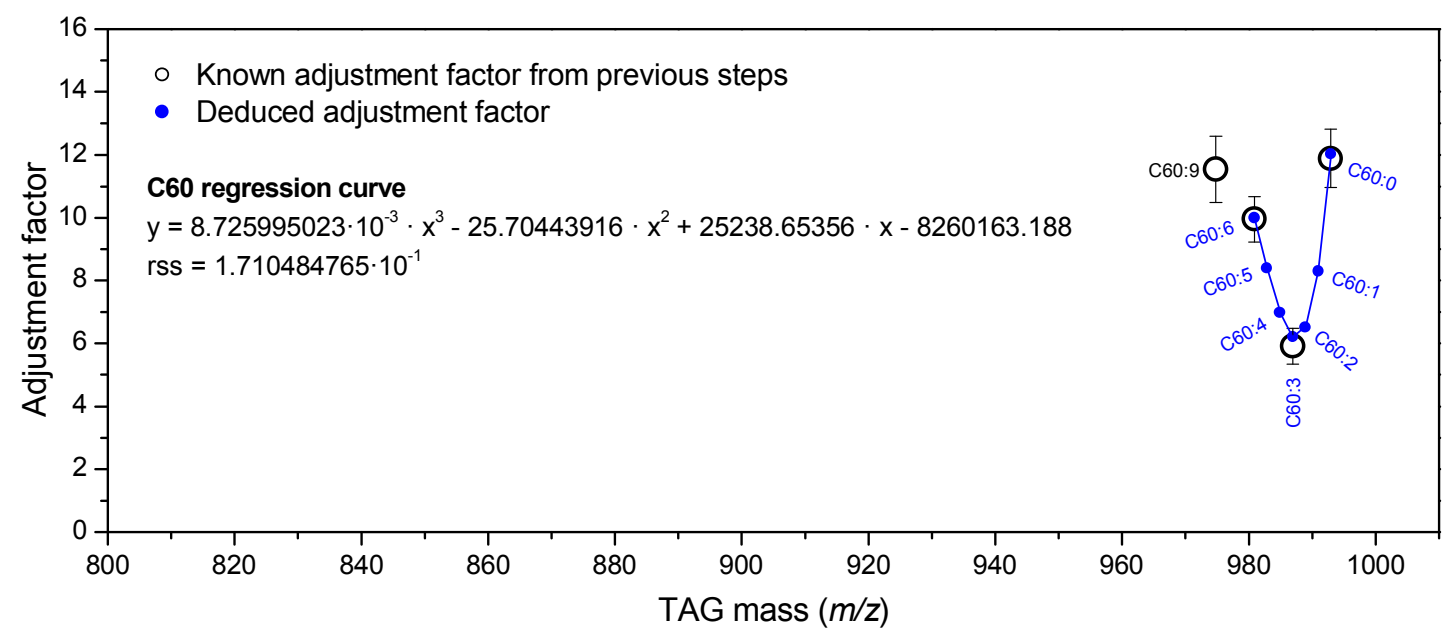

Figure S5. Derivation of the regression curves for deduction of the adjustment factors at TAG groups of C48, C50, C52, C54, C56, C58, and C60. (a) Derivation of a regression curve for the deduction of adjustment factors of TAGs in group C48. The adjustment factors for C48:0, C48:3, and C48:6, deduced from regression curves as shown in Figure S3-4, were fit with a quadratic regression curve for deduction of adjustment factors for the other TAGs in the C48 group. (b-f) Derivation of regression curves for the deduction of adjustment factors of TAGs in groups C50, C52, C54, C56, and C58. The adjustment factors for TAG:0, TAG:3, and TAG:6, deduced from regression curves as shown in Figure S3-4, were each fit with a quadratic regression curve for deduction of adjustment factors for the other TAGs in the C50, C52, C54, C56, and C58 groups. (g) Derivation of a regression curve for TAGs in group C60. The adjustment factor data for C60:0, C60:3, C60:6 and C60:9 were measured (Figure S3a), allowing fitting the C60 group with a cubic regression curve for deduction of adjustment factors of other TAGs in this group. The adjustment factor is defined as the NL signal intensity of internal standard divided by the NL signal intensity for each TAG, when the TAG and the internal standard are equimolar. The adjustment factors of the other TAGs were deduced by regression curves inserted (a-g), where "y" represents the adjustment factor, " $x$ " represents the precise $\mathrm{m} / \mathrm{z}$ of ammoniated TAG ions, and "rss" represents "residual sum of squares". The deduced adjustment factors for each TAG mass were listed in Table S1. 


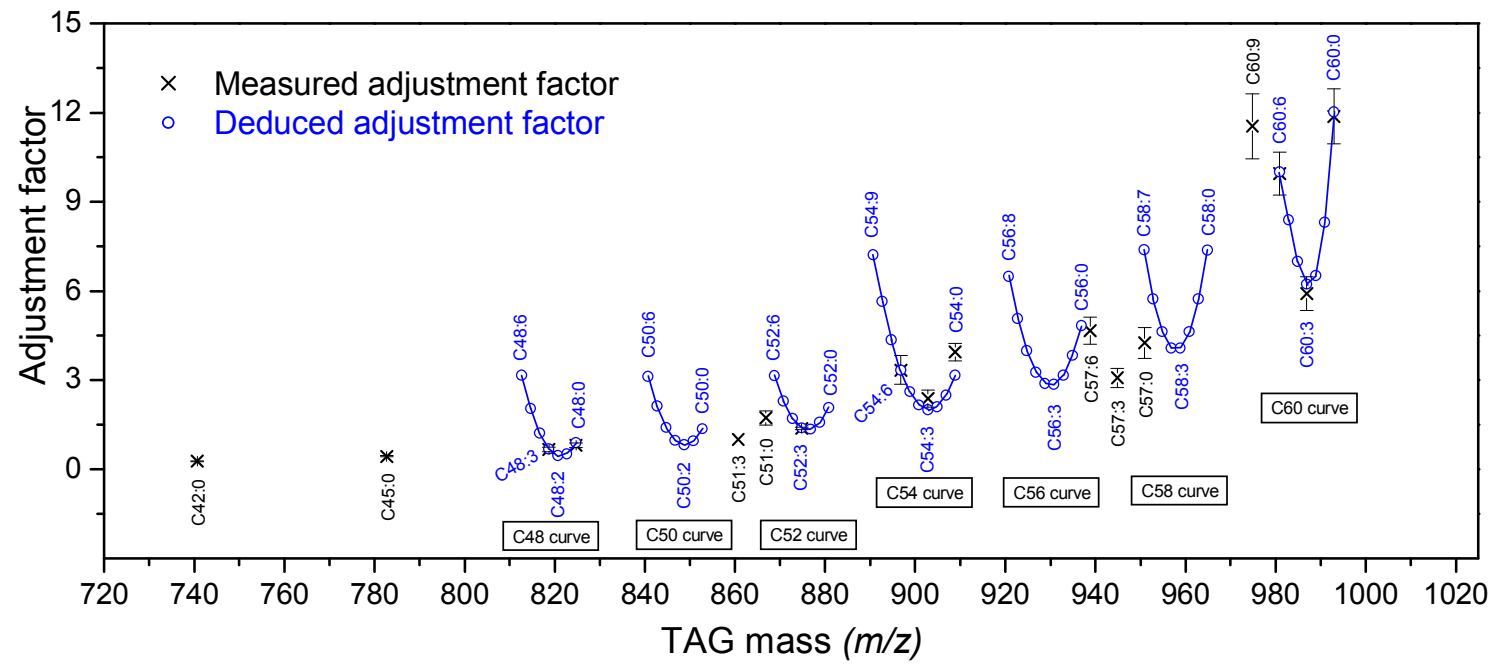

Figure S6. Measured adjustment factors for commercially available TAGs and deduced adjustment factors for seed oil TAGs. Along each curve, the seed oil TAG of a particular acyl carbon number with no double bonds is represented by the point at the highest $\mathrm{m} / \mathrm{z}$; increasing numbers of double bonds are associated with loss of $2 \mathrm{~m} / \mathrm{z}$. For the measured adjustment factors, the values are means $\pm S E(n \geq 5)$. The deduced adjustment factors for each TAG mass were listed in Table S1. 
(a)

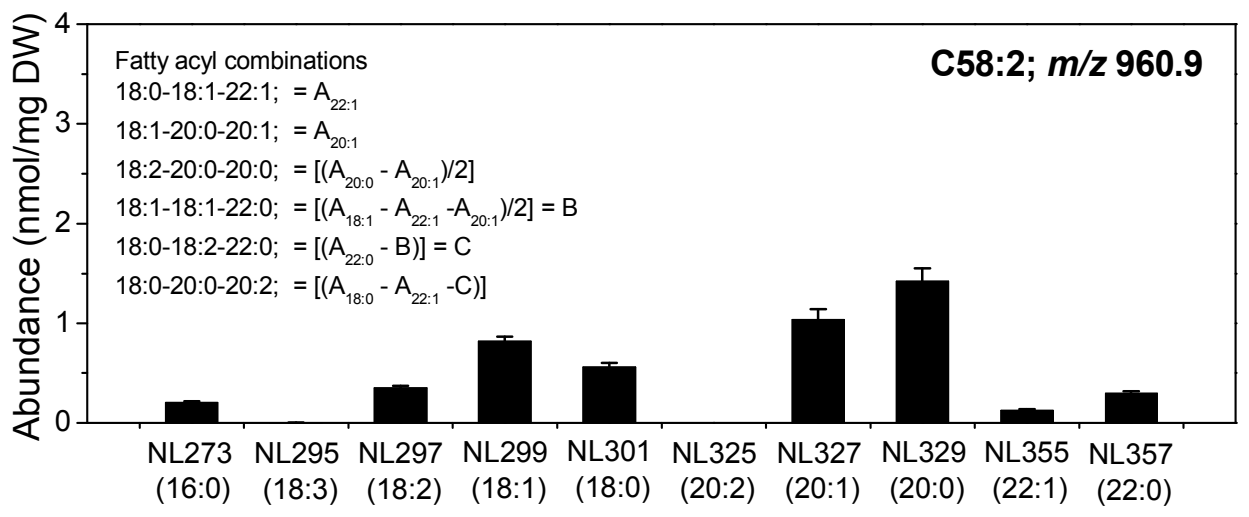

(b)

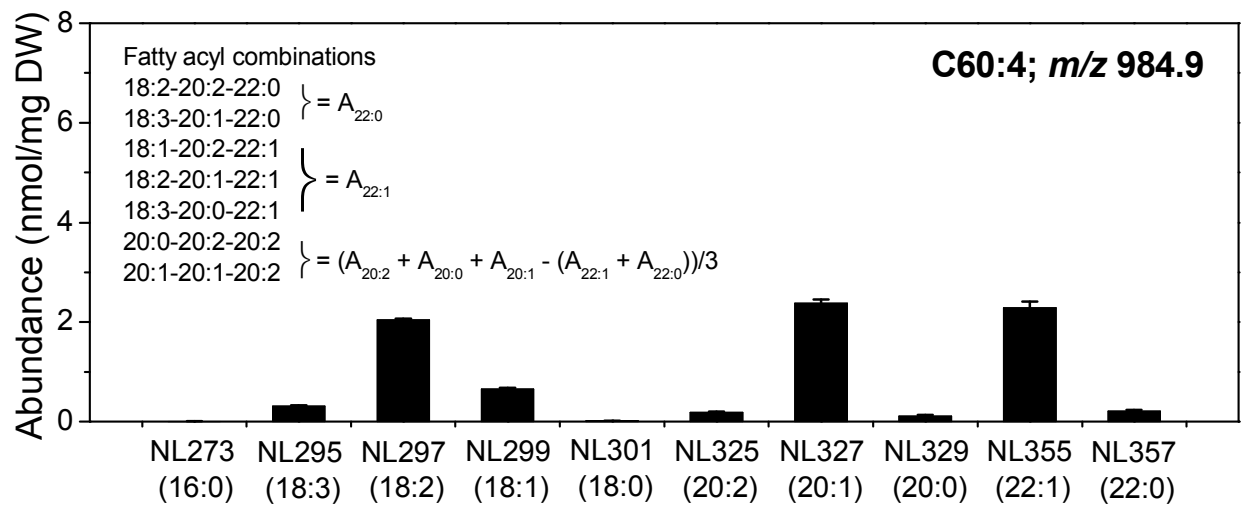

Figure S7. The abundance of 10 fatty acyl chains in TAGs at $m / z 860.9$ and $m / z$ 984.9. (a) The abundance of each fatty acyl chain at TAG $\mathrm{m} / \mathrm{z}$ 860.9. Six fatty acyl chain combinations can be deduced for $\mathrm{m} / \mathrm{z} 860.9$ (C58:2), and their calculation formulae are indicated. (b) The abundance of each fatty acyl chain at TAG $\mathrm{m} / \mathrm{z}$ 984.9. Seven fatty acyl chain combinations can be deduced for $\mathrm{m} / \mathrm{z} 984.9$ (C60:4), and their calculation formulae are indicated. The derivation for the calculation formulae are described in detail at Method S2. The complete data of the fatty acyl abundance at each TAG mass are listed in Table S2. Values are means \pm SE $(n=5)$. 
(a)
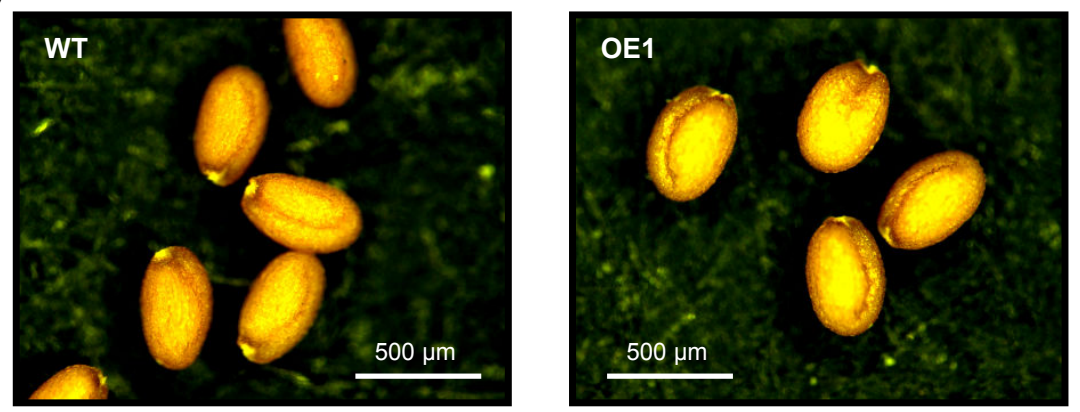

(b)

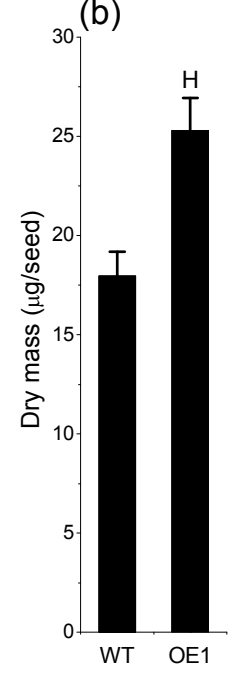

(c)

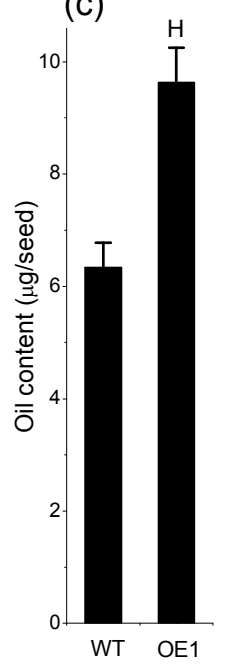

(d)

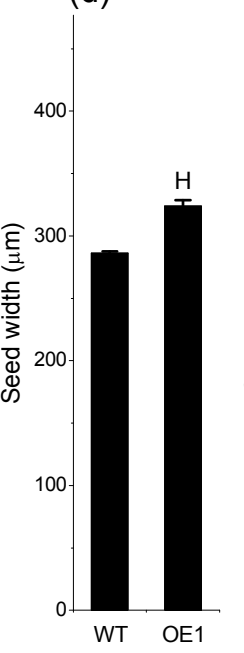

(e)

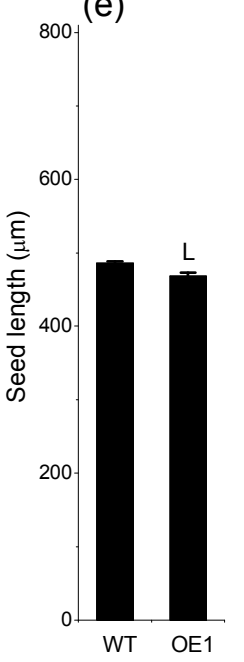

(f)

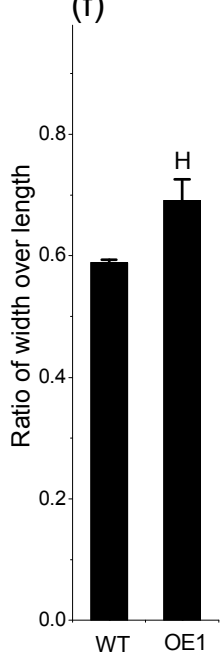

Figure S8. Characterization of Arabidopsis mutant seeds overexpressing pPLAlllס. (a) Morphology of mature Arabidopsis seeds of wild-type and pPLAIII overexpressors. WT, wild-type; OE, overexpressors. OE seeds were bigger and rounder than WT seeds. (b) Dry mass of individual seed. Five replicates of seed samples from each genotype were weighed and the number of the seeds from each replicate was counted. $\quad$ (c) Oil amount of individual seed. Seed numbers were counted and the seed oil content was measured by gas chromatography for five replicates from each genotype. (d) Seed width. (e) Seed length. (f) Ratio of width over length, an indicator of seed shape. Values are means $\pm S E$ $(n=5)$. HSignificantly higher and LSignifcantly lower, each at $P<0.05$, compared with the WT, based on Student's $t$ test. 
(a)

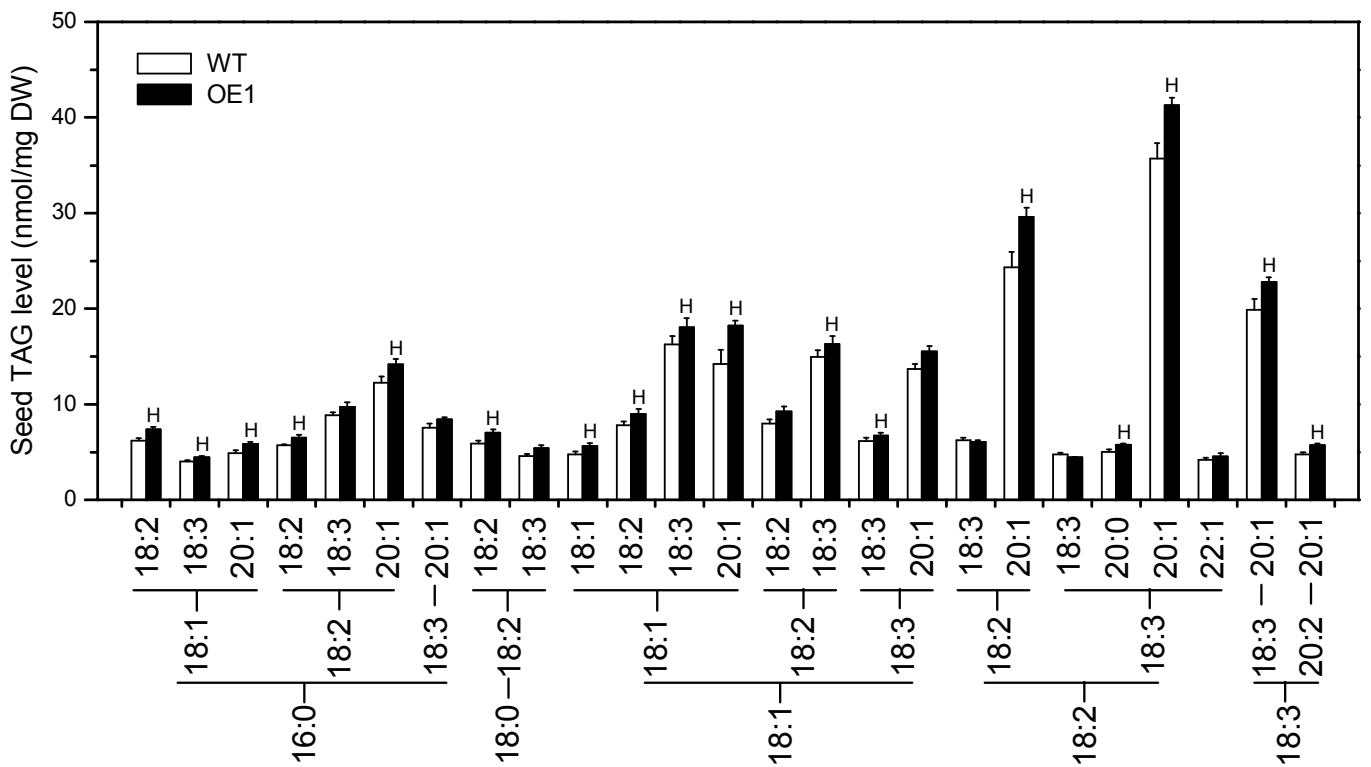

(b)

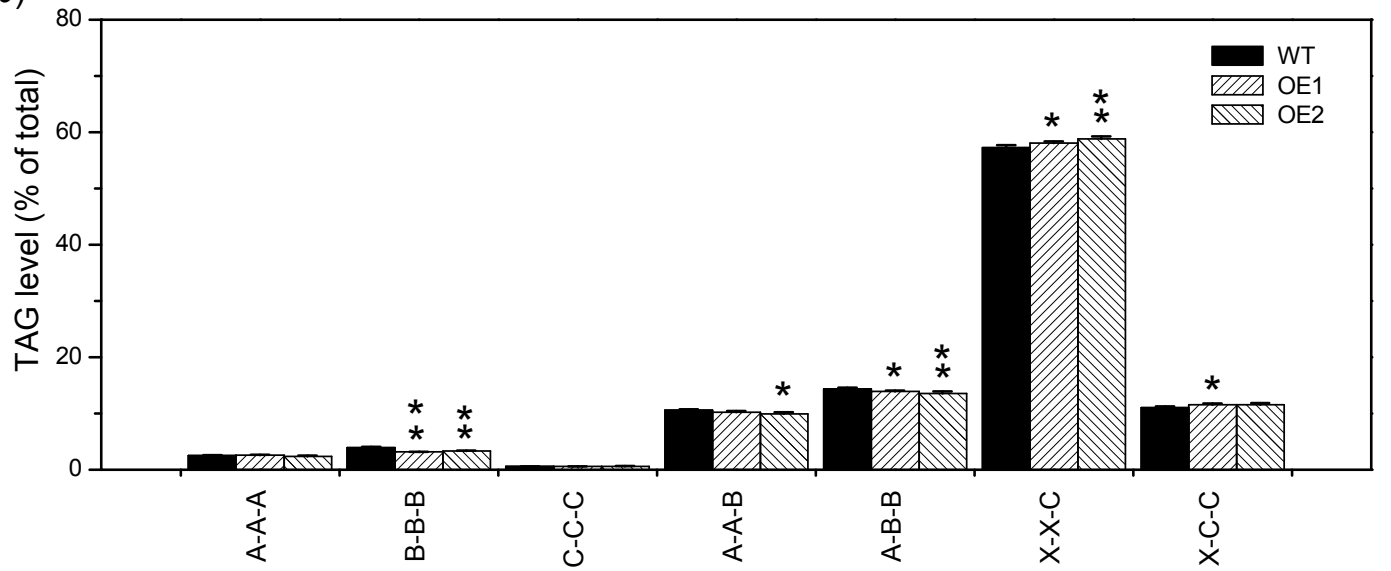

Figure S9. Levels of individual TAG species in Arabidopsis wild-type and pPLAlllס overexpressing seeds. (a) Levels of the most abundant 25 TAG molecular species are displayed. (b) TAG patterns of WT and OE. The snposition of acyl chains are not specified in the description of TAG molecules in this work. The fatty acyl combination of TAGs, such as A-A-A and B-B-B, were defined in Figure 5. WT, wild-type; OE, overexpressors. Values are means \pm SE $(n=5)$. "“*" refers to $P<0.1$ and "**” refers to $P<0.05$ as compared with the WT, based on Student's $t$ test. 
Table S1. Measured and deduced adjustment factors for commercially available TAGs and seed oil TAGs at $46 \mathrm{~m} / \mathrm{z}$. The adjustment factor is defined as the NL signal intensity of internal standard divided by the NL signal intensity for each TAG, when the TAG and the internal standard are equimolar. The values with SE represent the adjustment factors of commercially available TAGs measured by ESI-MS/MS. The values are means \pm SE $(n \geq 5)$. The adjustment factors of the seed TAGs were deduced from regression curves constructed as described in Experimental Procedures and in Method S1.

\begin{tabular}{|c|c|c|c|c|c|}
\hline \multirow{2}{*}{$\begin{array}{l}\text { TAG } \\
\text { C42:0 (tri14:0) }\end{array}$} & \multirow{2}{*}{$\frac{\text { Adjustment factor }}{{ }^{a} 0.26^{ \pm 0.01}}$} & \multirow{2}{*}{$\begin{array}{r}\text { TAG } \\
\text { C52:2 }\end{array}$} & Adjustment factor & TAG & Adjustment factor \\
\hline & & & 1.35 & C57:6 (tri19:2) & $4.66^{ \pm 0.46}$ \\
\hline C45:0 (tri15:0) & $0.43^{ \pm 0.02}$ & C52:1 & 1.58 & C57:3 (tri19:1) & $3.07 \pm 0.32$ \\
\hline C48:6 & 3.16 & C52:0 & 2.07 & C58:7 & 7.38 \\
\hline C48:5 & 2.04 & C54:9 & 7.21 & C57:0 (tri19:0) & $4.25^{ \pm 0.53}$ \\
\hline C48:4 & 1.21 & C54:8 & 5.64 & C58:6 & 5.73 \\
\hline C48:3 (tri16:1) & $0.67 \pm 0.08$ & C54:7 & 4.35 & C58:5 & 4.63 \\
\hline $\mathrm{C} 48: 3$ & 0.68 & C54:6 (tri18:2) & $3.34 \pm 0.49$ & C58:4 & 4.08 \\
\hline C48:2 & 0.45 & $\mathrm{C} 54: 6$ & 3.34 & C58:3 & 4.08 \\
\hline C48:1 & 0.52 & C54:5 & 2.61 & C58:2 & 4.63 \\
\hline C48:0 (tri16:0) & $0.80 \pm 0.08$ & C54:4 & 2.16 & C58:1 & 5.73 \\
\hline $\mathrm{C} 48: 0$ & 0.89 & C54:3 (tri18:1) & $2.37 \pm 0.29$ & C58:0 & 7.38 \\
\hline C50:6 & 3.12 & $\mathrm{C} 54: 3$ & 1.99 & C60:9 (tri20:3) & $11.54 \pm 1.06$ \\
\hline C50:5 & 2.13 & C54:2 & 2.10 & $\mathrm{C} 60: 9$ & 11.76 \\
\hline C50:4 & 1.41 & C54:1 & 2.50 & C60:6 (tri20:2) & $9.95^{ \pm 0.72}$ \\
\hline C50:3 & 0.97 & C54:0 (tri18:0) & $3.94 \pm 0.30$ & $\mathrm{C} 60: 6$ & 10.00 \\
\hline C50:2 & 0.82 & $\mathrm{C} 54: 0$ & 3.17 & C60:5 & 8.39 \\
\hline C50:1 & 0.95 & C56:8 & 6.49 & $\mathrm{C} 60: 4$ & 6.99 \\
\hline C50:0 & 1.36 & C56:7 & 5.07 & C60:3 (tri20:1) & $5.91 \pm 0.56$ \\
\hline C51:3 (tri17:1, IS) & Set as 1.0 & C56:6 & 3.99 & $\mathrm{C} 60: 3$ & 6.22 \\
\hline C51:0 (tri17:0) & $1.74 \pm 0.24$ & C56:5 & 3.27 & $\mathrm{C} 60: 2$ & 6.52 \\
\hline C52:6 & 3.14 & C56:4 & 2.89 & C60:1 & 8.31 \\
\hline C52:5 & 2.29 & C56:3 & 2.85 & C60:0 (tri20:0) & $11.88 \pm 0.93$ \\
\hline C52:4 & 1.71 & C56:2 & 3.17 & $\mathrm{C} 60: 0$ & 12.02 \\
\hline C52:3 (16:0-18:1-18:2) & $1.37 \pm 0.05$ & C56:1 & 3.83 & & \\
\hline C52:3 & 1.39 & C56:0 & 4.83 & & \\
\hline
\end{tabular}


Table S2. The abundance of 10 fatty acyl chains in each TAG $\mathrm{m} / \mathrm{z}$ group in Arabidopsis seed oil extract. Data from NL scans have been isotopically deconvoluted and adjustment factors have been applied. The abundance of each fatty acyl chain at each TAG mass was calculated from the spectra acquired in each of $10 \mathrm{NL}$ scan modes after comparing the decovoluted, corrected intensities with those of the internal standards. The fatty acyl abundance at each TAG mass is expressed in nmol per mg dry mass. Values are means \pm SE $(n=5)$.

\begin{tabular}{|c|c|c|c|c|c|c|c|c|c|c|c|}
\hline TAG mass & $A_{16: 0}$ & $A_{18: 3}$ & $A_{18: 2}$ & $A_{18: 1}$ & $A_{18: 0}$ & $A_{20: 2}$ & $A_{20: 1}$ & $A_{20: 0}$ & $A_{22: 1}$ & $A_{22: 0}$ & Total \\
\hline C48:0 & $0.021^{ \pm 0.00}$ & $0.000^{ \pm 0.00}$ & $0.000^{ \pm 0.00}$ & $0.000^{ \pm 0.00}$ & $0.000^{ \pm 0.00}$ & $0.000^{ \pm 0.00}$ & $0.000^{ \pm 0.00}$ & $0.001^{ \pm 0.00}$ & $0.000^{ \pm 0.00}$ & $0.000^{ \pm 0.00}$ & $0.022^{ \pm 0.00}$ \\
\hline C50:3 & $1.986^{ \pm 0.07}$ & $0.627^{ \pm 0.03}$ & $0.214^{ \pm 0.01}$ & $0.073^{ \pm 0.00}$ & $0.006^{ \pm 0.00}$ & $0.000^{ \pm 0.00}$ & $0.016^{ \pm 0.00}$ & $0.005^{ \pm 0.00}$ & $0.000^{ \pm 0.00}$ & $0.000^{ \pm 0.00}$ & $2.927^{ \pm 0.09}$ \\
\hline C50:2 & $3.991^{ \pm 0.13}$ & $0.000^{ \pm 0.00}$ & $1.526^{ \pm 0.02}$ & $0.092^{ \pm 0.00}$ & $0.013^{ \pm 0.00}$ & $0.000^{ \pm 0.00}$ & $0.010^{ \pm 0.00}$ & $0.006^{ \pm 0.00}$ & $0.000^{ \pm 0.00}$ & $0.000^{ \pm 0.00}$ & $5.638^{ \pm 0.13}$ \\
\hline C50:1 & $1.387^{ \pm 0.06}$ & $0.000^{ \pm 0.00}$ & $0.000^{ \pm 0.00}$ & $0.456^{ \pm 0.01}$ & $0.016^{ \pm 0.00}$ & $0.000^{ \pm 0.00}$ & $0.001^{ \pm 0.00}$ & $0.011^{ \pm 0.00}$ & $0.000^{ \pm 0.00}$ & $0.000^{ \pm 0.00}$ & $1.881^{ \pm 0.07}$ \\
\hline C50:0 & $0.012^{ \pm 0.00}$ & $0.001^{ \pm 0.00}$ & $0.002^{ \pm 0.00}$ & $0.000^{ \pm 0.00}$ & $0.028^{ \pm 0.00}$ & $0.000^{ \pm 0.00}$ & $0.000^{ \pm 0.00}$ & $0.003^{ \pm 0.00}$ & $0.000^{ \pm 0.00}$ & $0.000^{ \pm 0.00}$ & $0.048^{ \pm 0.01}$ \\
\hline C52:6 & $4.224^{ \pm 0.19}$ & $6.930^{ \pm 0.32}$ & $0.735^{ \pm 0.02}$ & $0.132^{ \pm 0.01}$ & $0.017^{ \pm 0.00}$ & $0.001^{ \pm 0.00}$ & $0.001^{ \pm 0.00}$ & $0.012^{ \pm 0.00}$ & $0.002^{ \pm 0.00}$ & $0.002^{ \pm 0.00}$ & $12.056^{ \pm 0.51}$ \\
\hline C52:5 & $10.286^{ \pm 0.41}$ & $8.354^{ \pm 0.24}$ & $7.997^{ \pm 0.20}$ & $0.559^{ \pm 0.02}$ & $0.019^{ \pm 0.00}$ & $0.008^{ \pm 0.00}$ & $0.007^{ \pm 0.00}$ & $0.029^{ \pm 0.01}$ & $0.003^{ \pm 0.00}$ & $0.007^{ \pm 0.00}$ & $27.269^{ \pm 0.83}$ \\
\hline C52:4 & $12.698^{ \pm 0.52}$ & $3.584^{ \pm 0.13}$ & $11.402^{ \pm 0.26}$ & $4.501^{ \pm 0.15}$ & $0.061^{ \pm 0.00}$ & $0.018^{ \pm 0.00}$ & $0.108^{ \pm 0.00}$ & $0.014^{ \pm 0.00}$ & $0.008^{ \pm 0.00}$ & $0.001^{ \pm 0.00}$ & $32.395^{ \pm 0.99}$ \\
\hline $\mathrm{C} 52: 3$ & $8.805^{ \pm 0.31}$ & $0.441^{ \pm 0.02}$ & $5.561^{ \pm 0.23}$ & $6.883^{ \pm 0.24}$ & $0.921^{ \pm 0.05}$ & $0.021^{ \pm 0.00}$ & $0.135^{ \pm 0.00}$ & $0.011^{ \pm 0.00}$ & $0.002^{ \pm 0.00}$ & $0.001^{ \pm 0.00}$ & $22.781^{ \pm 0.82}$ \\
\hline C52:2 & $5.232^{ \pm 0.27}$ & $0.001^{ \pm 0.00}$ & $1.274^{ \pm 0.05}$ & $5.418^{ \pm 0.28}$ & $2.017^{ \pm 0.08}$ & $0.001^{ \pm 0.00}$ & $0.141^{ \pm 0.01}$ & $0.015^{ \pm 0.00}$ & $0.000^{ \pm 0.00}$ & $0.000^{ \pm 0.00}$ & $14.099^{ \pm 0.66}$ \\
\hline C52:1 & $0.637^{ \pm 0.03}$ & $0.002^{ \pm 0.00}$ & $0.002^{ \pm 0.00}$ & $0.384^{ \pm 0.03}$ & $0.996^{ \pm 0.06}$ & $0.000^{ \pm 0.00}$ & $0.020^{ \pm 0.00}$ & $0.027^{ \pm 0.01}$ & $0.000^{ \pm 0.00}$ & $0.000^{ \pm 0.00}$ & $2.069^{ \pm 0.11}$ \\
\hline C52:0 & $0.016^{ \pm 0.01}$ & $0.013^{ \pm 0.00}$ & $0.004^{ \pm 0.00}$ & $0.006^{ \pm 0.00}$ & $0.041^{ \pm 0.01}$ & $0.000^{ \pm 0.00}$ & $0.000^{ \pm 0.00}$ & $0.003^{ \pm 0.00}$ & $0.000^{ \pm 0.00}$ & $0.000^{ \pm 0.00}$ & $0.083^{ \pm 0.01}$ \\
\hline C54:9 & $0.602^{ \pm 0.02}$ & $3.653^{ \pm 0.23}$ & $0.426^{ \pm 0.02}$ & $0.579^{ \pm 0.03}$ & $0.149^{ \pm 0.01}$ & $0.001^{ \pm 0.00}$ & $0.171^{ \pm 0.01}$ & $0.043^{ \pm 0.01}$ & $0.000^{ \pm 0.00}$ & $0.000^{ \pm 0.00}$ & $5.622^{ \pm 0.28}$ \\
\hline C54:8 & $0.096^{ \pm 0.01}$ & $9.960^{ \pm 0.44}$ & $4.221^{ \pm 0.21}$ & $0.218^{ \pm 0.02}$ & $0.056^{ \pm 0.01}$ & $0.004^{ \pm 0.00}$ & $0.001^{ \pm 0.00}$ & $0.009^{ \pm 0.00}$ & $0.001^{ \pm 0.00}$ & $0.000^{ \pm 0.00}$ & $14.566^{ \pm 0.65}$ \\
\hline C54:7 & $0.000^{ \pm 0.00}$ & $18.904^{ \pm 0.89}$ & $12.504^{ \pm 0.49}$ & $6.160^{ \pm 0.32}$ & $0.006^{ \pm 0.00}$ & $0.032^{ \pm 0.01}$ & $0.118^{ \pm 0.01}$ & $0.000^{ \pm 0.00}$ & $0.021^{ \pm 0.00}$ & $0.000^{ \pm 0.00}$ & $37.746^{ \pm 1.59}$ \\
\hline C54:6 & $0.193^{ \pm 0.02}$ & $15.254^{ \pm 0.65}$ & $21.909^{ \pm 0.67}$ & $14.951^{ \pm 0.71}$ & $1.753^{ \pm 0.11}$ & $0.075^{ \pm 0.01}$ & $0.204^{ \pm 0.01}$ & $0.003^{ \pm 0.00}$ & $0.044^{ \pm 0.01}$ & $0.001^{ \pm 0.00}$ & $54.387^{ \pm 2.10}$ \\
\hline C54:5 & $0.819^{ \pm 0.03}$ & $9.059^{ \pm 0.45}$ & $20.591^{ \pm 1.00}$ & $21.501^{ \pm 1.05}$ & $4.616^{ \pm 0.19}$ & $0.613^{ \pm 0.04}$ & $0.659^{ \pm 0.04}$ & $0.020^{ \pm 0.00}$ & $0.031^{ \pm 0.00}$ & $0.005^{ \pm 0.00}$ & $57.913^{ \pm 2.66}$ \\
\hline C54:4 & $8.051^{ \pm 0.19}$ & $5.981^{ \pm 0.25}$ & $12.845^{ \pm 0.53}$ & $15.606^{ \pm 0.73}$ & $6.203^{ \pm 0.28}$ & $0.991^{ \pm 0.03}$ & $7.545^{ \pm 0.43}$ & $0.102^{ \pm 0.01}$ & $0.035^{ \pm 0.00}$ & $0.004^{ \pm 0.00}$ & $57.361^{ \pm 2.32}$ \\
\hline C54:3 & $16.338^{ \pm 0.45}$ & $0.310^{ \pm 0.02}$ & $9.945^{ \pm 0.30}$ & $14.865^{ \pm 1.04}$ & $4.217^{ \pm 0.18}$ & $0.668^{ \pm 0.02}$ & $12.259^{ \pm 0.66}$ & $1.208^{ \pm 0.07}$ & $0.016^{ \pm 0.00}$ & $0.003^{ \pm 0.00}$ & $59.881^{ \pm 2.51}$ \\
\hline C54:2 & $6.594^{ \pm 0.17}$ & $0.019^{ \pm 0.00}$ & $1.252^{ \pm 0.02}$ & $5.240^{ \pm 0.31}$ & $3.096^{ \pm 0.19}$ & $0.002^{ \pm 0.00}$ & $4.880^{ \pm 0.31}$ & $2.265^{ \pm 0.12}$ & $0.012^{ \pm 0.00}$ & $0.001^{ \pm 0.00}$ & $23.497^{ \pm 1.12}$ \\
\hline C54:1 & $0.648^{ \pm 0.04}$ & $0.035^{ \pm 0.00}$ & $0.000^{ \pm 0.00}$ & $0.049^{ \pm 0.02}$ & $0.463^{ \pm 0.04}$ & $0.000^{ \pm 0.00}$ & $0.000^{ \pm 0.00}$ & $0.768^{ \pm 0.06}$ & $0.000^{ \pm 0.00}$ & $0.000^{ \pm 0.00}$ & $1.965^{ \pm 0.12}$ \\
\hline C54:0 & \multicolumn{11}{|c|}{ Not detectable } \\
\hline C56:8 & $0.230^{ \pm 0.02}$ & $1.964^{ \pm 0.07}$ & $0.612^{ \pm 0.03}$ & $0.071^{ \pm 0.01}$ & $0.066^{ \pm 0.01}$ & $0.935^{ \pm 0.05}$ & $0.071^{ \pm 0.02}$ & $0.051^{ \pm 0.01}$ & $0.001^{ \pm 0.00}$ & $0.000^{ \pm 0.00}$ & $4.001^{ \pm 0.17}$ \\
\hline C56:7 & $0.000^{ \pm 0.00}$ & $34.894^{ \pm 1.37}$ & $4.046^{ \pm 0.10}$ & $0.476^{ \pm 0.04}$ & $0.001^{ \pm 0.00}$ & $2.138^{ \pm 0.09}$ & $19.905^{ \pm 1.10}$ & $0.021^{ \pm 0.01}$ & $0.024^{ \pm 0.01}$ & $0.000^{ \pm 0.00}$ & $61.503^{ \pm 2.55}$ \\
\hline C56:6 & $0.035^{ \pm 0.01}$ & $40.985^{ \pm 1.61}$ & $31.364^{ \pm 0.71}$ & $2.603^{ \pm 0.13}$ & $0.101^{ \pm 0.01}$ & $2.875^{ \pm 0.09}$ & $35.694^{ \pm 1.68}$ & $2.719^{ \pm 0.20}$ & $0.045^{ \pm 0.00}$ & $0.000^{ \pm 0.00}$ & $116.421^{ \pm 4.25}$ \\
\hline C56:5 & $0.086^{ \pm 0.01}$ & $14.795^{ \pm 0.57}$ & $48.531^{ \pm 1.20}$ & $16.113^{ \pm 0.60}$ & $0.468^{ \pm 0.02}$ & $2.391^{ \pm 0.09}$ & $38.045^{ \pm 2.05}$ & $5.050^{ \pm 0.24}$ & $0.177^{ \pm 0.01}$ & $0.001^{ \pm 0.00}$ & $125.598^{ \pm 4.56}$ \\
\hline C56:4 & $0.883^{ \pm 0.04}$ & $3.652^{ \pm 0.25}$ & $18.562^{ \pm 0.54}$ & $23.906^{ \pm 0.71}$ & $3.519^{ \pm 0.22}$ & $1.199^{ \pm 0.04}$ & $22.004^{ \pm 1.19}$ & $5.909^{ \pm 0.20}$ & $0.838^{ \pm 0.04}$ & $0.007^{ \pm 0.00}$ & $80.480^{ \pm 3.02}$ \\
\hline C56:3 & $1.768^{ \pm 0.02}$ & $0.210^{ \pm 0.02}$ & $5.482^{ \pm 0.19}$ & $22.580^{ \pm 1.16}$ & $6.264^{ \pm 0.27}$ & $0.256^{ \pm 0.02}$ & $15.579^{ \pm 1.35}$ & $3.483^{ \pm 0.22}$ & $1.193^{ \pm 0.05}$ & $0.136^{ \pm 0.02}$ & $56.951^{ \pm 3.12}$ \\
\hline C56:2 & $0.847^{ \pm 0.03}$ & $0.004^{ \pm 0.00}$ & $0.276^{ \pm 0.07}$ & $3.239^{ \pm 0.17}$ & $2.982^{ \pm 0.14}$ & $0.000^{ \pm 0.00}$ & $0.955^{ \pm 0.23}$ & $2.241^{ \pm 0.21}$ & $0.342^{ \pm 0.02}$ & $0.258^{ \pm 0.02}$ & $11.145^{ \pm 0.79}$ \\
\hline C56:1 & $0.093^{ \pm 0.01}$ & $0.004^{ \pm 0.00}$ & $0.039^{ \pm 0.01}$ & $0.115^{ \pm 0.04}$ & $0.424^{ \pm 0.05}$ & $0.000^{ \pm 0.00}$ & $0.090^{ \pm 0.03}$ & $0.185^{ \pm 0.03}$ & $0.001^{ \pm 0.00}$ & $0.084^{ \pm 0.01}$ & $1.036^{ \pm 0.08}$ \\
\hline C56:0 & \multicolumn{11}{|c|}{ Not detectable } \\
\hline C58:7 & $0.003^{ \pm 0.00}$ & $3.598^{ \pm 0.13}$ & $0.430^{ \pm 0.02}$ & $0.064^{ \pm 0.01}$ & $0.001^{ \pm 0.00}$ & $0.245^{ \pm 0.01}$ & $0.690^{ \pm 0.05}$ & $0.000^{ \pm 0.00}$ & $1.680^{ \pm 0.08}$ & $0.000^{ \pm 0.00}$ & $6.712^{ \pm 0.22}$ \\
\hline C58:6 & $0.000^{ \pm 0.00}$ & $6.362^{ \pm 0.05}$ & $4.694^{ \pm 0.13}$ & $0.310^{ \pm 0.02}$ & $0.004^{ \pm 0.00}$ & $3.936^{ \pm 0.13}$ & $4.724^{ \pm 0.26}$ & $0.118^{ \pm 0.01}$ & $4.237^{ \pm 0.18}$ & $0.337^{ \pm 0.01}$ & $24.721^{ \pm 0.53}$ \\
\hline C58:5 & $0.002^{ \pm 0.00}$ & $7.211^{ \pm 0.20}$ & $7.282^{ \pm 0.20}$ & $1.845^{ \pm 0.05}$ & $0.011^{ \pm 0.00}$ & $4.332^{ \pm 0.15}$ & $18.279^{ \pm 0.79}$ & $0.699^{ \pm 0.03}$ & $3.970^{ \pm 0.19}$ & $0.626^{ \pm 0.03}$ & $44.256^{ \pm 1.13}$ \\
\hline C58:4 & $0.059^{ \pm 0.01}$ & $0.850^{ \pm 0.04}$ & $9.577^{ \pm 0.024}$ & $2.982^{ \pm 0.04}$ & $0.348^{ \pm 0.02}$ & $1.354^{ \pm 0.03}$ & $27.043^{ \pm 1.17}$ & $2.057^{ \pm 0.08}$ & $1.907^{ \pm 0.10}$ & $0.719^{ \pm 0.05}$ & $46.895^{ \pm 1.51}$ \\
\hline C58:3 & $0.269^{ \pm 0.02}$ & $0.161^{ \pm 0.02}$ & $1.540^{ \pm 0.04}$ & $5.609^{ \pm 0.21}$ & $0.612^{ \pm 0.04}$ & $0.158^{ \pm 0.01}$ & $10.814^{ \pm 0.79}$ & $3.408^{ \pm 0.14}$ & $1.291^{ \pm 0.05}$ & $0.415^{ \pm 0.02}$ & $24.277^{ \pm 1.22}$ \\
\hline C58:2 & $0.205^{ \pm 0.01}$ & $0.001^{ \pm 0.00}$ & $0.351^{ \pm 0.02}$ & $0.823^{ \pm 0.04}$ & $0.559^{ \pm 0.04}$ & $0.000^{ \pm 0.00}$ & $1.039^{ \pm 0.10}$ & $1.421^{ \pm 0.13}$ & $0.126^{ \pm 0.02}$ & $0.296^{ \pm 0.02}$ & $4.821^{ \pm 0.30}$ \\
\hline C58:1 & \multicolumn{11}{|c|}{ Not detectable } \\
\hline C58:0 & \multicolumn{11}{|c|}{ Not detectable } \\
\hline C60:6 & $0.000^{ \pm 0.00}$ & $1.402^{ \pm 0.00}$ & $0.656^{ \pm 0.05}$ & $0.021^{ \pm 0.02}$ & $0.000^{ \pm 0.01}$ & $0.630^{ \pm 0.00}$ & $0.191^{ \pm 0.04}$ & $0.000^{ \pm 0.02}$ & $0.820^{ \pm 0.00}$ & $0.003^{ \pm 0.02}$ & $3.722^{ \pm 0.12}$ \\
\hline C60:5 & $0.000^{ \pm 0.00}$ & $1.355^{ \pm 0.06}$ & $1.724^{ \pm 0.08}$ & $0.227^{ \pm 0.02}$ & $0.000^{ \pm 0.00}$ & $0.598^{ \pm 0.04}$ & $1.663^{ \pm 0.07}$ & $0.002^{ \pm 0.00}$ & $1.854^{ \pm 0.04}$ & $0.040^{ \pm 0.01}$ & $7.462^{ \pm 0.13}$ \\
\hline $\mathrm{C} 60: 4$ & $0.004^{ \pm 0.00}$ & $0.315^{ \pm 0.02}$ & $2.042^{ \pm 0.02}$ & $0.649^{ \pm 0.03}$ & $0.014^{ \pm 0.00}$ & $0.189^{ \pm 0.01}$ & $2.381^{ \pm 0.08}$ & $0.110^{ \pm 0.02}$ & $2.287^{ \pm 0.13}$ & $0.213^{ \pm 0.02}$ & $8.204^{ \pm 0.19}$ \\
\hline $\mathrm{C} 60: 3$ & $0.026^{ \pm 0.01}$ & $0.007^{ \pm 0.00}$ & $0.466^{ \pm 0.03}$ & $0.856^{ \pm 0.04}$ & $0.067^{ \pm 0.01}$ & $0.008^{ \pm 0.00}$ & $1.254^{ \pm 0.07}$ & $0.183^{ \pm 0.01}$ & $0.753^{ \pm 0.02}$ & $0.372^{ \pm 0.02}$ & $3.992^{ \pm 0.15}$ \\
\hline C60:2 & \multicolumn{11}{|c|}{ Not detectable } \\
\hline $\mathrm{C} 60: 1$ & \multicolumn{11}{|c|}{ Not detectable } \\
\hline C60:0 & \multicolumn{11}{|c|}{ Not detectable } \\
\hline Total & $87.15^{ \pm 2.70}$ & $200.90^{ \pm 7.04}$ & $250.09^{ \pm 5.69}$ & $180.35^{ \pm 7.61}$ & $40.13^{ \pm 1.84}$ & $23.68^{ \pm 0.71}$ & $226.70^{ \pm 11.93}$ & $32.21^{ \pm 1.62}$ & $21.66^{ \pm 0.81}$ & $3.54^{ \pm 0.16}$ & $1066.4^{ \pm 36.6}$ \\
\hline
\end{tabular}


Table S3. Levels of TAG molecular species in wild-type and pPLAIII $\delta$ overexpressing seeds of Arabidopsis. The fatty acyl abundances were determined from ion intensities in the multiple neutral loss scans of ammoniated intact TAG ions as described in the text using the adjustment factors in Table S1 and the complete results were shown in Table S2. The levels of fatty acyl combinations at each of $46 \mathrm{~m} / \mathrm{z}$ were calculated from the fatty acyl abundance using the "Calculation formulae" in the last column. The derivation for the calculation formulae were described in detail at Method S2 using demonstrations on $\mathrm{m} / \mathrm{z} 872.8$ (C52:4), m/z 924.8 (C56:6), m/z 926.8 (C56:5), m/z 960.9 (C58:2), and m/z 984.9 (C60:4). The TAG levels are expressed in absolute terms (nmol/mg dry mass) and relative terms ( $\%$ of total). Values are means $\pm S E(n=5)$.

\begin{tabular}{|c|c|c|c|c|c|c|c|c|c|}
\hline$m / z$ & {$\left[\mathrm{M}+\mathrm{NH}_{4}\right]^{+}$} & & $\mathrm{AF}$ & Combination & $\underset{\text { (nmol/mg) }}{\text { WT }}$ & $\begin{array}{l}\text { pPLAIIID-OE1 } \\
\text { (nmol/mg) }\end{array}$ & $\underset{(\mathrm{mol} \%)}{\mathrm{WT}} \quad \mathrm{pP}$ & $\begin{array}{l}\text { pPLAIIID-OE1 } \\
\text { (mol\%) }\end{array}$ & $\begin{array}{c}\text { aCalculation } \\
\text { formulae }\end{array}$ \\
\hline 824.8 & $\mathrm{C}_{51} \mathrm{H}_{102} \mathrm{O}_{6} \mathrm{~N}$ & C48:0 & 0.89 & $16: 0-16: 0-16: 0$ & $0.007^{ \pm 0.00}$ & $0.006^{ \pm 0.00}$ & $0.002^{ \pm 0.00}$ & ${ }^{*} 0.001^{ \pm 0.00}$ & $=\mathrm{A}_{16: 0} / 3$ \\
\hline 846.8 & $\mathrm{C}_{53} \mathrm{H}_{100} \mathrm{O}_{6} \mathrm{~N}$ & C50:3 & 0.97 & $16: 0-16: 0-18: 3$ & $0.871 \pm 0.03$ & $0.915^{ \pm 0.04}$ & $0.234^{ \pm 0.01}$ & ${ }^{*} 0.210^{ \pm 0.01}$ & $=\left(A_{16: 0}+A_{18: 3}\right) / 3$ \\
\hline 848.8 & $\mathrm{C}_{53} \mathrm{H}_{102} \mathrm{O}_{6} \mathrm{~N}$ & C50:2 & 0.82 & $16: 0-16: 0-18: 2$ & $1.839^{ \pm 0.05}$ & $1.994^{ \pm 0.10}$ & $0.494^{ \pm 0.02}$ & $0.458^{ \pm 0.01}$ & $=\left(A_{16: 0}+A_{18: 2}\right) / 3$ \\
\hline 850.8 & $\mathrm{C}_{53} \mathrm{H}_{104} \mathrm{O}_{6} \mathrm{~N}$ & C50:1 & 0.95 & $16: 0-16: 0-18: 1$ & $0.618^{ \pm 0.02}$ & ${ }^{*} 0.704^{ \pm 0.03}$ & $0.165^{ \pm 0.01}$ & $0.162^{ \pm 0.00}$ & $=\left(A_{16: 0}+A_{18: 1}\right) / 3$ \\
\hline 852.8 & $\mathrm{C}_{53} \mathrm{H}_{106} \mathrm{O}_{6} \mathrm{~N}$ & $\mathrm{C} 50: 0$ & 1.36 & $16: 0-16: 0-18: 0$ & $0.013^{ \pm 0.00}$ & $0.012^{ \pm 0.00}$ & $0.004^{ \pm 0.00}$ & $0.003^{ \pm 0.00}$ & $=\left(A_{16: 0}+A_{18: 0}\right) / 3$ \\
\hline 868.7 & $\mathrm{C}_{55} \mathrm{H}_{98} \mathrm{O}_{6} \mathrm{~N}$ & $\mathrm{C} 52: 6$ & 3.14 & $16: 0-18: 3-18: 3$ & $3.718^{ \pm 0.17}$ & $4.008^{ \pm 0.19}$ & $0.995^{ \pm 0.04}$ & $0.923^{ \pm 0.04}$ & $=\left(A_{16: 0}+A_{18: 3}\right) / 3$ \\
\hline 870.8 & $\mathrm{C}_{55} \mathrm{H}_{100} \mathrm{O}_{6} \mathrm{~N}$ & $\mathrm{C} 52: 5$ & 2.29 & $16: 0-18: 2-18: 3$ & $8.879 \pm 0.27$ & $9.723^{ \pm 0.49}$ & $2.385^{ \pm 0.12}$ & $2.235^{ \pm 0.08}$ & $=\left(A_{16: 0}+A_{18: 3}+A_{18: 2}\right) / 3$ \\
\hline 872.8 & $\mathrm{C}_{55} \mathrm{H}_{102} \mathrm{O}_{6} \mathrm{~N}$ & C52:4 & 1.71 & $\begin{array}{l}16: 0-18: 2-18: 2 \\
16: 0-18: 1-18: 3\end{array}$ & $\begin{array}{l}5.701^{ \pm 0.13} \\
4.043^{ \pm 0.13}\end{array}$ & $\begin{array}{l}{ }^{*} 6.506^{ \pm 0.31} \\
{ }^{*} 4.473^{ \pm 0.15}\end{array}$ & $\begin{array}{l}1.530^{ \pm 0.05} \\
1.082^{ \pm 0.02}\end{array}$ & $\begin{array}{c}1.495^{ \pm 0.05} \\
1.029^{ \pm 0.02}\end{array}$ & $\begin{array}{l}=A_{18: 2} / 2 \\
=\left(A_{18: 3}+A_{18: 1}\right) / 2\end{array}$ \\
\hline 874.8 & $\mathrm{C}_{55} \mathrm{H}_{104} \mathrm{O}_{6} \mathrm{~N}$ & C52:3 & 1.39 & $\begin{array}{l}16: 0-18: 0-18: 3 \\
16: 0-18: 1-18: 2\end{array}$ & $\begin{array}{l}0.681^{ \pm 0.04} \\
6.222^{ \pm 0.24}\end{array}$ & $\begin{array}{c}{ }^{*} 0.812^{ \pm 0.04} \\
{ }^{*} 7.342^{ \pm 0.30} \\
\end{array}$ & $\begin{array}{l}0.182^{ \pm 0.00} \\
1.663^{ \pm 0.02}\end{array}$ & $\begin{array}{l}0.187^{ \pm 0.01} \\
1.687^{ \pm 0.04}\end{array}$ & $\begin{array}{l}=\left(A_{18: 3}+A_{18: 0}\right) / 2 \\
=\left(A_{18: 2}+A_{18: 1}\right) / 2\end{array}$ \\
\hline 876.8 & $\mathrm{C}_{55} \mathrm{H}_{106} \mathrm{O}_{6} \mathrm{~N}$ & $\mathrm{C} 52: 2$ & 1.35 & $\begin{array}{l}16: 0-16: 0-20: 2 \\
16: 0-18: 0-18: 2 \\
16: 0-18: 1-18: 1\end{array}$ & $\begin{array}{l}0.001^{ \pm 0.00} \\
1.646^{ \pm 0.07} \\
2.709^{ \pm 0.14}\end{array}$ & $\begin{array}{r}0.000^{ \pm 0.00} \\
* 1.967^{ \pm 0.09} \\
* 3.306^{ \pm 0.16} \\
\end{array}$ & $\begin{array}{l}0.000^{ \pm 0.00} \\
0.440^{ \pm 0.01} \\
0.723^{ \pm 0.01}\end{array}$ & $\begin{array}{c}0.000^{ \pm 0.00} \\
0.452^{ \pm 0.01} \\
{ }^{*} 0.759^{ \pm 0.02}\end{array}$ & $\begin{array}{l}=A_{20: 2} \\
=\left(A_{18: 2}+A_{18: 0}\right) / 2 \\
=A_{18: 1} / 2\end{array}$ \\
\hline 878.8 & $\mathrm{C}_{55} \mathrm{H}_{108} \mathrm{O}_{6} \mathrm{~N}$ & C52:1 & 1.58 & $\begin{array}{c}16: 0-16: 0-20: 1 \\
16: 0-18: 0-18: 1\end{array}$ & $\begin{array}{l}0.020^{ \pm 0.00} \\
0.690^{ \pm 0.04}\end{array}$ & $\begin{array}{r}0.023^{ \pm 0.01} \\
{ }^{*} 0.819^{ \pm 0.03}\end{array}$ & $\begin{array}{l}0.005^{ \pm 0.00} \\
0.184^{ \pm 0.01}\end{array}$ & $\begin{array}{l}0.005^{ \pm 0.00} \\
0.188^{ \pm 0.00}\end{array}$ & $\begin{array}{l}=A_{20: 1} \\
=\left(A_{18: 1}+A_{18: 0}\right) / 2\end{array}$ \\
\hline 880.8 & $\mathrm{C}_{55} \mathrm{H}_{110} \mathrm{O}_{6} \mathrm{~N}$ & $\mathrm{C} 52: 0$ & 2.07 & $\begin{array}{l}16: 0-16: 0-20: 0 \\
16: 0-18: 0-18: 0\end{array}$ & $\begin{array}{l}0.003^{ \pm 0.00} \\
0.020^{ \pm 0.00}\end{array}$ & $\begin{array}{l}0.003^{ \pm 0.00} \\
0.024^{ \pm 0.01}\end{array}$ & $\begin{array}{l}0.001^{ \pm 0.00} \\
0.005^{ \pm 0.00}\end{array}$ & $\begin{array}{l}0.001^{ \pm 0.00} \\
0.006^{ \pm 0.00}\end{array}$ & $\begin{array}{l}=A_{20: 0} \\
=A_{18: 0} / 2\end{array}$ \\
\hline 890.7 & $\mathrm{C}_{57} \mathrm{H}_{96} \mathrm{O}_{6} \mathrm{~N}$ & $\mathrm{C} 54: 9$ & 7.21 & $18: 3-18: 3-18: 3$ & $1.218^{ \pm 0.08}$ & *1.033*0.05 & $0.325^{ \pm 0.02}$ & ${ }^{*} 0.238^{ \pm 0.01}$ & $=\mathrm{A}_{18: 3} / 3$ \\
\hline 892.7 & $\mathrm{C}_{57} \mathrm{H}_{98} \mathrm{O}_{6} \mathrm{~N}$ & $\mathrm{C} 54: 8$ & 5.64 & $18: 2-18: 3-18: 3$ & $4.727^{ \pm 0.21}$ & $4.461^{ \pm 0.06}$ & $1.268^{ \pm 0.06}$ & $* 1.028^{ \pm 0.02}$ & $=\left(A_{18: 3}+A_{18: 2}\right) / 3$ \\
\hline 894.8 & $\mathrm{C}_{57} \mathrm{H}_{100} \mathrm{O}_{6} \mathrm{~N}$ & $\mathrm{C} 54: 7$ & 4.35 & $\begin{array}{l}18: 1-18: 3-18: 3 \\
18: 2-18: 2-18: 3\end{array}$ & $\begin{array}{c}6.160^{ \pm 0.32} \\
6.252^{ \pm 0.25}\end{array}$ & $\begin{array}{l}6.724^{ \pm 0.31} \\
6.042^{ \pm 0.22}\end{array}$ & $\begin{array}{l}1.644^{ \pm 0.05} \\
1.676^{ \pm 0.07} \\
\end{array}$ & $\begin{array}{r}1.545^{ \pm 0.04} \\
* 1.389^{ \pm 0.02} \\
\end{array}$ & $\begin{array}{l}=\mathrm{A}_{18: 1} \\
=\mathrm{A}_{18: 2} / 2\end{array}$ \\
\hline 896.8 & $\mathrm{C}_{57} \mathrm{H}_{102} \mathrm{O}_{6} \mathrm{~N}$ & C54:6 & 3.34 & $\begin{array}{c}18: 0-18: 3-18: 3 \\
18: 1-18: 2-18: 3 \\
18: 2-18: 2-18: 2\end{array}$ & $\begin{array}{r}1.753^{ \pm 0.11} \\
14.951^{ \pm 0.71} \\
2.319^{ \pm 0.06} \\
\end{array}$ & $\begin{array}{l}* 2.095^{ \pm 0.08} \\
16.343^{ \pm 0.81} \\
{ }^{*} 2.124^{ \pm 0.08} \\
\end{array}$ & $\begin{array}{c}0.467^{ \pm 0.02} \\
3.990^{ \pm 0.06} \\
0.624^{ \pm 0.03}\end{array}$ & $\begin{array}{c}0.482^{ \pm 0.01} \\
* 3.753^{ \pm 0.10} \\
{ }^{*} 0.490^{ \pm 0.02}\end{array}$ & $\begin{array}{l}=A_{18: 0} \\
=A_{18: 1} \\
=\left(A_{18: 2}-A_{18: 1}\right) / 3^{b}\end{array}$ \\
\hline 898.8 & $\mathrm{C}_{57} \mathrm{H}_{104} \mathrm{O}_{6} \mathrm{~N}$ & C54:5 & 2.61 & $\begin{array}{c}16: 0-18: 3-20: 2 \\
18: 0-18: 2-18: 3 \\
18: 1-18: 1-18: 3 \\
18: 1-18: 2-18: 2\end{array}$ & $\begin{array}{r}0.613^{ \pm 0.04} \\
4.616^{ \pm 0.19} \\
16.273^{ \pm 0.88} \\
7.987^{ \pm 0.42}\end{array}$ & $\begin{array}{c}0.662^{ \pm 0.03} \\
* 5.432^{ \pm 0.29} \\
18.069^{ \pm 0.97} \\
* 9.266^{ \pm 0.52} \\
\end{array}$ & $\begin{array}{l}0.163^{ \pm 0.01} \\
1.234^{ \pm 0.03} \\
4.340^{ \pm 0.11} \\
2.129^{ \pm 0.04}\end{array}$ & $\begin{array}{c}0.152^{ \pm 0.00} \\
1.249^{ \pm 0.05} \\
4.148^{ \pm 0.13} \\
2.127^{ \pm 0.08}\end{array}$ & $\begin{array}{l}=A_{20: 2} \\
=A_{18: 0} \\
=A_{18: 3}-\left(A_{18: 0}+A_{20: 2}\right) \\
=\left(A_{18: 2}-A_{18: 0}\right) / 2\end{array}$ \\
\hline 900.8 & $\mathrm{C}_{57} \mathrm{H}_{106} \mathrm{O}_{6} \mathrm{~N}$ & C54:4 & 2.16 & $\begin{array}{c}16: 0-18: 3-20: 1 \\
16: 0-18: 2-20: 2 \\
18: 0-18: 1-18: 3 \\
18: 0-18: 2-18: 2 \\
18: 1-18: 1-18: 2\end{array}$ & $\begin{array}{l}7.545^{ \pm 0.43} \\
0.991^{ \pm 0.03} \\
0.000^{ \pm 0.00} \\
5.927^{ \pm 0.26} \\
7.803^{ \pm 0.37}\end{array}$ & $\begin{array}{c}8.413^{ \pm 0.23} \\
1.077^{ \pm 0.06} \\
0.000^{ \pm 0.00} \\
{ }^{*} 7.005^{ \pm 0.38} \\
{ }^{*} 8.993^{ \pm 0.51}\end{array}$ & $\begin{array}{c}2.010^{ \pm 0.04} \\
0.266^{ \pm 0.01} \\
0.000^{ \pm 0.00} \\
1.582^{ \pm 0.01} \\
2.083^{ \pm 0.04}\end{array}$ & $\begin{array}{c}1.936^{ \pm 0.03} \\
0.247^{ \pm 0.01} \\
0.000^{ \pm 0.00} \\
1.607^{ \pm 0.05} \\
2.062^{ \pm 0.06}\end{array}$ & $\begin{array}{l}=A_{20: 1} \\
=A_{20: 2} \\
=A_{18: 3}-A_{20: 1} \\
=\left(A_{18: 2}-A_{20: 2}\right) / 2 \\
=\left(A_{18: 1}-\left(A_{18: 3}-A_{20: 1}\right)\right) / 2\end{array}$ \\
\hline 902.8 & $\mathrm{C}_{57} \mathrm{H}_{108} \mathrm{O}_{6} \mathrm{~N}$ & $\mathrm{C} 54: 3$ & 1.99 & $\begin{array}{l}16: 0-18: 3-20: 0 \\
16: 0-18: 2-20: 1 \\
16: 0-18: 1-20: 2 \\
18: 0-18: 0-18: 3 \\
18: 0-18: 1-18: 2 \\
18: 1-18: 1-18: 1\end{array}$ & $\begin{array}{r}1.208^{ \pm 0.07} \\
12.259^{ \pm 0.66} \\
0.668^{ \pm 0.02} \\
0.000^{ \pm 0.00} \\
0.000^{ \pm 0.00} \\
4.733^{ \pm 0.34}\end{array}$ & $\begin{array}{r}1.314^{ \pm 0.03} \\
{ }^{*} 14.198^{ \pm 0.51} \\
0.730^{ \pm 0.04} \\
0.000^{ \pm 0.00} \\
0.000^{ \pm 0.00} \\
{ }^{*} 5.643^{ \pm 0.33}\end{array}$ & $\begin{array}{l}0.322^{ \pm 0.01} \\
3.268^{ \pm 0.04} \\
0.179^{ \pm 0.01} \\
0.000^{ \pm 0.00} \\
0.000^{ \pm 0.00} \\
1.258^{ \pm 0.05}\end{array}$ & $\begin{array}{l}0.303^{ \pm 0.01} \\
3.263^{ \pm 0.03} \\
0.168^{ \pm 0.01} \\
0.000^{ \pm 0.00} \\
0.000^{ \pm 0.00} \\
1.295^{ \pm 0.05}\end{array}$ & $\begin{array}{l}=A_{20: 0} \\
=A_{20: 1} \\
=A_{20: 2} \\
=A_{18: 3}-A_{20: 0} \\
=A_{18: 2}-A_{20: 1} \\
=A_{18: 1}-A_{20: 2}-\left(A_{18: 2}-A_{20: 1}\right)\end{array}$ \\
\hline
\end{tabular}


Table S3 (Continued-2)

\begin{tabular}{|c|c|c|c|c|c|c|c|c|c|}
\hline$m / z$ & {$\left[\mathrm{M}+\mathrm{NH}_{4}\right]^{+}$} & & AF & Combination & $\begin{array}{c}\text { WT } p \\
\text { (nmol/mg) }\end{array}$ & $\begin{array}{l}\text { pPLAIIIJ-OE1 } \\
\text { (nmol/mg) }\end{array}$ & $\underset{(m o l \%)}{\text { WT }} \quad$ pF & $\begin{array}{l}\text { pPLAIIID-OE1 } \\
\text { (mol\%) }\end{array}$ & $\begin{array}{l}\text { aCalculation } \\
\text { formulae }\end{array}$ \\
\hline 904.8 & $\mathrm{C}_{57} \mathrm{H}_{110} \mathrm{O}_{6} \mathrm{~N}$ & C54:2 & 2.10 & $\begin{array}{l}16: 0-18: 2-20: 0 \\
16: 0-18: 1-20: 1 \\
16: 0-18: 0-20: 2 \\
18: 0-18: 0-18: 2 \\
18: 0-18: 1-18: 1\end{array}$ & $\begin{array}{l}2.265^{ \pm 0.12} \\
4.880^{ \pm 0.31} \\
0.002^{ \pm 0.00} \\
0.000^{ \pm 0.00} \\
0.270^{ \pm 0.02}\end{array}$ & $\begin{array}{c}{ }^{*} 2.673^{ \pm 0.03} \\
{ }^{*} 5.842^{ \pm 0.21} \\
0.000^{ \pm 0.00} \\
0.000^{ \pm 0.00} \\
0.395^{ \pm 0.09}\end{array}$ & $\begin{array}{l}0.604^{ \pm 0.01} \\
1.299^{ \pm 0.03} \\
0.001^{ \pm 0.00} \\
0.000^{ \pm 0.00} \\
0.072^{ \pm 0.01}\end{array}$ & $\begin{array}{l}0.616^{ \pm 0.01} \\
1.343^{ \pm 0.02} \\
0.000^{ \pm 0.00} \\
0.000^{ \pm 0.00} \\
0.090^{ \pm 0.02}\end{array}$ & $\begin{array}{l}=A_{20: 0} \\
=A_{20: 1} \\
=A_{20: 2} \\
=A_{18: 2}-A_{20: 0} \\
=\left(A_{18: 1}-A_{20: 1}\right) / 2\end{array}$ \\
\hline 906.9 & $\mathrm{C}_{57} \mathrm{H}_{112} \mathrm{O}_{6} \mathrm{~N}$ & C54:1 & 2.50 & $\begin{array}{c}16: 0-16: 0-22: 1 \\
16: 0-18: 1-20: 0 \\
16: 0-18: 0-20: 1 \\
18: 0-18: 0-18: 1\end{array}$ & $\begin{array}{l}0.000^{ \pm 0.00} \\
0.768^{ \pm 0.06} \\
0.000^{ \pm 0.00} \\
0.232^{ \pm 0.02}\end{array}$ & $\begin{array}{r}0.000^{ \pm 0.00} \\
{ }^{*} 0.935^{ \pm 0.04} \\
0.000^{ \pm 0.00} \\
{ }^{*} 0.334^{ \pm 0.02}\end{array}$ & $\begin{array}{l}0.000^{ \pm 0.00} \\
0.205^{ \pm 0.01} \\
0.000^{ \pm 0.00} \\
0.061^{ \pm 0.00}\end{array}$ & $\begin{array}{c}0.000^{ \pm 0.00} \\
0.215^{ \pm 0.00} \\
0.000^{ \pm 0.00} \\
{ }^{*} 0.077^{ \pm 0.00}\end{array}$ & $\begin{array}{l}=A_{22: 1} \\
=A_{20: 0} \\
=A_{20: 1} \\
=\left(A_{18: 0}-A_{20: 1}\right) / 2\end{array}$ \\
\hline 908.9 & $\mathrm{C}_{57} \mathrm{H}_{114} \mathrm{O}_{6} \mathrm{~N}$ & $\mathrm{C} 54: 0$ & 3.17 & Not detectable & & & & & \\
\hline 920.8 & $\mathrm{C}_{59} \mathrm{H}_{102} \mathrm{O}_{6} \mathrm{~N}$ & $\mathrm{C} 56: 8$ & 6.49 & $18: 3-18: 3-20: 2$ & $0.966^{ \pm 0.04}$ & $0.955^{ \pm 0.03}$ & $0.259 \pm 0.01$ & ${ }^{*} 0.220^{ \pm 0.01}$ & $=\left(\mathrm{A}_{18: 3}+\mathrm{A}_{20: 2}\right) / 3$ \\
\hline 922.8 & $\mathrm{C}_{59} \mathrm{H}_{104} \mathrm{O}_{6} \mathrm{~N}$ & C56:7 & 5.07 & $\begin{array}{l}18: 3-18: 3-20: 1 \\
18: 2-18: 3-20: 2\end{array}$ & $\begin{array}{r}19.905^{ \pm 1.10} \\
3.092^{ \pm 0.06}\end{array}$ & $\begin{array}{r}* 22.812^{ \pm 0.50} \\
{ }^{*} 2.295^{ \pm 0.09}\end{array}$ & $\begin{array}{c}5.304^{ \pm 0.10} \\
0.830^{ \pm 0.03}\end{array}$ & $\begin{array}{c}5.260^{ \pm 0.17} \\
0.759^{ \pm 0.02}\end{array}$ & $\begin{array}{l}=A_{20: 1} \\
=\left(A_{18: 2}+A_{20: 2}\right) / 2\end{array}$ \\
\hline 924.8 & $\mathrm{C}_{59} \mathrm{H}_{106} \mathrm{O}_{6} \mathrm{~N}$ & C56:6 & 3.99 & $\begin{array}{c}18: 3-18: 3-20: 0 \\
18: 2-18: 3-20: 1 \\
18: 2-18: 2-20: 2 \\
18: 1-18: 3-20: 2\end{array}$ & $\begin{array}{r}2.719^{ \pm 0.20} \\
35.694^{ \pm 1.68} \\
0.000^{ \pm 0.00} \\
2.603^{ \pm 0.13}\end{array}$ & $\begin{array}{c}3.027^{ \pm 0.06} \\
* 41.282^{ \pm 0.83} \\
0.000^{ \pm 0.00} \\
{ }^{*} 3.029^{ \pm 0.14}\end{array}$ & $\begin{array}{l}0.722^{ \pm 0.03} \\
9.524^{ \pm 0.06} \\
0.000^{ \pm 0.00} \\
0.694^{ \pm 0.01}\end{array}$ & $\begin{array}{l}0.698^{ \pm 0.02} \\
9.507^{ \pm 0.17} \\
0.000^{ \pm 0.00} \\
0.696^{ \pm 0.02}\end{array}$ & $\begin{array}{l}=A_{20: 0} \\
=A_{20: 1} \\
=\left(A_{18: 2}-A_{20: 1}\right) / 2 \\
=A_{18: 1}\end{array}$ \\
\hline 926.8 & $\mathrm{C}_{59} \mathrm{H}_{108} \mathrm{O}_{6} \mathrm{~N}$ & $\mathrm{C} 56: 5$ & 3.27 & $\begin{array}{l}18: 2-18: 3-20: 0 \\
18: 2-18: 2-20: 1 \\
18: 1-18: 3-20: 1 \\
18: 1-18: 2-20: 2 \\
18: 0-18: 3-20: 2\end{array}$ & $\begin{array}{r}5.050^{ \pm 0.24} \\
24.324^{ \pm 1.63} \\
13.721^{ \pm 0.53} \\
1.924^{ \pm 0.08} \\
0.468^{ \pm 0.03} \\
\end{array}$ & $\begin{array}{r}{ }^{*} 5.774^{ \pm 0.14} \\
{ }^{*} 29.607^{ \pm 0.97} \\
{ }^{*} 15.544^{ \pm 0.53} \\
2.169^{ \pm 0.12} \\
{ }^{*} 0.594^{ \pm 0.02} \\
\end{array}$ & $\begin{array}{l}1.347^{ \pm 0.02} \\
6.477^{ \pm 0.22} \\
3.667^{ \pm 0.05} \\
0.515^{ \pm 0.02} \\
0.125^{ \pm 0.00}\end{array}$ & $\begin{array}{l}1.332^{ \pm 0.05} \\
6.809^{ \pm 0.10} \\
3.575^{ \pm 0.06} \\
0.498^{ \pm 0.02} \\
{ }^{*} 0.137^{ \pm 0.01} \\
\end{array}$ & $\begin{array}{l}=A_{20: 0} \\
=A_{20: 1}-C \\
=A_{18: 1}-B=C \\
=A_{20: 2}-A_{18: 0}=B \\
=A_{18: 0}\end{array}$ \\
\hline 928.8 & $\mathrm{C}_{59} \mathrm{H}_{110} \mathrm{O}_{6} \mathrm{~N}$ & $\begin{array}{c}\text { C56:4 } \\
18: 1-18: 3-2 \\
18: 0-18: 3-2 \\
18: 0-18: 2-2\end{array}$ & $\begin{array}{l}2.89 \\
20: 0 \text { and } \\
20: 1 \text { and } \\
20: 2 \text { and }\end{array}$ & $\begin{array}{l}16: 0-18: 3-22: 1 \\
16: 0-20: 2-20: 2 \\
18: 2-18: 2-20: 0 \\
18: 1-18: 2-20: 1 \\
18: 1-18: 1-20: 2\end{array}$ & $\begin{array}{c}0.838^{ \pm 0.04} \\
0.050^{ \pm 0.02} \\
5.909^{ \pm 0.20} \\
22.004^{ \pm 1.19} \\
1.149^{ \pm 0.06}\end{array}$ & $\begin{array}{c}0.806^{ \pm 0.01} \\
0.098^{ \pm 0.02} \\
{ }^{*} 7.090^{ \pm 0.20} \\
* 27.382^{ \pm 0.80} \\
{ }^{*} 1.378^{ \pm 0.06}\end{array}$ & $\begin{array}{c}0.225^{ \pm 0.01} \\
0.014^{ \pm 0.01} \\
1.580^{ \pm 0.02} \\
5.869^{ \pm 0.13} \\
0.307^{ \pm 0.01}\end{array}$ & $\begin{array}{c}{ }^{*} 0.186^{ \pm 0.01} \\
0.022^{ \pm 0.00} \\
1.633^{ \pm 0.05} \\
{ }^{*} 6.301^{ \pm 0.10} \\
0.317^{ \pm 0.01}\end{array}$ & $\begin{array}{l}=A_{22: 1} \\
=A_{16: 0}-A_{22: 1} \\
=A_{20: 0} \\
=A_{20: 1} \\
=A_{20: 2}-\left(A_{16: 0}-A_{22: 1}\right)\end{array}$ \\
\hline 930.9 & $\mathrm{C}_{59} \mathrm{H}_{112} \mathrm{O}_{6} \mathrm{~N}$ & $\mathrm{C} 56: 3$ & 2.85 & $\begin{array}{l}16: 0-18: 3-22: 0 \\
16: 0-18: 2-22: 1 \\
16: 0-20: 1-20: 2 \\
18: 0-18: 3-20: 0 \\
18: 1-18: 2-20: 0 \\
18: 0-18: 2-20: 1 \\
18: 1-18: 1-20: 1 \\
18: 0-18: 1-20: 2\end{array}$ & $\begin{array}{r}0.136^{ \pm 0.02} \\
1.193^{ \pm 0.05} \\
0.439^{ \pm 0.07} \\
0.077^{ \pm 0.02} \\
3.406^{ \pm 0.23} \\
0.883^{ \pm 0.17} \\
14.258^{ \pm 1.46} \\
0.001^{ \pm 0.00}\end{array}$ & $\begin{array}{r}0.162^{ \pm 0.01} \\
1.322^{ \pm 0.07} \\
0.446^{ \pm 0.04} \\
0.118^{ \pm 0.02} \\
4.436^{ \pm 0.05} \\
1.109^{ \pm 0.12} \\
* 18.199^{ \pm 0.56} \\
0.000^{ \pm 0.00}\end{array}$ & $\begin{array}{l}0.036^{ \pm 0.00} \\
0.321^{ \pm 0.02} \\
0.119^{ \pm 0.02} \\
0.021^{ \pm 0.01} \\
0.906^{ \pm 0.03} \\
0.243^{ \pm 0.06} \\
3.769^{ \pm 0.22} \\
0.000^{ \pm 0.00}\end{array}$ & $\begin{array}{c}0.037^{ \pm 0.00} \\
0.303^{ \pm 0.01} \\
0.103^{ \pm 0.01} \\
0.028^{ \pm 0.01} \\
* 1.024^{ \pm 0.03} \\
0.255^{ \pm 0.03} \\
4.190^{ \pm 0.10} \\
0.000^{ \pm 0.00}\end{array}$ & $\begin{array}{l}=A_{22: 0} \\
=A_{22: 1} \\
=\left[\left(A_{16: 0}-A_{22: 0}-A_{22: 1}\right)\right]=E \\
=\left[\left(A_{18: 3}-A_{22: 0}\right)\right]=B \\
=\left[\left(A_{20: 0}-B\right)\right]=C \\
=\left[\left(A_{18: 2}-A_{22: 1}-C\right)\right]=D \\
=\left[\left(A_{20: 1}-E-D\right)\right] \\
=\left[\left(A_{20: 2}-E\right)\right]\end{array}$ \\
\hline 932.9 & $\mathrm{C}_{59} \mathrm{H}_{114} \mathrm{O}_{6} \mathrm{~N}$ & C56:2 & 3.17 & $\begin{array}{l}16: 0-18: 2-22: 0 \\
16: 0-18: 1-22: 1 \\
16: 0-20: 1-20: 1 \\
16: 0-20: 0-20: 2 \\
18: 0-18: 2-20: 0 \\
18: 1-18: 1-20: 0 \\
18: 0-18: 1-20: 1 \\
18: 0-18: 0-20: 2\end{array}$ & $\begin{array}{l}0.258^{ \pm 0.02} \\
0.342^{ \pm 0.02} \\
0.247^{ \pm 0.04} \\
\text { Not detecta } \\
0.075^{ \pm 0.05} \\
2.165^{ \pm 0.18} \\
0.708^{ \pm 0.25} \\
\text { Not detecta }\end{array}$ & $\begin{array}{l}{ }^{*} 0.340^{ \pm 0.02} \\
{ }^{*} 0.452^{ \pm 0.04} \\
0.140^{ \pm 0.06} \\
\text { able } \\
0.104^{ \pm 0.06} \\
{ }^{*} 2.763^{ \pm 0.05} \\
0.975^{ \pm 0.09} \\
\text { able }\end{array}$ & $\begin{array}{l}0.069^{ \pm 0.00} \\
0.092^{ \pm 0.01} \\
0.067^{ \pm 0.01} \\
0.019^{ \pm 0.01} \\
0.575^{ \pm 0.02} \\
0.181^{ \pm 0.06}\end{array}$ & $\begin{array}{r}0.078^{ \pm 0.01} \\
0.103^{ \pm 0.01} \\
0.032^{ \pm 0.01} \\
\\
0.023^{ \pm 0.01} \\
{ }^{\star} 0.638^{ \pm 0.02} \\
0.224^{ \pm 0.02}\end{array}$ & $\begin{array}{l}=A_{22: 0} \\
=A_{22: 1} \\
=\left[\left(A_{16: 0}-A_{22: 0}-A_{22: 1}\right)\right]=C \\
=\left[\left(A_{18: 2}-A_{22: 0}\right)\right]=B \\
=\left[\left(A_{20: 0}-B\right)\right] \\
=\left[\left(A_{20: 1}-C\right)\right]\end{array}$ \\
\hline 934.9 & $\mathrm{C}_{59} \mathrm{H}_{116} \mathrm{O}_{6} \mathrm{~N}$ & C56:1 & 3.83 & $\begin{array}{l}16: 0-18: 1-22: 0 \\
16: 0-18: 0-22: 1 \\
16: 0-20: 0-20: 1 \\
18: 0-18: 1-20: 0 \\
18: 0-18: 0-20: 1\end{array}$ & $\begin{array}{l}0.084^{ \pm 0.01} \\
0.001^{ \pm 0.00} \\
0.130^{ \pm 0.04} \\
0.055^{ \pm 0.02} \\
0.184^{ \pm 0.03}\end{array}$ & $\begin{array}{l}0.098^{ \pm 0.02} \\
0.000^{ \pm 0.00} \\
0.158^{ \pm 0.01} \\
0.074^{ \pm 0.04} \\
0.238^{ \pm 0.02}\end{array}$ & $\begin{array}{l}0.023^{ \pm 0.00} \\
0.000^{ \pm 0.00} \\
0.033^{ \pm 0.01} \\
0.015^{ \pm 0.01} \\
0.048^{ \pm 0.01}\end{array}$ & $\begin{array}{l}0.023^{ \pm 0.00} \\
0.000^{ \pm 0.00} \\
0.036^{ \pm 0.00} \\
0.017^{ \pm 0.01} \\
0.055^{ \pm 0.01}\end{array}$ & $\begin{array}{l}=A_{22: 0} \\
=A_{22: 1} \\
=\left[\left(A_{20: 0}-B\right)\right] \\
=\left[\left(A_{18: 1}-A_{22: 0}\right)\right]=B \\
=\left[\left(A_{18: 0}-A_{22: 1}-B\right) / 2\right]\end{array}$ \\
\hline 936.9 & $\mathrm{C}_{59} \mathrm{H}_{118} \mathrm{O}_{6} \mathrm{~N}$ & C56:0 & 4.83 & Not detectable & & & & & \\
\hline
\end{tabular}


Table S3 (Continued-3)

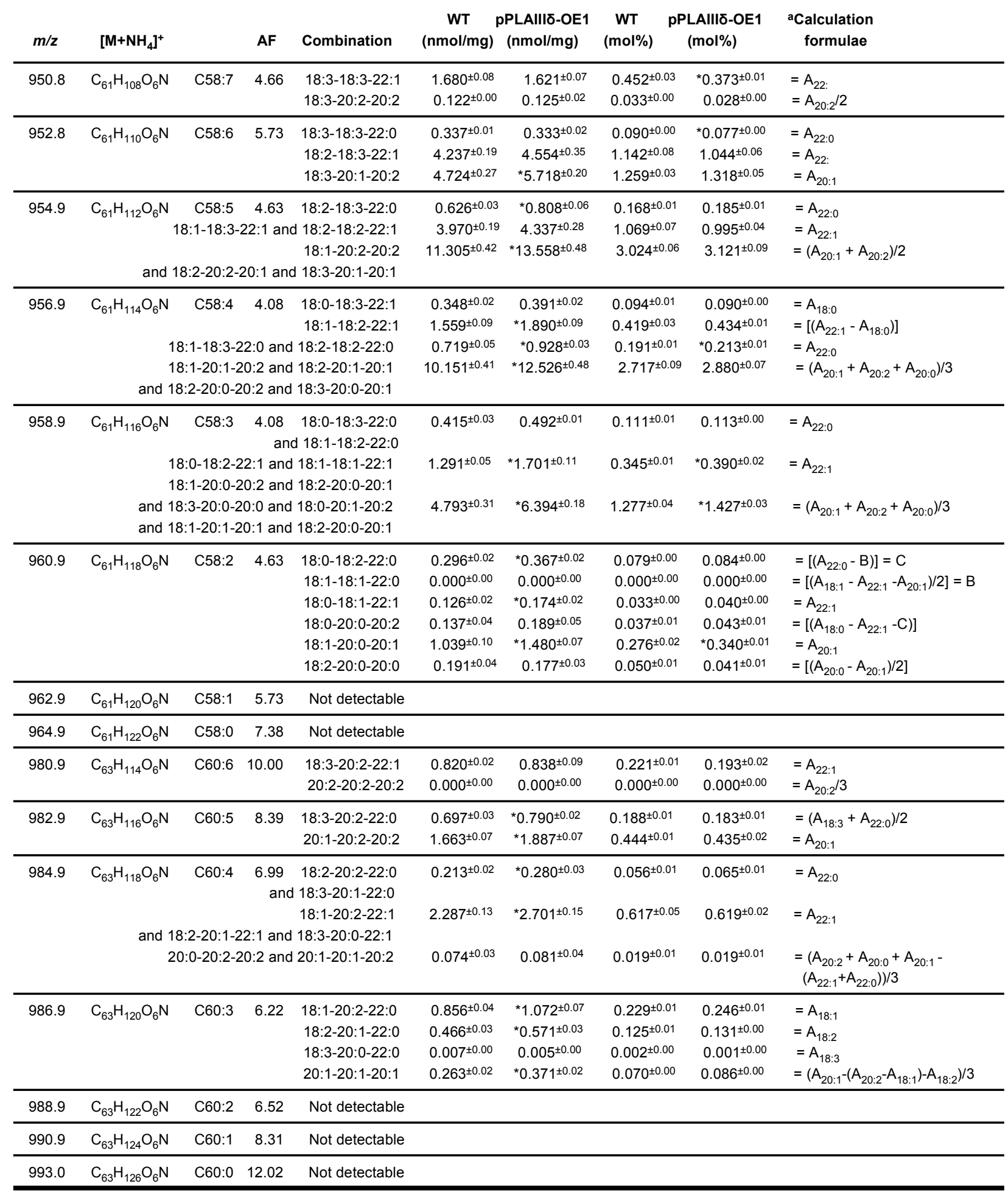

"AF" stands for "Adjustment Factor" for abundances of fatty acyl species associated with TAGs of particular $\mathrm{m} / \mathrm{z}$. Adjustment factor is defined as the NL signal intensity of internal standard/ the NL signal intensity of each TAG, when the TAG and the internal standard are equimolar. The adjustment factor for seed TAGs were determined as described in Experimental Procedures. " $\mathrm{A}_{16.0}$ " represents the abundance of fatty acyl chains of 16:0 at each TAG mass $(\mathrm{m} / \mathrm{z})$, calculated from the NL spectra as described in the text. ${ }^{b}$ The value is set as zero if equal or blow zero wherever there is a minus function in the formula. WT, wild-type; OE, overexpressor. ${ }^{*} \mathrm{P}<0.05$ compared with the WT, based on Student's $t$ test. 
Table S4. Fatty acyl combination analysis of seed oil TAGs. Abundance for each FA was calculated by summing the corrected abundance (after isotopic deconvolution, application of adjustment factors, and normalization to internal standard) at each of the 46 TAG $\mathrm{m} / \mathrm{z}$ within each NL scan; the sum of these values in each NL scan represents the total abundance of that FA in TAG. "a (\%)" represents the total FA-pool size of a1 (16:0), a2 (18:1), and a3 (18:0); "b (\%)" represents the FA pool size of b1 (18:2) and b2 (18:3); "c (\%) represent FA pool size of c1 (20:0), c2 (20:1), c3 (20:2), c4 (22:0), and c5 (22:1). The sn-position of acyl chains are not specified in the description of TAG molecules in this work. The calculation of random acyl combinations of TAG, such as A-A-A (\%) and B-B-B (\%), is described in Experimental Procedures. The measured TAG acyl combinations, such as A-A-A (\%) and B-B-B (\%), were obtained by summing the appropriate TAG species shown in Table S3. "X" represents " $A+B$ ", which were combined in some species to allow unambiguous assignment in cases where fatty acyl combinations of individual molecular species were not differentiated (Table S3).

\begin{tabular}{cllllll} 
FA-pool (\%) & WT-1 & WT-2 & WT-3 & WT-4 & WT-5 & Average \pm SE \\
\hline NL16:0 (a1, \%) & 8.90 & 7.89 & 7.85 & 8.64 & 7.63 & $8.18 \pm 0.25$ \\
NL18:3 (b1, \%) & 19.01 & 18.66 & 18.41 & 19.25 & 18.91 & $18.85 \pm 0.15$ \\
NL18:2 (b2, \%) & 24.08 & 24.19 & 23.21 & 23.12 & 22.69 & $23.46 \pm 0.29$ \\
NL18:1 (a2, \%) & 16.30 & 16.63 & 17.47 & 17.24 & 16.96 & $16.92 \pm 0.21$ \\
NL18:0 (a3, \%) & 3.89 & 3.61 & 3.71 & 3.71 & 3.94 & $3.77 \pm 0.06$ \\
NL20:2 (c1, \%) & 2.49 & 2.16 & 2.23 & 2.23 & 2.01 & $2.22 \pm 0.08$ \\
NL20:1 (c2, \%) & 19.77 & 21.45 & 21.56 & 20.62 & 22.60 & $21.19 \pm 0.47$ \\
NL20:0 (c3, \%) & 2.93 & 2.96 & 3.05 & 3.01 & 3.20 & $3.03 \pm 0.05$ \\
NL22:1 (c4, \%) & 2.31 & 2.11 & 2.16 & 1.85 & 1.77 & $2.04 \pm 0.10$ \\
NL22:0 (c5, \%) & 0.33 & 0.35 & 0.36 & 0.33 & 0.35 & $0.34 \pm 0.01$ \\
\hline & & & & & & \\
FA-pool (\%) & WT-1 & WT-2 & WT-3 & WT-4 & WT-5 & Average \pm SE \\
\hline a (\%) & 29.09 & 28.14 & 29.03 & 29.59 & 28.54 & $28.88 \pm 0.25$ \\
b (\%) & 43.09 & 42.84 & 41.61 & 42.37 & 41.59 & $42.30 \pm 0.31$ \\
c (\%) & 27.82 & 29.02 & 29.36 & 28.04 & 29.87 & $28.82 \pm 0.39$ \\
\hline
\end{tabular}

Random acyl combination of TAG by fatty acid abundance

\begin{tabular}{lllllll} 
& WT-1 & WT-2 & WT-3 & WT-4 & WT-5 & Average \pm SE \\
\hline A-A-A (\%) & 2.46 & 2.23 & 2.45 & 2.59 & 2.32 & $2.41 \pm 0.06$ \\
B-B-B (\%) & 8.00 & 7.86 & 7.21 & 7.61 & 7.20 & $7.58 \pm 0.17$ \\
C-C-C (\%) & 2.15 & 2.44 & 2.53 & 2.20 & 2.67 & $2.40 \pm 0.10$ \\
A-A-B (\%) & 10.94 & 10.18 & 10.52 & 11.13 & 10.16 & $10.59 \pm 0.20$ \\
B-B-A (\%) & 16.21 & 15.49 & 15.08 & 15.94 & 14.81 & $15.51 \pm 0.26$ \\
X-X-C (\%) & 43.48 & 43.86 & 43.95 & 43.56 & 44.07 & $43.79 \pm 0.11$ \\
X-C-C (\%) & 16.76 & 17.93 & 18.26 & 16.97 & 18.77 & $17.74 \pm 0.38$ \\
\hline
\end{tabular}

Measured acyl combination of TAG

\begin{tabular}{lcccccc} 
& WT-1 & WT-2 & WT-3 & WT-4 & WT-5 & Average \pm SE \\
\hline A-A-A (\%) & 2.36 & 2.35 & 2.46 & 2.66 & 2.54 & $2.48 \pm 0.06$ \\
B-B-B (\%) & 4.33 & 3.74 & 3.92 & 4.11 & 3.37 & $3.89 \pm 0.16$ \\
C-C-C (\%) & 0.51 & 0.53 & 0.54 & 0.53 & 0.55 & $0.53 \pm 0.01$ \\
A-A-B (\%) & 10.53 & 10.28 & 10.79 & 10.88 & 10.10 & $10.52 \pm 0.15$ \\
B-B-A (\%) & 15.01 & 14.03 & 13.99 & 14.69 & 13.86 & $14.31 \pm 0.23$ \\
X-X-C (\%) & 55.82 & 57.51 & 57.43 & 56.79 & 58.60 & $57.23 \pm 0.46$ \\
X-C-C (\%) & 11.45 & 11.55 & 10.87 & 10.35 & 10.98 & $11.04 \pm 0.22$ \\
\hline
\end{tabular}

